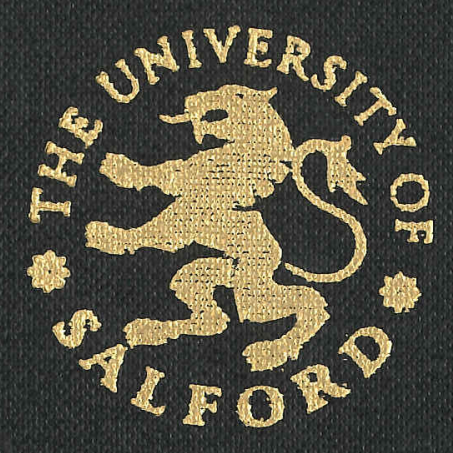

COMPARISON OF CONVENTIONAL AND

CATALYTIC IN-SITU COMBUSTION PROCESSES FOR OIL RECOVERY

MUSA BASHIR ABUHESA

M.Sc. Thesis 


\section{COMPARISON OF CONVENTIONAL AND CATALYTIC IN-SITU COMBUSTION PROCESSES FOR OIL RECOVERY}

MUSA BASHIR ABUHESA

A Thesis Submitted to

THE UNIVERSITY OF SALFORD

For the degree of

MASTER OF SCIENCE (MSc)

Under the supervision of

PROFESSOR R. HUGHES

Chemical Engineering Unit

University of Salford

Salford

M5 4WT

2003 
Dedicated to my mother, in Libya,

my wife, my sons (Ammar, Mohamed and Bashir) and my daughters

(Suhaila, Suzan and Sundess). 
DECLARATION

Unless otherwise stated, the work in this thesis is that of the author, and has not previously been submitted in part or in whole, at this or any other establishment.

$$
\begin{aligned}
& \text { with bost wishes } \\
& \qquad \text { Con llughtur. }
\end{aligned}
$$




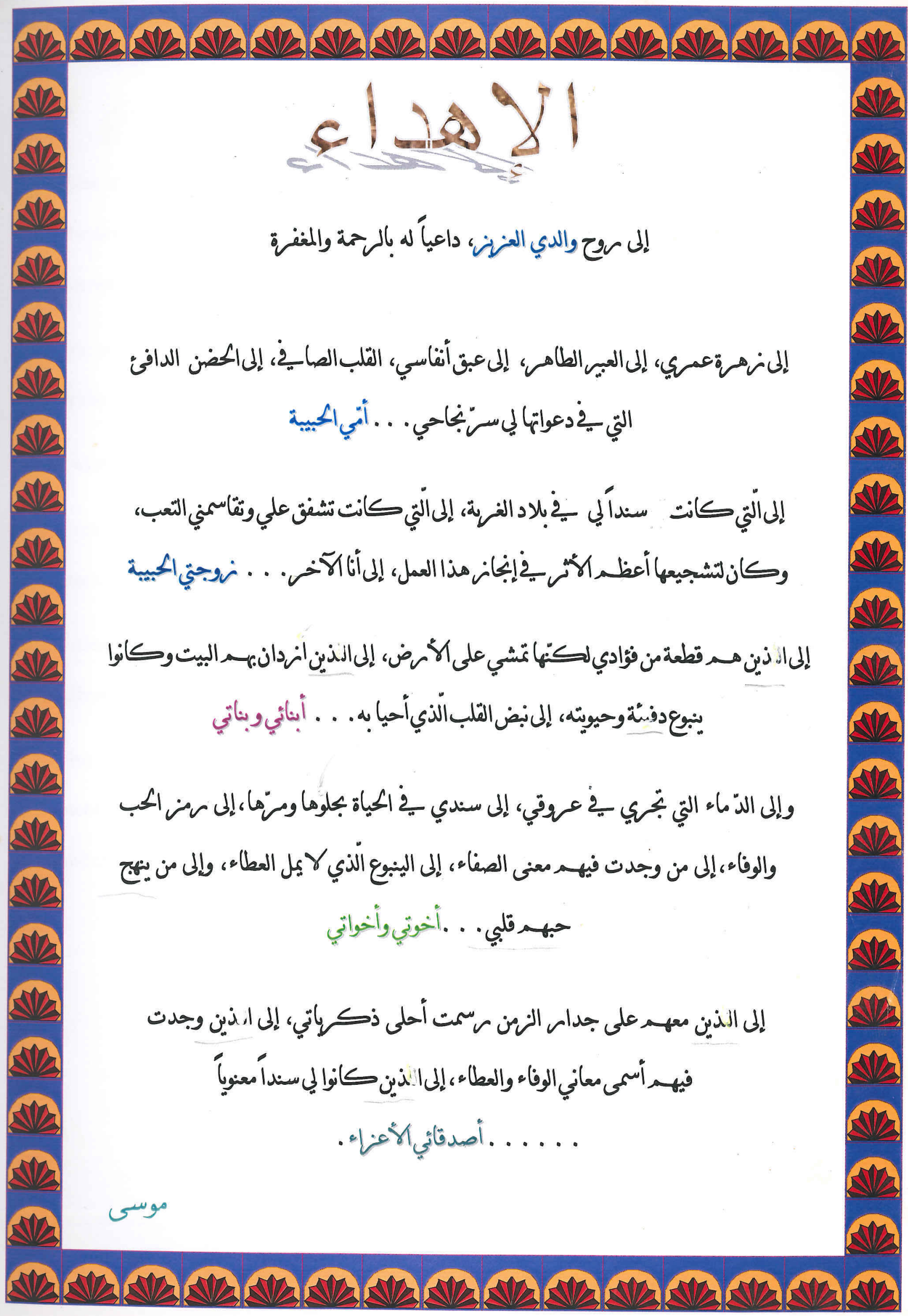




\section{ACKNOWLEDGEMENT}

First of all, I wish to express my deepest gratitude to my supervisor, Professor Ronald Hughes, for his helpful guidance and advice, great patience, understanding and encouragement during the course of the research.

Sincere thanks to $\mathrm{Dr} H$. Al-Saffar for his assistance and to Mr Barry Wild for his presence in the laboratory when help was needed.

I wish to thank department secretary, Mrs Maria Hughes.

I am grateful to thank the staff members of Chemical Engineering Unit for help and discussion.

I also wish to express my appreciation to the management of Zuietina Oil Company, Libya, for the financial support.

Finally, I would like to thank my mother and my elder brother Massaood for their inspiration and my family for sincere moral support, especially my wife for her understanding and patience during these years of study and research. 


\section{$\underline{\text { ABSTRACT }}$}

In-situ combustion (ISC) is the process of injecting air or oxygen enriched air into an oil reservoir through injection wells. Initially, communication within the reservoir is created and then the crude oil is ignited, so that a combustion front is propagated towards the produced well. It is able to improve the quality of crude oil via thermal cracking in the reservoir. To achieve the required refining and marketing specifications, further upgrading beyond that achievable by thermal cracking is performed by catalytic processing in the reservoir.

In this study, four series (four runs each) of laboratory in-situ combustion experiments were performed to test the concept of using in-situ combustion to catalytically upgrade a medium-heavy Clair crude oil (19.8 API), using a low-pressure combustion cell. Samples of the crude oil/sand mixture were packed into the tubular cell and subjected to a heating program from room temperature to $400^{\circ} \mathrm{C}$, in a flow of air with an operating pressure of 3 bars. Two modes of experiments were conducted using a horizontal tube position; first by packing the sample bed at the middle part of combustion cell and packing the catalyst bed at the outlet end of the sample bed, and secondly, by using a small-perforated tube inserted in the outlet fitting of combustion tube, which serves as a horizontal well with the catalyst packed around the perforated section of the perforated tube. Tests were performed for both non-catalytic and catalytic procedures and for both dry and wet forward combustion runs. The results, which are analysed and discussed and based on the stabilised period of combustion (HTO region), show that the presence 
and loading of catalyst promote the combustion reactions and upgraded oil is produced. The hydrogen/carbon $(H / C)$ ratio for all tests decreased as the combustion temperature increased, and was lower than that of the original crude oil. The $\mathrm{CO} /\left(\mathrm{CO}+\mathrm{CO}_{2}\right)$ ratios averaged from 0.20 to 0.26 in the non-catalytic tests, compared with 0.15 to 0.19 for the catalyst tests. These values demonstrated the success of the combustion processes. The air requirement and fuel consumption were observed to be slightly higher in the catalytic run experiments compared with the non-catalytic experiments, while they decreased slightly in wet combustion runs compared with dry runs. Also, from the catalytic experiments, it was found that the catalyst activity decreased with time, as could be observed in the slight reduction of the produced oil's API gravity for both the last two runs.

Generally, the produced oil from the catalytic runs was upgraded by up to 11 points compared with up to 5 points for non-catalytic runs; these compare very favourably with the original crude oil $\left(19.8^{\circ} \mathrm{API}\right)$. High oil recoveries were achieved for all runs and ranged from $\sim 53$ to $74 \%$ OOIP. The highest oil recovery was achieved during wet non-catalytic tests, while the lowest was achieved during the dry catalytic tests. 


\section{TABLE OF CONTENTS}

DECLARATION III

ACKNOWLDEDGMENT IV IV I

$\begin{array}{lll}\text { ABSTRACT V } & \text { V }\end{array}$

TABLE OF CONTENTS NII

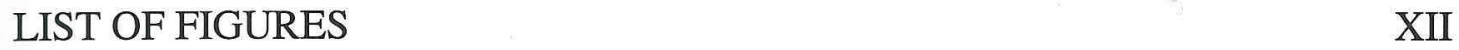

$\begin{array}{ll}\text { LIST OF TABLES } & \text { XVII }\end{array}$

CHAPTER 1 - INTRODUCTION 1

1.1 Introduction 2

1.2 Organization of the Thesis 4

CHAPTER 2 - GENERAL REVIEW OF ENHANCED OIL RECOVERY 5

2.1 Introduction 6

2-2 EOR methods $\quad 7$

$\begin{array}{ll}\text { 2.2.1 Miscible Methods } & 7\end{array}$

2.2.1.1 Hydrocarbon miscible displacement 8

2.2.1.2 Carbon dioxide displacement 8

2.2.1.3 Inert gas injection 9

2.2.2 Chemical Methods 9

2.2.2.1 Polymer methods 9

$\begin{array}{ll}\text { 2.2.2.2 Surfactant methods } & 10\end{array}$

2-2-2-3 Alkaline methods $\quad 10$ 
2.2.3.1 Hot fluid injection

2.2.3.2 Cyclic steam stimulation

2.2.3.3 In-situ combustion (ISC) PROCESSES

\subsection{Introduction}

3.2 Reaction Kinetics of In-Situ Combustion

3.2.1 Low temperature oxidation

3.2.2 Medium temperature oxidation

3.2.3 High temperature oxidation

3.3 Reaction Kinetic Studies

3.4 Thermal Recovery using Horizontal Wells

3.5 Catalytic Upgrading of Crude Oil 35

3.5.1 Crude oil upgrading technology 39

3.5.2 Catalytic in-situ upgrading processes $\quad 40$

3.5.2.1 In-situ catalytic upgrading using down-hole injection $\quad 40$

3.5.2.2 "Burn and turn" in-situ catalytic upgrading 41

3.5.2.3 Combustion assisted catalytic upgrading $\quad 43$

3.6 Conclusions $\quad 44$ 
$\begin{array}{ll}4.1 \text { Introduction } & 47\end{array}$

4.2 Experimental Equipment $\quad 47$

$\begin{array}{ll}\text { 4.2.1 Combustion cell } & 47\end{array}$

4.2.2 Flow metering and pressure regulation $\quad 52$

4.2.3 Temperature measurement and control $\quad 53$

4.2.4 Fluid production unit $\quad 54$

4.2.5 Gas analysis unit $\quad 55$

4.2.5.1 The GC column (CTR I) $\quad 55$

4.2.5.2 Calibration of the CTR I column 56

4.3 Experimental Procedure 58.

4.3.1 Mixing of sample matrix $\quad 58$

4.3.2 Packing procedure for the combustion cell 60

$\begin{array}{ll}\text { 4.3.2.1 First mode } & 60\end{array}$

$\begin{array}{ll}\text { 4.3.2.2 Second mode } & 61\end{array}$

4.3.3 Operating Procedure 62

4.3.4 Measurement of API gravity 63

4.3.5 Shut down procedure $\quad 64$

CHAPTER 5 - RESULTS AND DISCUSSIONS

5.1 Introduction $\quad 66$

5.2 First Mode Experiments $\quad 68$

5.2.1 In-situ combustion (ISC) experiments $\quad 69$

$\begin{array}{ll}\text { 5.2.1.1 Produced gas composition } & 69\end{array}$ 
5.2.1.4 Air requirement

5.2.1.5 Fuel consumption

5.2.1.6 Produced oil

5.2.2 Catalytic in-situ combustion (CISC) experiments (first mode) 86

5.2.2.1 Produced gas composition

5.2.2.2 H/C and carbon molar ratios

5.2.2.3 Oxygen utilization

5.2.2.4 Air requirement

5.2.2.5 Fuel consumption

5.2.2.6 Produced oil

5.3 Second Mode Experiments (perforated tube experiments)

5.3.1 General introduction

5.3.1.1 Produced gas composition

5.3.1.2 H/C and carbon molar ratios

5.3.1.3 Oxygen utilization

5.3.1.4 Air requirement

5.3.1.5 Fuel consumption

\subsubsection{Produced oil}

5.3.2 Comparison between first and second mode experiments

5.4 Catalytic Life Tests (first mode) 
6.1.1 Centrally Packed Tube Position Experiments

6.1.2 Perforated tube (horizontal producer well) experiments

6.2 Recommendations for Future Work

REFERENCES

APPENDICES 


\section{LIST OF FIGURES}

Figure 2.1: Dry forward combustion, temperature and saturation profiles

Figure 2.2: Wet forward combustion, temperature and saturation profiles

Figure 2.3: Reverse forward combustion, temperature and saturation profiles

Figure 3.1: In-Situ catalytic upgrading scheme with downhole injection

Processing

Figure 3.2: "Burn and Turn" in-situ catalytic process

Figure 3.3: Combustion assisted in-situ catalytic upgrading process

Figure 3.4: "Toe to Heel" air injection process with downhole catalyst bed

Figure 4.1: Schematic flow diagram of the experimental apparatus

Figure 4.2: Cross sectional view of combustion cell (mode I)

Figure 4.3: Cross sectional view of combustion cell (mode II)

Figure 4.4: Operational diagram of the flow sensor device in mass

flow controller

Figure 4.5: Cut-away view of CTR I column

Figure 4.6: CTR I calibration curve

Figure 5.1: Temperature and produced gas composition

$$
\text { Run-1, WOC, } \mathrm{S}_{\mathrm{o}}=20 \%, \mathrm{Sw}=0
$$

Figure 5.2: Temperature and produced gas composition

$$
\text { Run-2, WOC, } S_{0}=40 \%, S_{w}=0
$$

Figure 5.3: Temperature and produced gas composition

$$
\text { Run-3, WOC, } S_{o}=40 \%, S_{w}=20 \%
$$


Figure 5.4: Temperature and produced gas composition

$$
\text { Run-4, WOC, } S_{o}=40 \%, S_{w}=0 \text {, Air flow rate }=375 \mathrm{ml} / \mathrm{min}
$$

Figure 5.5: Atomic H/C and carbon molar ratios

$$
\text { Run-1, WOC, } S_{0}=20 \%, S_{w}=0
$$

Figure 5.6: Atomic H/C and carbon molar ratios

$$
\text { Run-2, WOC, } \mathrm{S}_{\mathrm{o}}=40 \%, \mathrm{~S}_{\mathrm{w}}=0
$$

Figure 5.7: Atomic $\mathrm{H} / \mathrm{C}$ and carbon molar ratios

$$
\text { Run-3, WOC, } \mathrm{S}_{\mathrm{o}}=40 \%, \mathrm{~S}_{\mathrm{w}}=20 \%
$$

Figure 5.8: Atomic H/C and carbon molar ratios

$$
\text { Run-4, WOC, } S_{0}=40 \%, S_{\mathrm{w}}=0 \text {, Air flow rate }=375 \mathrm{ml} / \mathrm{min}
$$

Figure 5.9: Oxygen utilization and Temperature

$$
\text { Run-1, WOC, } \mathrm{S}_{\mathrm{o}}=20 \%, \mathrm{~S}_{\mathrm{w}}=0
$$

Figure 5.10: Oxygen utilization and Temperature

$$
\text { Run-2, WOC, } S_{\mathrm{o}}=40 \%, \mathrm{~S}_{\mathrm{w}}=0
$$

Figure 5.11: Oxygen utilization and Temperature

$$
\text { Run-3, WOC, } \mathrm{S}_{\mathrm{o}}=40 \%, \mathrm{~S}_{\mathrm{w}}=20 \%
$$

Figure 5.12: Oxygen utilization and Temperature

$$
\text { Run-4, WOC, } S_{\mathrm{o}}=40 \%, \mathrm{~S}_{\mathrm{w}}=0 \text {, Air flow rate }=375 \mathrm{ml} / \mathrm{min}
$$

Figure 5.13: Temperature and produced gas composition

$$
\text { Run-5, WC (1 gm), } \mathrm{S}_{\mathrm{o}}=20 \%, \mathrm{~S}_{\mathrm{W}}=0
$$

Figure 5.14: Temperature and produced gas composition

$$
\text { Run-6, WC (1 gm), } \mathrm{S}_{\mathrm{o}}=40 \%, \mathrm{~S}_{\mathrm{w}}=0
$$

Figure 5.15: Temperature and produced gas composition

$$
\text { Run-7, WC (5 gm), So }=40 \%, S_{w}=0
$$


Figure 5.16: Temperature and produced gas composition

$$
\text { Run-8, WC (5 gm), } \mathrm{S}_{\mathrm{o}}=40 \%, \mathrm{~S}_{\mathrm{w}}=20 \%
$$

Figure 5.17: Atomic H/C and carbon molar ratios

$$
\text { Run-5, WC (1 gm), } \mathrm{S}_{\mathrm{o}}=20 \%, \mathrm{~S}_{\mathrm{w}}=0
$$

Figure 5.18: Atomic H/C and carbon molar ratios

$$
\text { Run-6, WC (1 gm), } \mathrm{S}_{\mathrm{o}}=40 \%, \mathrm{~S}_{\mathrm{w}}=0
$$

Figure 5.19: Atomic H/C and carbon molar ratios

$$
\text { Run-7, WC (5 gm), So }=40 \%, S_{w}=0
$$

Figure 5.20: Atomic H/C and carbon molar ratios

$$
\text { Run-8, WC (5 gm), } \mathrm{S}_{\mathrm{o}}=40 \%, \mathrm{~S}_{\mathrm{w}}=20 \%
$$

Figure 5.21: Oxygen utilization and Temperature

$$
\text { Run-5, WC (1 gm), } S_{o}=20 \%, S_{w}=0
$$

Figure 5.22: Oxygen utilization and Temperature

$$
\text { Run-6, WC (1 gm), } \mathrm{S}_{\mathrm{o}}=40 \%, \mathrm{~S}_{\mathrm{w}}=0
$$

Figure 5.23: Oxygen utilization and Temperature

$$
\text { Run-7, WC (5 gm), So }=40 \%, \mathrm{~S}_{\mathrm{w}}=0
$$

Figure 5.24: Oxygen utilization and Temperature

$$
\text { Run-8, WC (5 gm), } \mathrm{S}_{\mathrm{o}}=40 \%, \mathrm{~S}_{\mathrm{w}}=20 \%
$$

Figure 5.25: Temperature and produced gas composition

$$
\text { Run-9, PWOC, } \mathrm{S}_{\mathrm{o}}=40 \%, \mathrm{~S}_{\mathrm{w}}=0
$$

Figure 5.26: Temperature and produced gas composition

$$
\text { Run-10, PWC, } \mathrm{S}_{\mathrm{o}}=40 \%, \mathrm{~S}_{\mathrm{w}}=0
$$

Figure 5.27: Temperature and produced gas composition

$$
\text { Run-11, PWOC, } \mathrm{S}_{\mathrm{o}}=40 \%, \mathrm{~S}_{\mathrm{w}}=20 \%
$$


Figure 5.28: Temperature and produced gas composition

$$
\text { Run-12, PWC, } S_{\mathrm{o}}=40 \%, \mathrm{~S}_{\mathrm{w}}=20 \%
$$

Figure 5.29: Atomic H/C and carbon molar ratios

$$
\text { Run-9, PWOC, } \mathrm{S}_{\mathrm{o}}=40 \%, \mathrm{~S}_{\mathrm{W}}=0
$$

Figure 5.30: Atomic $\mathrm{H} / \mathrm{C}$ and carbon molar ratios

$$
\text { Run-10, PWC, } \mathrm{S}_{\mathrm{o}}=40 \%, \mathrm{~S}_{\mathrm{w}}=0
$$

Figure 5.31: Atomic $\mathrm{H} / \mathrm{C}$ and carbon molar ratios

$$
\text { Run-11, PWOC, } \mathrm{S}_{\mathrm{o}}=40 \%, \mathrm{~S}_{\mathrm{W}}=20 \%
$$

Figure 5.32: Atomic $\mathrm{H} / \mathrm{C}$ and carbon molar ratios

$$
\text { Run-12, PWC, } \mathrm{S}_{\mathrm{o}}=40 \%, \mathrm{~S}_{\mathrm{w}}=20 \%
$$

Figure 5.33: Oxygen utilization and Temperature

$$
\text { Run-9, PWOC, } \mathrm{S}_{\mathrm{o}}=40 \%, \mathrm{~S}_{\mathrm{w}}=0
$$

Figure 5.34: Oxygen utilization and Temperature

$$
\text { Run-10, PWC, } S_{o}=40 \%, S_{w}=0
$$

Figure 5.35: Oxygen utilization and Temperature

$$
\text { Run-11, PWOC, } \mathrm{S}_{\mathrm{o}}=40 \%, \mathrm{~S}_{\mathrm{W}}=20 \%
$$

Figure 5.36: Oxygen utilization and Temperature

$$
\text { Run-12, PWC, } S_{0}=40 \%, S_{w}=20 \%
$$

Figure 5.37: Temperature and produced gas composition

$$
\text { Run-13, WFC, } \mathrm{S}_{\mathrm{o}}=40 \%, \mathrm{~S}_{\mathrm{w}}=0
$$

Figure 5.38: Temperature and produced gas composition

$$
\text { Run-14, WUC, } S_{\mathrm{o}}=40 \%, \mathrm{~S}_{\mathrm{w}}=0
$$

Figure 5.39: Temperature and produced gas composition

$$
\text { Run-15, WRUC, } \mathrm{S}_{\mathrm{o}}=40 \%, \mathrm{~S}_{\mathrm{w}}=0
$$


Figure 5.40: Temperature and produced gas composition

Run-16, WRRUC, $\mathrm{S}_{\mathrm{o}}=40 \%, \mathrm{~S}_{\mathrm{w}}=0$

Figure 5.41: API gravity changes and $\%$ of catalyst weight changes

for catalyst life tests 


\section{LIST OF TABLES}

Table 4.1: Sand properties $\quad 59$

Table 4.1: Crude oil properties $\quad 59$

Table 5.1: Common operating conditions $\quad 67$

Table 5.2: Produced gas composition: first set (first mode) 72

Table 5.3: Combustion performance: first set, (first mode) 83

Table 5.4: Produced gas composition: second set, (first mode) 88

Table 5.5: Combustion performance: second set, (first mode) 92

Table 5.6: Produced gas composition (second mode runs) 104

Table 5.7: Combustion performance (second mode runs) 108

Table 5.8: Comparison between mode I and mode II 116 


\section{CHAPTER ONE}

INTRODUCTION 


\subsection{INTRODUCTION}

In the early stage of oil production, the internal energy of the reservoir is large enough to allow the oil to be produced naturally, i.e. by depletion, until eventually the production rates become uneconomic. The recovery of a higher percentage of the oil remaining in the oil-bearing formations after depletion of initial reservoir energy has constituted a major challenge of the petroleum industry for a number of years. Oil recovery processes may be subdivided into three major categories: primary, secondary and tertiary (or enhanced oil recovery). The oil recovery rate by primary and secondary processes ranges from 35 to $40 \%$ depending on oil and reservoir properties.

Enhanced oil recovery $(E O R)$, therefore, aims to recover the oil, which is left "unrecovered" by conventional reservoir production techniques. Enhanced oil recovery processes include mainly miscible/immiscible gas injection, chemical flooding, thermal recovery and almost any technique, which is able to increase oil recovery. Thermal processes constitute an important sector of enhanced oil recovery techniques. They are designed to reduce the viscosity of the remaining oil in place by increasing the temperature of the reservoir matrix. Also, they modify the capillary forces in the oilrock matrix and thereby improve the mobility in the displacement of oil and increase sweep efficiency. There are two main methods of thermal recovery, namely; hot fluid injection and in-situ combustion (ISC). The former method has found most success in bitumen and tar sands, while in-situ combustion is finding increasing consideration for conventional lighter oil reservoirs.

In-situ combustion or fire flooding is a thermal oil recovery technique, which offers many advantages overall other processes, such as: less energy consumption, more 
efficient overall drive mechanism and less total environment impact. In-situ combustion can be wet or dry, forward or reverse. In this process, air, oxygen or oxygen enriched air is injected into the reservoir through the injection wells, the oil is ignited near the well bore, and the heat generated from the combustion reaction between the injected gas and the residual crude oil is used to mobilise and recover the oil. In this technique, a complex process that involves chemical and physical reactions is coupled with simultaneous heat and mass transfer in a multi-phase environment (Burger and Sahuquet, 1972). The fuel necessary to sustain the combustion front is supplied by the heavy residual material or "coke" that deposits on the sand grains during distillation, thermal and catalytic cracking, pyrolysis, etc. of crude oil ahead of the combustion front. The availability of this fuel has been considered the most complicated problem in the process. Fuel availability for combustion, has been discussed in detail by a number of researchers. Some of these researchers related the problem to the reservoir fluid and rock properties, while others, attribute the problem to the displacement mechanisms that occur ahead of the combustion front.

Horizontal well technology has been used in enhanced oil recovery projects, especially in thermal recovery. A combination of in-situ combustion and horizontal wells could be used to increase oil production rates, total recovery and also upgrade the quality of the produced oil (Greaves and Al-Shamali, 1996).

The world's supply of crude oil is steadily and inexorably moving toward poorer quality. The challenge will be to improve the quality of crude oil, to achieve market value and also environmental concerns. Upgrading of the crude oil has the aim of removing the heaviest, least desirable fractions while leaving behind oil, which has 
been greatly reduced in its metal, sulphur, nitrogen and Conradson carbon content. One potential way of achieving this involves placing of catalyst near the production well, so that produced fluid will pass through the catalytic bed, resulting in upgrading of produced oil.

The purpose of this work was to carry out a series of in-situ combustion experiments to investigate the feasibility of in-situ thermo-catalytic oxidation of heavy-medium Clair oil $\left(19.8^{\circ} A P I\right)$. Most of the experiments were performed using a combustion tube positioned horizontally, in which a catalytic bed was placed at the end of the sample bed in some of the experiments. Also in other tests, experiments were performed using a perforated tube, fixed to the outlet fitting of the same combustion tube, which serves as a horizontal well, and the catalytic bed in these catalytic runs was placed around the perforated section of perforated tube.

\subsection{ORGANISATION OF THE THESIS}

In the following Chapter (Chapter two), a general review of enhanced oil recovery processes is presented with emphasis on in-situ combustion. Chapter three follows this, reporting on the work that has been previously performed in the area of air injection/insitu combustion, in the field and laboratory and which includes a survey of the numerous experimental techniques employed and the various results, so obtained. The experimental apparatus used and procedures followed in this work are described in Chapter four, while the next Chapter (Chapter five) deals with the analysis of the results and discussion. Finally, the conclusions drawn from these results and recommendations for future work are presented in Chapter six. 


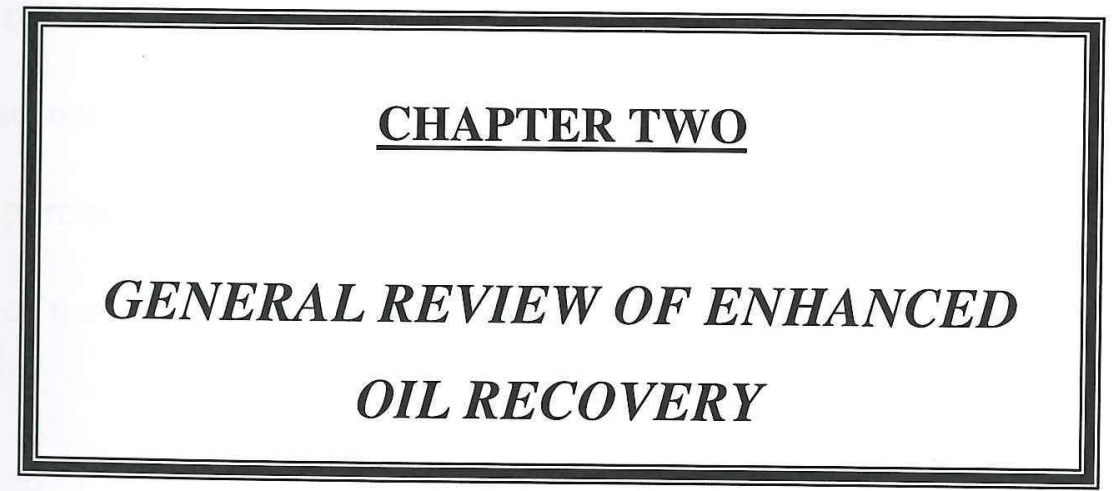




\subsection{INTRODUCTION}

Following the discovery of an oil field, when an oil well is connected with a reservoir and the oil production started, the well bore becomes an area of lower pressure. The energy required to allow the fluid to flow from under-ground to the surface (well head), is the existing natural pressure in the reservoir. Subsequently, some of this pressure will be released. The oil still flows to the surface, but more slowly and electrical submersible pumps can help the flow; this process is called the Primary recovery method.

Once the oil production rate by primary recovery methods becomes uneconomic, due to the diminution of sufficient reservoir energy, injecting either water or gas into the reservoir to build up the pressure that had become decreased during the primary recovery process, can increase the oil production. This process is termed as the Secondary recovery method.

On average, two-thirds of the reserves remain unrecoverable (Boberg, 1988) using the primary and secondary oil recovery methods due to:

- Only a portion of any reservoir can be contacted by the displacing fluid.

- Not all of the oil can be displaced from the rock that is contacted by the displacing fluid.

- Heavier, low gravity oils are frequently too viscous to move to the production wells at rates sufficient to support an economic operation.

Therefore, to improve the maximum oil recovery, new recovery methods need to be evolved. These methods are enhanced oil recovery (EOR) methods, or tertiary recovery methods. 


\subsection{EOR METHODS}

Enhanced oil recovery is the application of technologies which involve the use of heat, gases, chemicals, horizontal drilling and indeed, any other techniques to extract the remaining oil in the reservoir after the use of conventional primary and secondary recovery methods, (Egbogah, 1994). The target for EOR is the incremental oil that can be economically produced from a petroleum reservoir and which cannot be economically recovered by conventional primary and secondary methods. Most of the enhanced oil recovery $(E O R)$ techniques are designed to either reduce the viscosity of the remaining oil in place, or modify capillary forces (lower interfacial tension) and thereby increase the sweep efficiency and displacement of the drive, (Poettmann, 1983). Enhanced oil recovery processes can be subdivided into three major categories: miscible, chemical and thermal.

\subsubsection{Miscible Methods}

The term "miscible" refers to the ability of fluids to mix with each other. The principle of these methods is to inject solvent into the reservoir, which will dissolve the oil, increasing its volume, decreasing its viscosity and allowing it to flow more easily. When two fluids are miscible on mixing together in all proportions, the resultant mixture remains as a single phase; therefore, no interface exists and consequently no interfacial tension is present between the fluids. Two types of miscible displacement are usually employed, first contact and multi contact (Holm, 1986). The first contact is the injection of solvent (low molecular weight hydrocarbons such as butane, propane or LPG), which will mix with the oil in the reservoir. In the multi contact process, the miscibility is not 
achieved on first contact with the oil in the reservoir, but it is achieved in the reservoir through mass transfer between the injection fluid and the oil in the reservoir under dynamic conditions. The miscible methods are classified into three groups, depending on the fluid injected:

- Hydrocarbon Miscible Displacement.

- Carbon Dioxide Displacement.

- Inert Gas Injection.

\subsubsection{Hydrocarbon Miscible Displacement}

This technique involves the injection of liquid petroleum gases ( $L P G)$, which will completely dissolve the reservoir oil, and sweep the solvent-oil mixture to the production well. The main object of miscible hydrocarbon displacement is to reduce or eliminate the interfacial tension forces between the oil and the driving fluid. The process starts with the injection of a LPG slug, followed by injection of natural gas or gas and water to push the solvent oil mixture to the production wells.

\subsubsection{Carbon Dioxide Displacement}

$\mathrm{CO}_{2}$ is not miscible at the first contact, but the miscibility is achieved under the sufficient pressure and temperature. It can act as an immiscible and a miscible displacement agent, depending on the composition and condition of the oil reservoir, (Poettman, 1983). The $\mathrm{CO}_{2}$ vaporises or extracts hydrocarbons from the crude oil. The main advantages of this technique are that the pressure required for achieving miscibility 
achieved on first contact with the oil in the reservoir, but it is achieved in the reservoir through mass transfer between the injection fluid and the oil in the reservoir under dynamic conditions. The miscible methods are classified into three groups, depending on the fluid injected:

- Hydrocarbon Miscible Displacement.

- Carbon Dioxide Displacement.

- Inert Gas Injection.

\subsubsection{Hydrocarbon Miscible Displacement}

This technique involves the injection of liquid petroleum gases ( $L P G)$, which will completely dissolve the reservoir oil, and sweep the solvent-oil mixture to the production well. The main object of miscible hydrocarbon displacement is to reduce or eliminate the interfacial tension forces between the oil and the driving fluid. The process starts with the injection of a LPG slug, followed by injection of natural gas or gas and water to push the solvent oil mixture to the production wells.

\subsubsection{Carbon Dioxide Displacement}

$\mathrm{CO}_{2}$ is not miscible at the first contact, but the miscibility is achieved under the sufficient pressure and temperature. It can act as an immiscible and a miscible displacement agent, depending on the composition and condition of the oil reservoir, (Poettman, 1983). The $\mathrm{CO}_{2}$ vaporises or extracts hydrocarbons from the crude oil. The main advantages of this technique are that the pressure required for achieving miscibility 
is sufficiently lower than that required for miscibility with other methods. The carbon dioxide swells the oil and reduces its viscosity and it is neither hazardous nor explosive.

\subsubsection{Inert Gas Injection}

An inert gas could be used in this technique, such as flue gas or nitrogen. The phenomena of miscible displacement of reservoir fluids by this technique occur only in a narrow range of fluid composition, pressure and temperatures, which limits the number of reservoirs viable to this technique.

\subsubsection{Chemical Methods}

Chemical methods are improved water flooding methods. Their aim is to reduce the interfacial tension between the oil and the water by introducing special chemicals into the water flood, which mobilise the by-passed oil in the reservoir. There are basically three types of chemical flooding:

- Polymer flooding.

- Surfactant flooding.

- Alkaline flooding.

\subsubsection{Polymer flooding}

In this method, water-soluble polymers are added to the injected water to thicken it by raising its viscosity and improving the mobility ratio, which will increase the sweep efficiency. They also reduce the total volume of water needed to reach the maximum 
residual oil saturation. In general, there are two types of polymers, which can be used to increase the viscosity of the water:

Polyacrylamides, which are synthetically, produced material obtained by polymerisation of long chain of hydrocarbon molecules.

Polysaccharides, which are produced by cultured microorganisms and then dried and mixed with the injection water to create a very high viscosity fluid.

\subsubsection{Surfactant flooding}

Surfactant flooding using surface-active agents is aimed at obtaining very low interfacial tensions between the water and reservoir oil and improving displacement efficiency. In this process, a slug of surfactant (such as a sulfonate) is injected to lower interfacial tension between the displacing and displaced fluids. The injected surfactant slug is then followed by a larger slug of polymer drive to improve surfactant solubility in the water phase and provide mobility control. The high cost and risk associated with the injected chemicals has limited this application.

\subsubsection{Alkaline flooding}

Alkaline or caustic flooding is relatively the least expensive EOR processes. It involves the injection of cheap chemicals, such as sodium or ammonium hydroxide. These chemicals react with natural organic acids present in the crude oil to form surfactants within the reservoir. The surfactant formed works to move additional amounts of oil to the producing well. This process is not well understood and only a limited number of field trials have been undertaken with limited success. 


\subsubsection{Thermal Methods}

Thermal methods are designed to reduce the viscosity of the remaining heavy and medium oil in place by increasing the temperature of the reservoir matrix. Also, they modify the capillary forces in the oil-rock matrix and thereby improve mobility in the displacement of oil and increase sweep efficiency. Thermal processes contribute about $80 \%$ of the total oil produced by EOR methods (Ahner and Sufi, 1990). Thermal energy is introduced by hot fluid injection from the surface (hot-fluid injection), or generated by burning a part of original oil in the reservoir (in-situ combustion).

In thermal processes, (Jha and Verkoczy, 1984) oil displacement results from:

- Viscosity reduction, primarily due to heat and secondly, due to dissolution of insitu generated carbon dioxide in oil.

- Thermal expansion of the oil resulting in increased relative permeability.

- Distillation and thermal cracking of oil.

- A solution gas drive from produced gas, which facilitates the flow of fluids within the reservoir toward the production well.

- The increased pressure gradient, imposed by the injection air.

There are three categories of thermal recovery methods:

- Hot Fluid Injection.

- Cyclic steam Stimulation.

- In-Situ Combustion. 


\subsubsection{Hot Fluid injection}

In these techniques, preheated fluids are injected into a relatively cold reservoir to raise its temperature and displace the oil. Water, steam or gases are used as heated fluids.

\section{A - Hot Water Drive}

Hot water drive involves the injection of hot water to drive the residual oil through the reservoir to the oil production wells. The water is filtered and treated, before the injection, to control corrosion and minimise swelling of clays in the reservoir. The leading edge of the injected hot water front losses heat so rapidly that it quickly reaches the initial reservoir temperature. Thus, at the leading edge of the displacement front, the oil mobility is that of the unheated oil.

\section{B - Steam Drive}

Steam drive or continuous steam injection, is the most widely used thermal drive process involving hot fluid injection. It involves generating steam on the surface and injecting it down to the reservoir through injection wells. The injected steam will condense (form hot water) and cool. The heat generated from the steam and hot water turns the lighter hydrocarbons to gases by vaporisation. These gases move ahead of the steam, condense into liquids that will act as a solvent bank, dilute the oil, reduce its viscosity and serve to extract the oil in-place from the reservoir rock. In this way, additional gas drive is provided, and the hot water will move the thinned oil to the production wells. 


\section{C- Hot Gas Drive}

It involves the injection of hot noncondensable gases. Because of their low viscosity, displacement efficiencies are low. Due to the low density of the gases, the stripping of light components and their condensation needs high injection rates. Heat losses for hot gas injection are greater than for any of other two techniques mentioned above.

\subsubsection{Cyclic Steam Stimulation}

This is a cyclic process in which the same well is used for injection and production (also known as steam soak or "huff and puff"). This process can be divided into three stages; steam injection, soaking and production. In first stage the steam is injected for a short period of time (2 to 6 weeks) into a production well. In second stage, the steam injection is stopped and the well closed and the reservoir is allowed to soak for few days to allow sufficient heat dissipation. The well is then put back on production. Oil production commences at an elevated rate and eventually declines as the heat is dissipated. The well is then restimulated. Heat from injected steam increases the reservoir temperature, results in thermal expansion of the reservoir fluids and causing compression of solution gas. The resulting increase in the mobility of the crude oils due to the reduction in its viscosity, leads to an increase in productivity. The process is repeated several times until it becomes uneconomic. It is not just the reduction in oil viscosity that increases production, but other positive benefits associated with production stimulation include: thermal expansion of the fluids and reduced residual oil saturation (Prats, 1982). 


\subsubsection{In-Situ Combustion (ISC)}

In-situ combustion is a thermal recovery process in which heat is generated within the reservoir by igniting a part of the oil in place to improve the flow of the unburned region. The combustion is supported by continuous injection of air, oxygen-enriched air or steam/air injection at one or more wells. In the field, the ignition is started either by electrical means or by a gas burner, and in some cases auto ignition can be achieved, (Tadema and Weijdema, 1970). The heat generated in the combustion zone is responsible for distillation and vaporisation processes. The lighter fractions of crude oil are evaporated and condense downstream in the cooler zones forming an oil bank, while the heavier fractions remain behind and are transformed into coke. Usually the temperature reached at the combustion front is much greater than the water saturation temperature, in most cases between 400 and $600^{\circ} \mathrm{C}$ (Burger et al 1985). Compared with other thermal methods of oil recovery, in-situ combustion has certain potential advantages, such as high thermal efficiency, high oil recovery, less total environment impact and better economics, (Xia and Greaves, 2001, b).

Laboratory work has contributed a great deal to the understanding of in-situ combustion. The main techniques used in the laboratory work are combustion tubes and the already well-established thermal analysis techniques; namely thermogravimetric analysis (TGA), differential scanning calorimetry $(D S C)$ and differential thermal analysis (DTA).

There are basically two significant variations of in-situ combustion, depending on the direction of the combustion front. When the combustion front moves in the same direction as the injected air; the process is termed as forward combustion, which 
includes dry and wet combustion. The other process is reverse combustion whereby the combustion front moves counter to the direction of the injected air.

\section{A- Dry Forward Combustion:}

This technique is the most commonly used form of combustion where only air or oxygen-enriched air is injected into the reservoir. The injected air sustains combustion front that moves through the reservoir, which displaces most of the reservoir oil and consumes as fuel some of the heavier oil components that are frequently referred to as "coke". Behind the combustion front, the reservoir rock is clean, dry and hot.

Figure 2.1 shows the mechanisms of dry forward combustion under steady state conditions. Four zones, described below occur during this process from the direction of upstream (injection well) to the downstream (production well), (Burger et al, 1985). Zone 1. In this part, combustion has already taken place, so it is completely clean.

Zone 2. The combustion zone; oxygen is consumed by the combination of reactions involving the hydrocarbons and the coke remaining in the rock surface. The temperature reaches its maximum in this zone.

Zone 3. The coke formation zone. The heavy oil fractions, which have been, neither displaced nor vaporised, undergo pyrolysis.

Zone 4. No further chemical changes happen in this zone. It swept by the effluent gases and the displaced fluids, and the following phenomena take place:

$\mathbf{a}$ - Nearest the reaction zone, in the down stream region successive vaporisation and condensation of the light oil fractions and interstitial water take place. 
b - In the region where the temperature is lower than that of water condensation, a water bank is observed in which water saturation is higher than the initial saturation, which displaces a zone with oil saturation higher than the original oil saturation. Beyond the oil bank, the formation gradually approaches its initial conditions.

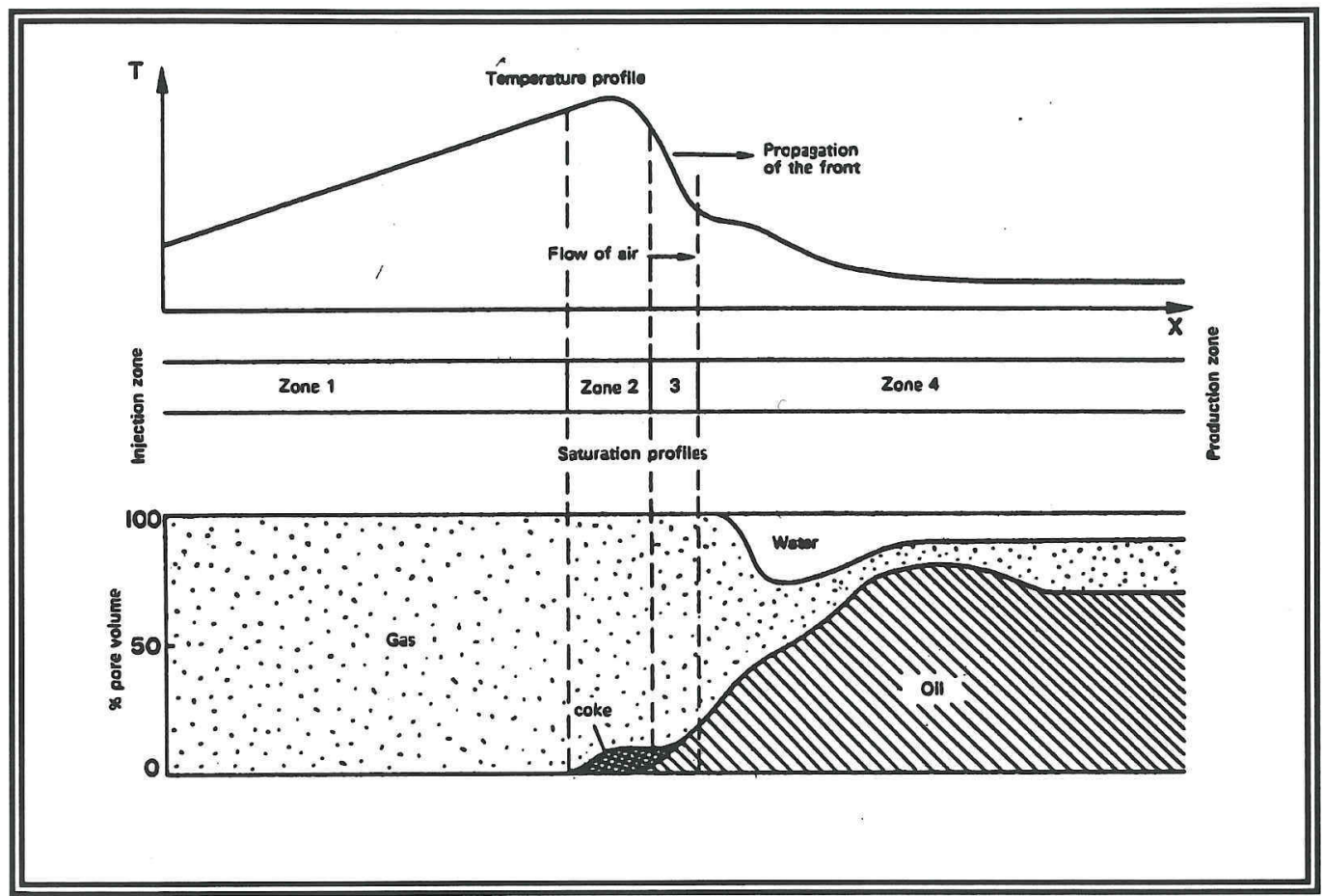

Figure 2.1: Dry forward combustion, Temperature and saturation profiles, (Burger et al 1985)

\section{B- Wet Forward Combustion:}

Wet forward combustion also known as COFCOW process (combination of forward combustion and water flood), is a recovery technique, which was conceived to improve the economics of dry forward combustion. In the dry forward combustion process more than half of the heat generated underground will exist between the air injection well and 
the combustion front. Because of the high heat capacity of water, and its latent heat of vaporisation, this problem may be overcome. In this process, the water may be injected simultaneously or alternately with the air. All or a part of the water will vaporise, pass through the combustion front and thereby transfer heat from the front downstream. Because of the higher rate of heat propagation through the oil sand, air compression requirements to achieve a given level of oil recovery are lower than for dry combustion. In addition, fuel consumption is less than for dry combustion because of the greater volume of steam passing ahead of the combustion front, (Boberg, 1988). Figure 2.2 shows this process under steady state condition. Five zones exist in the reservoir between the injection and production wells, which are described below, (Burger et al, 1985).

Zone 1. This zone is swept by the combustion front and contains little or no hydrocarbons. However, since the temperature is lower than that of boiling point of water, the pores contain liquid water saturation, the remainder of the space being occupied by the injected air.

Zone 2. In this zone water is present in the vapour phase, and the pores are saturated with a mixture of injected air and steam.

Zone 3. The combustion zone. Oxygen is consumed in the combustion of hydrocarbons and coke is formed in the down-stream part of the zone.

Zone 4. The vaporisation-condensation zone. Progressive condensation of steam and combustion water takes place in the zone. In addition, some light and medium oil fractions are vaporised and carried downstream. If the temperature is high enough certain chemical reactions may occur. 
Zone 5. Downstream of the previous zone is a zone of high backpressure, due to the formation of a water bank produced by the oil bank. Further downstream the formation gradually approaches its original conditions.

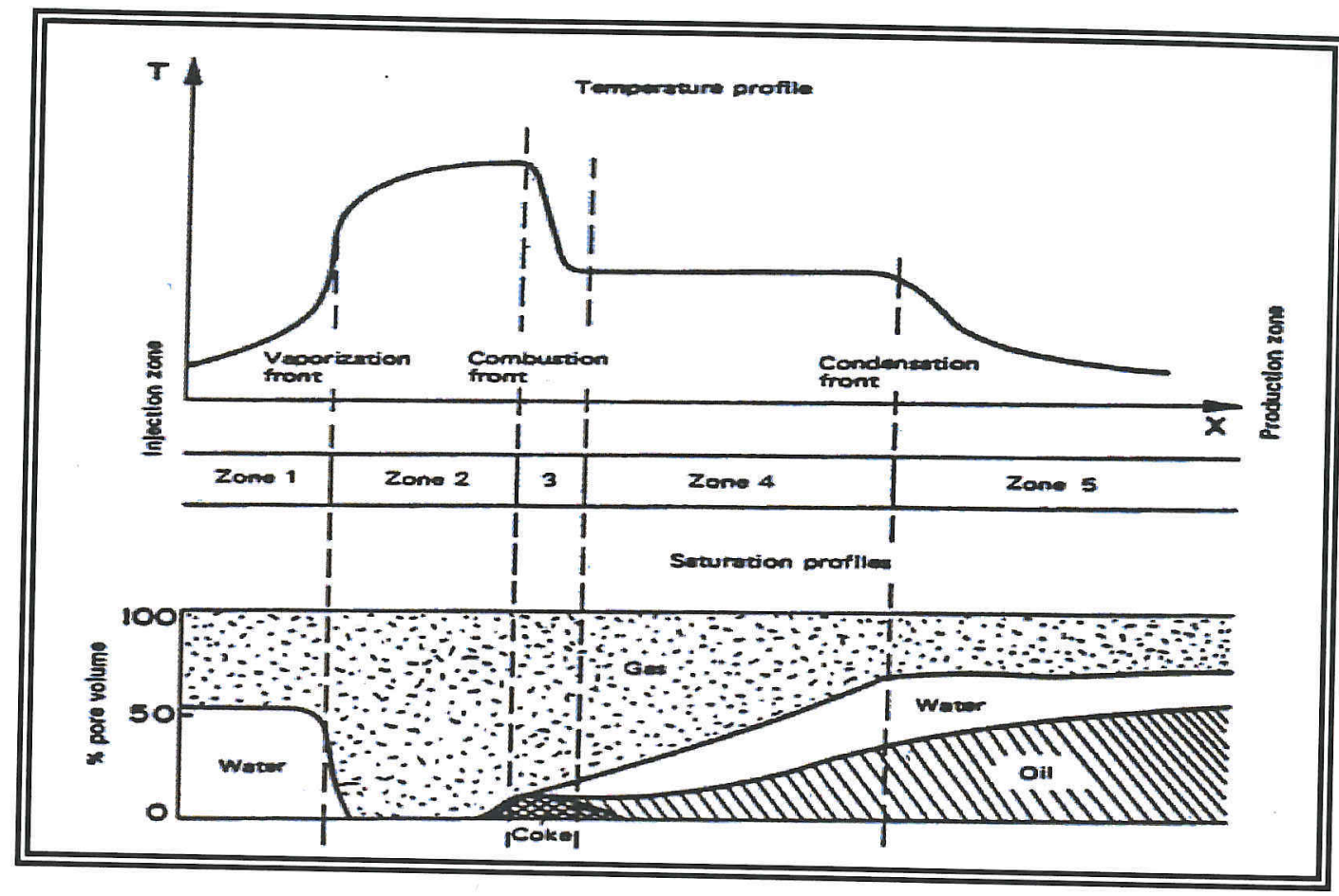

Figure 2.2: Wet forward combustion, Temperature and saturation profiles, (Burger et al 1985)

\section{$C$ - Reverse Combustion:}

As the name implies, in this process the direction of the combustion front movement is counter to that of airflow, thus air is injected into the injection well and the ignition initiated at the production well.

The objective of this process was the recovery of heavy oil tars, which have little or no mobility, and also remedies the possibility of pore blockage by liquids. As the crude and 
the combustion front contact, the crude is cracked severely and a large amount of solid fuel is formed. This is in contrast with the flow of heated crude in dry forward combustion process, in which substantial fractions of the heated crude moves away from the high temperature combustion zone and only a small amount of fuel is formed.

The following zones as can be seen in Figure 2.3 can be distinguished starting upstream and moving along the reservoir, (Burger et al, 1985):

Zone 1. The porous medium is at original conditions, however it is being swept by air, and if the temperature is high enough and oil easily oxidisable, certain oxidation reactions may occur.

Zone 2. The temperature increases by conduction from the hot zone downstream. The start of oxidation also contributes to the temperature increase. The following phenomena occur: vaporisation of the formation water, distillation of the oil light fractions and cracking of some hydrocarbons in the presence of oxygen. The liquid and vapour fractions are displaced downstream.

Zone 3. The combustion zone. The temperature reaches its maximum value. The oxygen not used in the reaction in the preceding zones is consumed in the oxidation and combustion reactions of the more reactive hydrocarbon molecules.

Zone 4. The unburned coke remains deposited on the matrix while the vapour and the fluids (liquid or vapour phase) flow downstream. If there were no heat losses, the downstream temperature is the same as that of combustion front. In real field applications, the temperature decreases with distance from the combustion zone. Thus condensation of the distilled oil fractions occurs. 


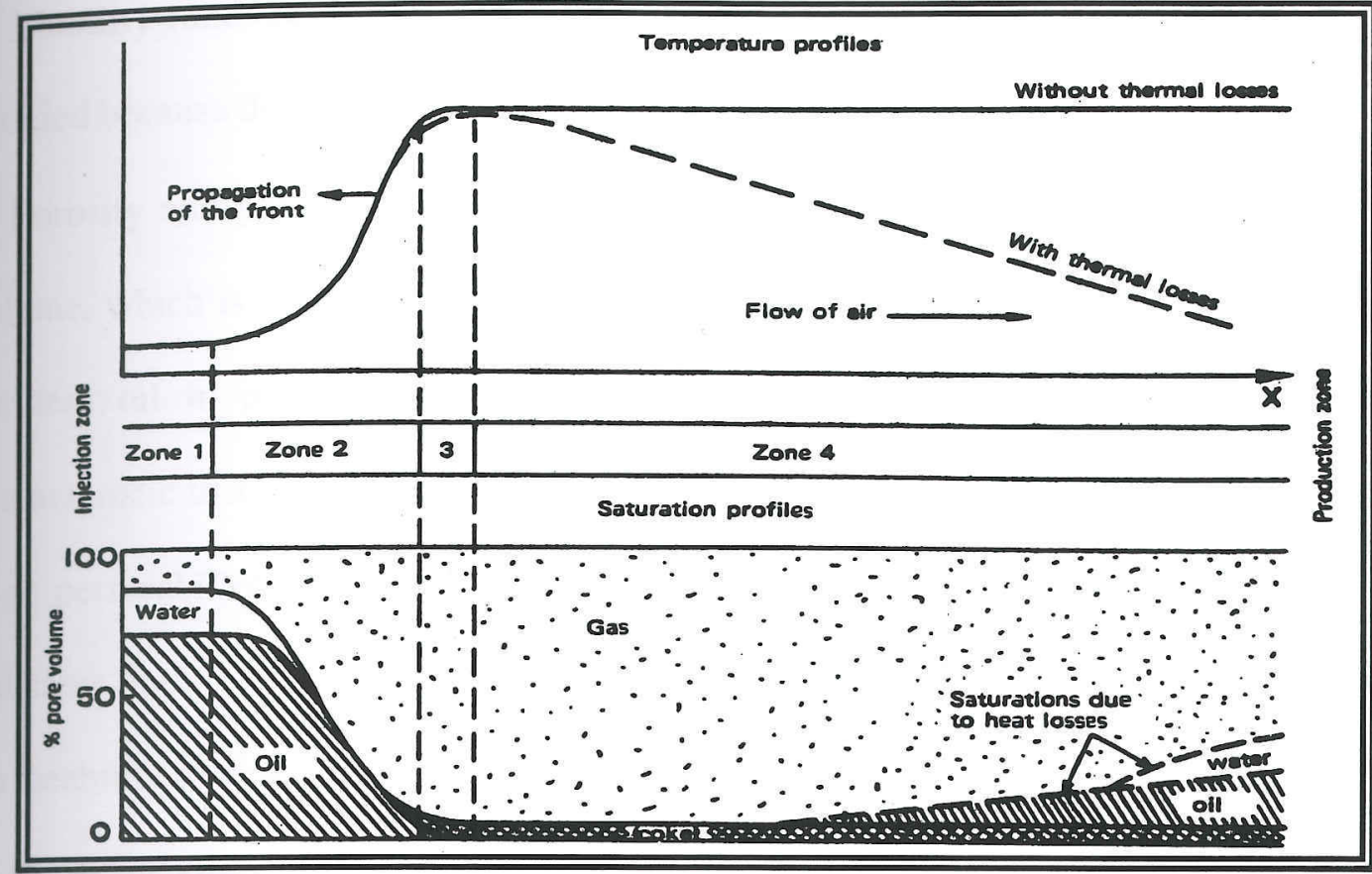

Figure 2.3: Reverse combustion,

Temperature and saturation profiles, (Burger et al 1985)

\subsection{RESERVOIR CHARACTERISTICS}

The efficiency of enhanced oil recovery processes is influenced by reservoir characteristics, which must be considered in process selection and project economics of the in-situ combustion process. These characteristics include:

- Depth: Technically, deeper reservoirs mean higher injection pressure and higher reservoir pressure and temperature. This helps in controlling the movement of the injected fluids. In-situ combustion has been used successfully in reservoirs at depths from 50 to $3350 \mathrm{~m}$ (White, 1985).

- Heterogeneity: Heterogeneities can minimise the movement of the lighter injection fluids to the top of the formation. This may occur when shale breaks exist in the reservoir, which prevent the migration of fluids through the formation. 
- Mobility ratio: reservoirs with extremely low or high water/oil ratios should be avoided because they have special requirements.

- Porosity and permeability: porosity is one of the components that make up the volume, which is available and is related to the oil in place. The lower the porosity, the less oil in place and the more rock to be heated. Permeability is a rock characteristic that describes the ease, which the fluid may move through porous rock. High permeability indicates relative ease in moving through rock; low permeability indicates the opposite. Successful projects have occurred in high porosity and permeability reservoirs.

- Strata thickness: This is particularly important because it has a pronounced effect on the fraction of heat that remains in the reservoir. It must be thicker than about $2 \mathrm{~m}$ to avoid excessive heat losses.

- Water saturation: Water saturation relates to the amount of oil in place and it determines the amount of water that might be produced with the crude oil expected to be recovered. It is also an important factor in the corrosion environment.

In summary, high porosity and permeability, low mobility ratios and thick pay sections are beneficial reservoir characteristic for in-situ combustion processing.

\subsection{OPERATIONAL PROBLEMS}

The operational problems plaguing in-situ combustion projects include poor injectivity, slow production response, early oxygen breakthrough, difficulty in sustaining combustion, erosion, corrosion, gas locking of download pumps, scaling, emulsion and explosion hazards. 


\section{CHAPTER THREE}

LITERATURE REVIEW OF IN-SITU COMBUSTION PROCESSES 


\subsection{INTRODUCTION}

The first known in-situ combustion application was in the early 1900's, when under ground combustion was accidentally started from air injection that was used to drive the oil towards the producing well. Production increased and the effect of heat on the reservoir was noted. The produced gas showed a composition of 10 to $15 \% \mathrm{CO}_{2}$ (Schumacher, 1980). The first field experiments of in-situ combustion (ISC) were conducted in the former Soviet Union in the late of 1930's. In 1952, the Mobil and Sinclair oil companies carried out in-situ combustion tests. Mobil's work was aimed at the unrecoverable heavy oil, while Sinclair tackled the light oils that were left in the reservoir after a water flood (Gates and Ramey, 1958). Both tests were successful in recovering additional oil. Kuhn and Koch (1953) presented the first major presentation of laboratory and field data regarding in-situ combustion. In 1954, Grant and Szasz (1954) published a concise history of the early work on in-situ combustion and presented the results of field tests, which were operated from 1948 to 1953 . These researchers visualized a travelling heat wave ...i.e., the injected cool air carried the heat left behind the burned zone to the downstream section. By the late 1950 's, all thermal oil recovery processes were similar with some variations for improvement over the basic in-situ combustion process. The basic in-situ combustion process may be described as a heat wave that moves outward from the ignition well, driving all reservoir fluids ahead of it to the producing wells. McNeil and Moss (1957) and Gates and Ramey (1958) showed that this heat wave is sustained by the oxidation of the reservoir oil by the injected air. 
Nelson and McNiel (1961) designed a full-scale in-situ combustion project, and outlined a procedure to correlate the combustion tube data with field projects. They presented basic equations for the estimation of parameters, which influence the in-situ combustion process from the engineering and economic aspects. In 1964, Mene Grande Oil Co. started an ISC air injection process in the $\mathrm{P}_{2-3}$ sand reservoir in the Miga field of Eastern Venezuela (Terwelliger et al, 1975). Hardy et al (1972) reported a successful combustion project following a successful waterflood in a light oil reservoir. In spite of these intense studies and because of the complex nature of the process, many aspects of ISC process are still not completely understood.

Turta (1994) has reported that 14 active commercial in-situ combustion projects were operating world-wide in 1994, while Moore et al (1997) have reported on 28 ISC projects carried out in Canada. The first was started by Shell in 1958, while Amoco started the latest in 1994.

\subsection{REACTION KINETICS OF IN-SITU COMBUSTION}

The studies of the kinetics of crude oil oxidation reactions involved in in-situ combustion have been conducted by a number of investigators, (Tadema, 1959; Bousaid and Ramey, 1968; Weijdema, 1968; Burger and Sahuquet, 1972; Dabbous and Fulton, 1974 and Fassihi and Brigham, 1981).

The oxidation of oil is accomplished whenever it contacts with oxygen. It is simply a chemical reaction in which the addition of oxygen or elimination of hydrogen from a compound takes place. In-situ combustion is probably the most complex enhanced oil recovery process, because of the overlap of several competing chemical reactions 
occurring over different temperature ranges. These reactions can be divided into three groups:

- Low temperature oxidation (LTO) reactions.

- Medium temperature oxidation (MTO) "fuel deposition" reactions.

- High temperature oxidation (HTO) "fuel combustion" reactions.

\subsubsection{Low Temperature Oxidation}

Low temperature oxidation (LTO) reactions are the reactions between oxygen and crude oil at temperatures below $\sim 300^{\circ} \mathrm{C}$. The occurrence of LTO, during in-situ combustion processes, is due to the presence of free oxygen in the low temperature region of the formation. LTO reactions are characterised by either no carbon oxides or low levels of these in the produced gas stream. In other words, more oxygen reacts with the hydrocarbons than can be found in the produced gases. LTO affects only the lighter components of the hydrocarbon, and results in the production of various oxygenated hydrocarbons, such as aldehydes, alcohols, ketones, acids and peracids, along with the associated production of water (Burger and Sahquet, 1972). The resulting oxygenated crude can have significantly higher viscosity, lower volatility and lower gravity than the original oil due to subsequent production of asphaltenes from there oxygenates.

Alexander et al (1962) studied the effect of LTO on fuel formation by subjecting a sample of oil and sand to a continuous air injection and heating schedule. The fuel content was increased, because oxygen was not completely consumed at the high temperature combustion front. Also, they emphasised that LTO reactions increase the oil viscosity and alter the distillation characteristics of crude oil. 
Low temperature oxidation ( $L T O$ ) takes place upon air injection, either before or after ignition (when oxygen is available downstream of the combustion front). Okandan (1982), Moss and Cady (1982) and Fassihi et al (1984) stated that LTO causes a decrease in the oil's API gravity and significantly increases the amount of fuel available for combustion.

Vossoughi (1986) noticed that decreasing the crude oil/surface area ratio enhanced the LTO peak. This was confirmed by Hughes et al (1987), who showed that the extent of LTO reaction increases with an increase of surface area, and that the carbon oxides were produced at lower temperatures.

Meyers et al (1986) presented results of an experimental study on the low temperature oxidation of four kinds of crude oil of gravity ranging from 10 to $31^{\circ} \mathrm{API}$. The LTO of these oils was presented as a function of time, temperature and oxygen partial pressure. It causes an increase in both oil viscosity and density, and the rate of viscosity increase was dependent on the oil's API gravity, origin and composition.

\subsubsection{Medium Temperature Oxidation}

Medium temperature oxidation (MTO) or (fuel deposition), which may occur at temperatures above $\sim 300^{\circ} \mathrm{C}$; plays an important role in the crude oil combustion. It occurs in a reservoir undergoing in-situ combustion as a result of physical and chemical changes that are inflicted upon the reservoir oil. As the oil is heated through intermediate temperatures, it undergoes several overlapping reaction stages of pyrolysis i.e., distillation, visbreaking and coking, (Abu-Khamsin et al, 1988). In distillation, light hydrocarbons volatilise as their vapour pressure exceeds their partial pressure in the gas 
phase. At higher temperatures, mild cracking (visbreaking) of the oil occurs in which hydrocarbons lose small side groups and hydrogen atoms to form more stable, less branched compounds. At temperatures above $360^{\circ} \mathrm{C}$, the residual oil cracks into volatile fractions and non-volatile heavy residue consisting of coke, tar and pitch, which make the primary fuel for combustion. The amount of fuel deposited, is a very important factor in in-situ combustion project design because the maximum oil recovery is the difference between the initial oil in place and the amount of fuel deposited. The amount of fuel deposition for combustion was observed to increase with decreasing API gravity, (Alexander et al, 1962 and Showalter, 1963).

Burger and Sahuquet (1972) stated that there is no residual fuel deposition as long as the high temperature zone existed. When water was injected along with air, the fuel deposition decreased as a result of more efficient sweep in the steam plateau.

Grant and Szasz (1954), Alexander et al (1962), Dabbous (1971) and Fassihi et al (1984) detected that the overall fuel deposition is actually associated with a complex series of exothermic reactions that collectively are referred to as low temperature oxidation, thermal cracking (visbreaking and coking) and that the velocity of the combustion front is related to the quantity of fuel available for combustion.

The mechanism of fuel deposition is controlled by two processes, the evaporation of crude oil components and the kinetics of thermal cracking reaction. These two processes determine how much fuel eventually will be burned and how much fuel will be left as coke for combustion reaction (Lin et al, 1984). 


\subsubsection{High Temperature Oxidation}

High temperature oxidation (HTO) or fuel combustion is the main factor responsible for generating heat in the reservoir i.e., the principle mechanism for the in-situ combustion process, (Lerner et al, 1985). HTO reactions take place during cracking processes, which may occur above $\sim 360^{\circ} \mathrm{C}$ in combustion zone, between oxygen in the gas phase and the heavy residue of oil that had been deposited on the rock matrix at lower temperatures. Carbon dioxide, carbon monoxide and water are the main products of these reactions. The effectiveness of in-situ combustion depends on the rate at which heat is generated by the combustion process and the efficiency of the heat utilization, which in turn depends on reservoir fluid distribution and the thermal properties of the reservoir rock matrix and the surrounding rock. HTO reactions can be represented by the following equation: (Burger et al 1985)

$$
\mathrm{CH}_{\mathrm{x}}+(1-m / 2+x / 4) \mathrm{O}_{2} \rightarrow(1-m) \mathrm{CO}_{2}+m \mathrm{CO}+x / 2 \mathrm{H}_{2} \mathrm{O}
$$

Where,

$$
\begin{aligned}
& m=\text { Molar ratio } \mathrm{CO} /\left(\mathrm{CO}+\mathrm{CO}_{2}\right) . \\
& x=\text { Atomic hydrogen/carbon }(\mathrm{H} / \mathrm{C}) \text { ratio of the fuel. }
\end{aligned}
$$

The heat generated from these reactions provides the thermal energy that drives the process for crudes subjected to LTO reactions prior to combustion. The amount and type of fuel deposited affects the HTO reaction.

The combustion reaction rate $(\mathrm{Rc})$ of crude oil in a porous medium has been expressed by Wilson et al (1963), Bousaid and Ramey (1968) and Fassihi et al (1984) as follows:

$$
\mathrm{R}_{\mathrm{c}}=\mathrm{k}_{\mathrm{i}} \mathrm{Po}_{2}{ }^{\mathrm{mi}} \mathrm{C}_{\mathrm{f}}{ }^{\mathrm{ni}}
$$


Where, $\quad \mathrm{C}_{\mathrm{f}}=$ instantaneous concentration of fuel

$\mathrm{k}=$ reaction constant

$\mathrm{PO}_{2}=$ partial oxygen pressure

$\mathrm{m}=$ reaction order with respect of oxygen

$\mathrm{n}=$ reaction order with respect of fuel concentration

$i=$ reaction regime

The reaction rate is often assumed to be first order with respect to fuel for each reaction concentration, (i.e. $\mathrm{n}=1$ ), (Fassihi et al, 1984).

The reaction constant " $k$ ", is normally expressed as a function of temperature " $T$ ", by the Arrhenius equation:

$$
\mathrm{k}=\mathrm{A}_{\mathrm{r}}(-\mathrm{E} / \mathrm{RT})
$$

Where,

$$
\begin{aligned}
& \mathrm{A}_{\mathrm{r}}=\text { Arrhenius constant } \\
& \mathrm{E}=\text { activation energy } \\
& \mathrm{R}=\text { universal gas constant } \\
& \mathrm{T}=\text { absolute temperature }
\end{aligned}
$$

The hydrocarbon fuel being consumed is different for each class of oxidation reaction:

- For LTO, it is unreacted crude.

- For MTO, it is the light hydrocarbon formed by cracking.

- For HTO, it is the solid hydrocarbon (coke) deposited by pyrolysis. 


\subsection{REACTION KINETIC STUDIES}

The traditional concept of in-situ combustion is that of a propagating high temperature combustion zone, which displaces oil towards the production wells. The injection gas may be normal air, enriched air or depleted air. The fuel for the process is normally assumed to be a coke-like substance, which is deposited on the mineral matrix by thermal cracking or pyrolysis reactions that occur on the leading edge of the combustion region, (Moore, 1993). The main interest in studying in-situ combustion kinetics is to find out the conditions required to achieve ignition and sustain higher temperature oxidation. The ability to maintain a stable combustion temperature front depends on the extent of the exothermic combustion reactions involved (Burger and Sahuquet, 1972), and arising from this the velocity of the burning front.

Tadema (1959) observed two different combustion reactions, which occurred at about 270 and $400^{\circ} \mathrm{C}$. Analysis of the produced gases showed that oxygen was taken up near $270^{\circ} \mathrm{C}$, with a small fraction of oxygen consumed to form carbon oxides, while the majority reacted with hydrogen to form water. At $400^{\circ} \mathrm{C}$, mainly carbon dioxide and monoxide were formed, little water was produced and a hydrocarbon residue was observed. He also reported that the atomic hydrogen/carbon ratio of burned fuel decreased with increasing temperature.

Dietz and Weijdema (1968) in describing the basic principle of wet combustion; classified the processes into "normal wet" and "partially quenched" corresponding to increasing amounts of water injected. They concluded that the air requirement per unit of formation swept during partially quenched combustion was lower than that in dry and normal wet combustion. 
Weijdema (1968) classified three stages in the oxidation of the crude oil: (1) at lower temperatures oxygen is taken up in the oil molecules; (2) at increased temperatures oxidative cracking occurs, which leaves a coke residue; (3) at high temperatures the coke is burnt.

Bousaid and Ramey (1968), Burger and Sahuquet (1972) and Fassihi and Brigham, (1981) confirmed the occurrence of three major reactions in in-situ combustion process. Parrish and Craig (1969) identified the major benefit of the wet combustion process, to be a marked reduction in the air to oil ratio because less oil was burned as fuel. Consequently, more oil is recoverable. Alderman and Osoba (1971) and Garon and Wygal (1974) obtained similar results.

Dabbous (1971) stated that for combustion to proceed and be sustained, it is necessary for the injected gas to pass through the combustion zone to react with the fuel, so that, the burning front propagates and is self-sustained.

Burger and Sahuquet (1972) demonstrated the influence of additives (copper and nickel oxides) on the combustion of crude oil by evolved gas analysis (EGA) experiments. Two successive oxidation peaks were obtained. The first peak corresponded to low oxidation temperature, and the second peak corresponded to the combustion of coke with a low $\mathrm{H} / \mathrm{C}$ ratio while most of the oxygen consumed is transformed to carbon oxides. They also observed that in the presence of additives, the oxidation reactions shifted to a lower temperature and the area under the second peak is increased. They illustrated the first result by an increase of the oxidation rate when catalyst is present, while the second result was due to the formation of a larger coke amount. 
Thomas et al (1979) described the overall forward combustion process by a simple twostep chain reaction, namely fuel lay-down and fuel burn-off, which are essentially competitive and both kinetically controlled.

Fassihi et al (1980 \& 1984) and Fassihi and Brigham (1981) conducted experiments and showed by produced gas analysis, that the combustion of crude oil in porous media is not a simple reaction, but follows several consecutive reactions. They classified three groups of reactions, namely low temperature reactions (LTO), medium temperature reactions (MTO) and high temperature reactions (HTO) and postulated that LTO reactions are heterogeneous (gas-liquid) and MTO reactions are mainly homogeneous (gas phase) and are a result of oxidation of the distillation and pyrolysis products, while HTO reactions are heterogeneous and are the result of the combustion of a heavy residual of oil deposited on the solid matrix.

Vossoughi et al (1983) studied the effect of clay on the combustion of crude oil. They found that the addition of Kaolinite clay mineral or silica powder significantly changed the shape of crude oil combustion analysis curves. The effects observed corresponded to a shifting of the large amount of heat produced from a higher to a lower temperature range and the average heat evolved was increased. They stated that the crude oil weight loss, under constant conditions of atmosphere and heating rate, was lower in the absence of clay than in its presence, which indicates the effect of clay on the chemical reactions occurring.

Bagci (1986) studied the reaction kinetics of five crude oils in dry and wet combustion experiments. He observed three main reactions: low temperature oxidation, fuel deposition and high temperature oxidation reactions. The molar $\mathrm{CO}_{2} / \mathrm{CO}$ ratios varied 
during LTO and fuel deposition, but were constant during HTO. The atomic H/C ratios decreased with an increase in temperature and their wet combustion values were lower than those for dry combustion.

Moore et al (1988) carried out ten combustion tube experiments on Athabasca bitumen, to investigate the effect of the injection of wet air on oil recovery. Dry runs showed a lower oil recovery than the corresponding normal wet experiments. They also concluded that the fuel consumption and air requirement decreased with an increasing WAR.

Greaves et al (1988) found that the addition of clay has a catalytic effect on the carbon deposition reaction, leaving the carbon combustion reaction unaffected, and they concluded that the combustion kinetics of medium-heavy crude oil sand-pack are dependent on fuel concentration, oxygen partial pressure, and combustion peak temperature.

Hughes et al (1996) stated that the type of porous media significantly affects the nature of reactions taking place in in-situ combustion.

Al-Saffar et al (2000) carried out experiments to study the oxidation kinetics of North Sea crude oils. They concluded that LTO reactions are still occurring to some extent together with HTO reactions and there is a degree of interaction between these reaction regimes. 


\subsection{THERMAL RECOVERY USING HORIZONTAL WELLS}

Thermal recovery processes using horizontal wells are divided into two main categories, which are steam-assisted gravity drainage (SAGD) and displacement processes, (Aguilera et al, 1991).

In recent years, horizontal wells have been very successful in increasing productivity, adding reserves and improving the overall cost-effectiveness of field operations. Horizontal wells are being used more frequently worldwide by the oil and gas industry to improve the economics of hydrocarbon production. The main advantages of horizontal wells are enhanced production rates, improved sweep efficiency, increased steam injectivity, minimized gas and water coning and water production, and a decrease in number of wells required for field development. This last point is especially important in thermal oil recovery projects, where several closely spaced vertical wells are required for economic development. Vertical oil wells cross a production formation for only short distances; however, horizontal wells can be placed within a reservoir to cover longer distances, up to several hundred meters, which leads to enhanced production possibilities. When horizontal wells are used as producers, they provide a large producing capacity with high producing rates, (Joshi, 1991).

\subsubsection{Laboratory Studies Using Horizontal Wells}

Several investigations have been conducted to evaluate the performance of horizontal wells in different EOR methods. By placing the horizontal producer well close to the bottom of the oil zone, the only path for the mobilized gas and liquids to leave the formation is via top-to bottom flow, directly into the horizontal production well. 
Joshi (1988) performed low steam-assisted gravity drainage (SAGD) experiments. He suggested that production rates are two to five times greater than unstimulated vertical well production due to the large reservoir contact area.

Islam et al (1989) reported a new method by using horizontal wells, for heavy-oil reservoirs containing a water zone. It involves electromagnetic heating of the production wells with gravity stabilized gas or water injection. They found that recoveries as high as $77 \%$ OOIP might be obtained.

A laboratory study was carried out by Greaves et al (1993) to study the use of horizontal producer wells (both single and dual-horizontal well configuration) in dry forward in-situ combustion processes. They concluded that the sweep efficiency and heavy oil recovery were increased when using horizontal producer wells. The volumetric sweep efficiency increased from $59 \%$ to $70 \%$, over the vertical well case, and the oil recovery increased accordingly.

Bagci et al (1992 and 1993) reported that in cyclic steam injection, the use of horizontal wells increased the oil recovery by $30-50 \%$.

\subsection{CATALYTIC UPGRADING OF CRUDE OIL}

There currently exists a large supply of heavy and medium crude oils, which is relatively uneconomical to produce. However, there are processes available, which can be used in a downhole environment to upgrade them. A process which is especially favourable for downhole implementation is the use of in-situ combustion to generate 
reactive gases, such as $\mathrm{CO}_{2}$, and to drive produced fluids over a near well bore catalyst heated bed, (Moore et al, 1999).

A successful in-situ catalytic upgrading project entails several distinct technologies: placement of catalysts in an oil bearing formation near the well; mobilisation of reactants, including the original crude oil and co-reactants, such as hydrogen, water, or carbon monoxide, over the catalyst bed; creation of the necessary processing conditions, to achieve a reasonable catalytic upgrading; and finally production of the upgraded oil. Certain minerals and metallic derivatives of reservoir rock have catalytic effects on the fuel formation and combustion, (Dirci and Vossoughi, 1987).

There have been some attempts reported at in-situ upgrading, taking advantage of the fact that simple thermal processing of crude oil can result in a degree of upgrading through visbreaking or thermal cracking, (Speight, 1991).

Wiesz and Goodwin (1966) studied the combustion rate of coke deposited within porous catalyst particles in the absence of appreciable diffusion effects, and emphasized that: (a) the rate of combustion was independent of the source and structure of the coke, (b) the presence of oxides of the transition metals resulted in a coke burning rate higher than the uncatalysed rate at any given temperature, (c) both the catalyst and uncatalysed coke combustion had an activation energy of $157 \pm 7 \mathrm{~kJ} / \mathrm{gmole}$.

The literature on catalytic cracking shows that increasing catalyst-site density and acid strength favours increased rate of coke formation, (Tanabe, 1970). 
Using thermal analysis methods, Burger and Sahuquet (1972) have found that the presence of metallic derivatives of iron, nickel, copper, vanadium, ...etc, either in the oil or in the matrix, catalysed the oxidation reactions of crude oil components.

Fassihi et al (1984), Greaves et al (1987) and Rashidi and Bagci (1991) studied the effect of clay content and metallic derivatives on the oxidation reaction. They observed lower activation energies for the reactions involved in the combustion process. Also they reported that increasing the clay content increased the air required due to increased fuel availability, which is indicative of the catalytic effect of the clay and metallic derivatives.

Ranjbar (1995) performed pyrolysis and combustion tests to examine the influence of thermo-catalytic reactions on the amount and reactivity of fuel in an in-situ combustion process. He used rocks of varying mineralogical composition and crude oils with different contents of asphaltenes and resins and reported that the controlling mechanism of fuel formation is the conversion of crude oil components by radical polymerisation.

Moore et al (1999) used a combustion tube to carry out dry forward combustion experiments using Middle-Eastern crude oil of $15^{\circ} \mathrm{API}$ gravity. In one experiment, they packed the last three zones of the tube at the production end, with a mixture of sand and catalyst using a 50/50 volume ratio. The catalyst used was fresh alumina-supported nickel molybdenum. Another experiment was conducted without catalyst, but with the same operating parameters. They reported an 8 points API gravity increase and 50\% sulphur removal in the oil produced from the catalytic run. The heated catalyst converts $\mathrm{CO}$ to additional $\mathrm{H}_{2}$, probably by the water-gas shift reaction. High API gravity oil was 
produced but the API gravity is decreased as the combustion front propagates toward the production end, which suggests that the catalyst activity decreased with time.

Weissman et al (1996), have studied the effect of $\mathrm{Co}-\mathrm{Mo} / \mathrm{Al}_{2} \mathrm{O}_{3}$ catalyst on upgrading of the crude oil; they found that the crude oil gravity increased by 8 points of API and the sulphur content decreased up to $50 \%$.

Kisler and Shallcross (1996) studied the effect of metallic catalysts on light oil oxidation; they concluded that some metallic catalysts such as, copper, sodium and iron enhanced the fuel combustion reactions, while magnesium and cobalt reduced the amount of fuel available.

Castanier and Brigham (1997) reported that metallic additives, such as, cooper, iron, aluminium and nickel created changes in the nature and amount of fuel formed during in-situ combustion. These changes appear to depend on the oil type used.

Ovalles et al (1998) have studied the upgrading of extra heavy crude oil using a dispersed molybdenum catalyst in the presence of methane as a source of hydrogen. They reported an increase of API gravity of 7 degrees and a reduction of sulphur content of $16 \%$ compared with the original crude oil.

Al-Saghr (1998) has studied the down hole catalytic upgrading of heavy crude oil, using $3 \mathrm{D}$ system combustion experiments. The catalyst bed was placed along the horizontal well in a line drive. He concluded that the oil produced by in-situ combustion (non-catalytic) is upgraded by 2 to 3 points compared with the original crude oil. In catalytic experiments, dry and wet, the upgrading was higher, ranging from 7 to 10 points, respectively. 


\subsubsection{Crude Oil Upgrading Technology}

The objective of an upgrading process is to remove the heaviest, least desirable fractions while leaving behind oil that has been greatly reduced in its metal, nitrogen, sulphur and Conradson carbon content. Upgrading methods range from simple visbreaking, which lowers oil viscosity to increase its mobility, to sophisticated chemical processes capable to converting heavy or medium crude oil into high quality synthetic lighter crude oil. There are two basic methods for medium and heavy oil upgrading: carbon removal and hydrogen addition, (Al-Saghr, 1998).

Carbon removal (coking), basically removes the heavy asphaltene fraction of the crude oil, thereby increasing the hydrogen carbon ratio of liquid fraction. Carbon removal processes can be catalytic or non-catalytic. Non-catalytic processes include thermal cracking, physical separation, gasification and combustion. Thermal cracking and physical separation processes produce a high carbon residue stream (coke), which is usually used as fuel in combustion processes. Gasification and combustion processes convert the residue feed to either gas or energy. Catalytic carbon removal processes use a catalyst to absorb the coke into its surface, which is then removed via combustion in the treating vessel.

Hydrogen addition (hydrocracking) is a catalytic process, in which the feedstock is reacted in the presence of hydrogen. The $\mathrm{H} / \mathrm{C}$ ratio is increased as more hydrogen atoms are attached to cracked chains of carbon-hydrogen molecules. Hydrogen addition processes provide the greatest liquid yields for a given feed but the high hydrogen consumption associated with these processes is one of the main drawbacks. 


\subsubsection{Catalytic In-situ Upgrading Processes}

Several processing options can be concocted to achieve near well-bore in-situ upgrading, in which oil is passed over a fixed bed of catalyst. Weissman et al (1996) and Moore et al (1999) were the first to introduce the concept of placing a solid catalyst in the reservoir, to achieve downhole upgrading, (Greaves and Xia, 2001).

Weissman et al (1996) have proposed placing the catalyst near the production end, the catalysts being placed by conventional gravel packing techniques. The heated oil and hot gases, generated by combustion reaction, are passed over the catalyst bed and hydrogenation takes place to produce upgraded oil. They proposed three different insitu upgrading processes.

\subsubsection{In-situ catalytic upgrading using downhole injection}

In this process, the hydrogen or other upgraded gas is injected into a preheated bed of catalyst placed in the vicinity of the production well. Reservoir fluids pass over the heated catalyst zone and contact the injected hydrogen or upgraded gas; the oil is then upgraded. Figure 3.1 shows the process mechanism. 


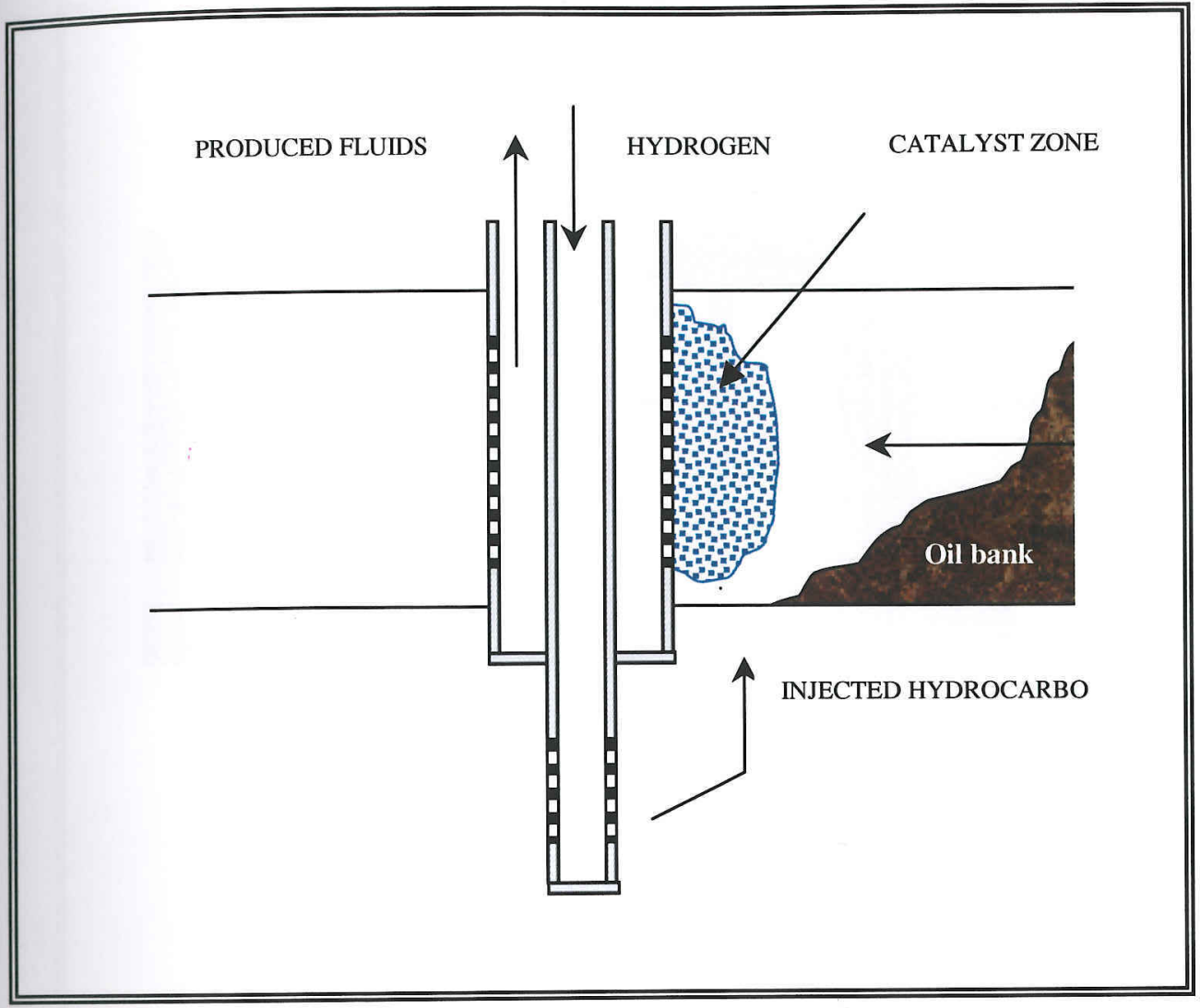

Figure 3.1: In-situ catalytic upgrading scheme with

downhole injection processing, (Weissman et al, 1996)

\subsubsection{2 "Burn and Turn" in-situ catalytic upgrading}

Two stages are carried out in this process; firstly, air is injected and a dry or wet combustion is initiated in the oil-saturated catalyst bed and allowed to propagate for some distance. As the burn started, the area adjacent to the well is heated. In the second stage, the well is brought to production, reservoir fluids and combustion gases pass over the heated catalyst, and the produced oil is upgraded. Because the catalyst activity deteriorates rapidly, the catalyst must be reactivated using a steam/air mixture. The process is shown in Figure 3.2 . 


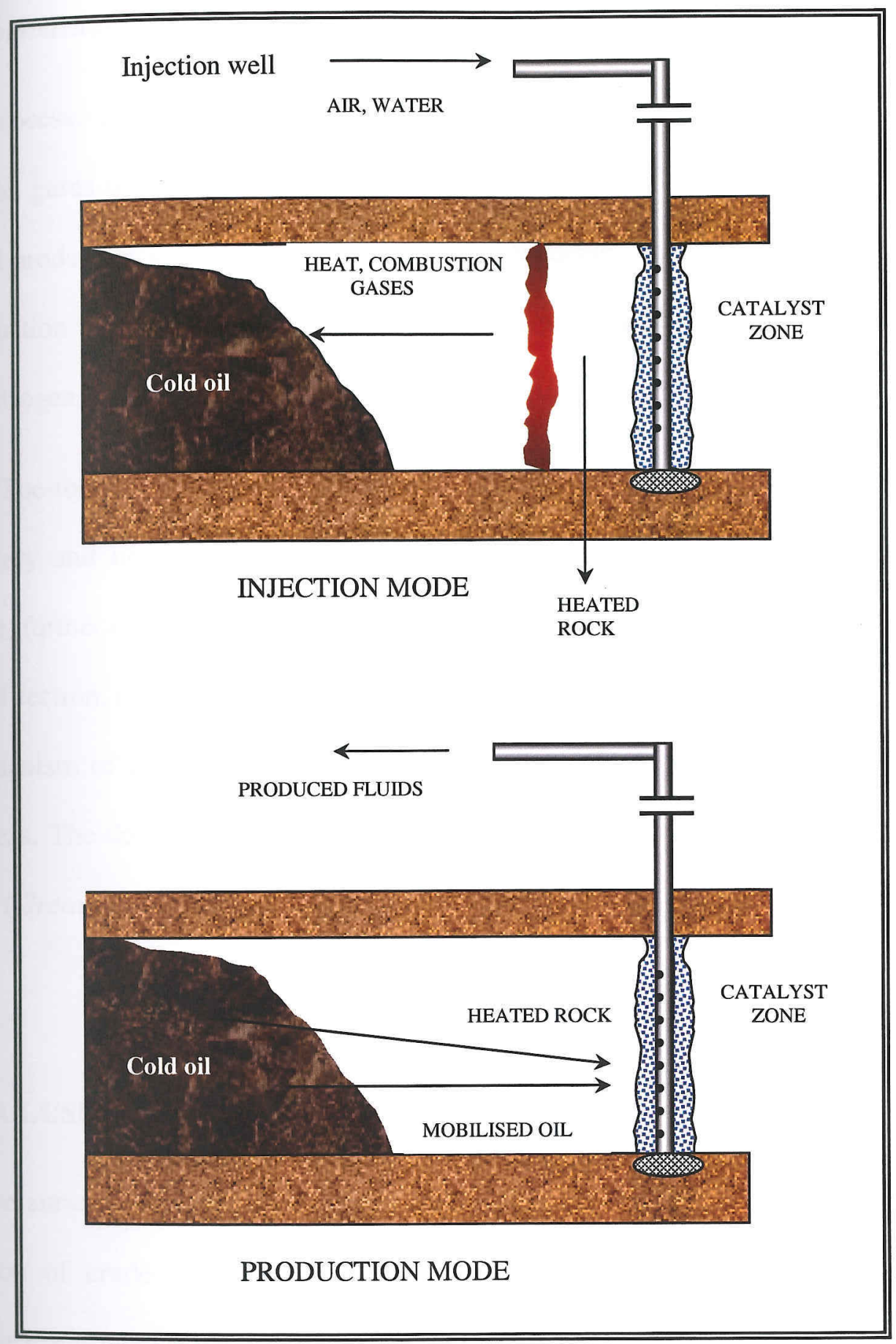

Figure 3.2: "Burn and Turn" in-situ catalytic process, (Weissman et al, 1996) 


\subsubsection{Combustion assisted in-situ catalytic upgrading}

In this process, a dry or wet combustion is used to drive reservoir fluids and combustion gases over a catalyst bed placed near a production well, between the sand phase and production casing. The catalyst bed can be heated by thermal override from the combustion front, or by down hole electrical, steam, or gasification methods. As a result, hydrogenation takes place and upgraded oil is produced.

THAI - "Toe-to-Heel Air injection" is an integrated horizontal wells in-situ process for the recovery and upgrading of medium to heavy crude oil. In addition to thermal upgrading, further upgrading can be achieved by emplacing a catalyst layer around the perforated section, along the length of horizontal producer, creating a downhole reactor. The mechanism of oil displacement in THAI is very different from the conventional ISC process. The downhole catalytic process CAPRI is simply the catalytic extension of THAI, (Greaves and Xia, 2001). The process diagrams are shown in Figures 3.3 and 3.4 .

\subsection{CONCLUSIONS}

The above survey shows that the overall oxidation reactions occurring during in-situ combustion of crude oils in porous media are a result of an overlap of several competing reactions occurring over different temperature ranges. These reactions are, low temperature oxidation, medium temperature oxidation and high temperature oxidation. The kinetics of these oxidation reactions have been the subject of many investigations, in order to find out the rate, order and the mechanism of these reactions. Many parameters which effect the rate of oxidation were studied, such as, crude oil 
type, API gravity, air flux, temperature, heating rate, presence of catalyst, presence of water ...etc. If the combustion temperature is sufficiently high, the fuel is mainly carbon and the principal reaction products are carbon oxides.

Horizontal well technology is being used in enhanced oil recovery projects, especially in thermal recovery. Horizontal wells are used to enhance production rates, to improve sweep efficiency, and to increase ultimate oil recovery.

Several processing options have been developed to accomplish near well bore in-situ upgrading of crude oils. They are designed to pass oil over a fixed bed of catalyst prior entering the production well. Forcing the oil to flow over a heated zone prior to production results in some upgrading of the oil, as compared with the original oil, due to thermal effects. Passing the oil over a hydro-processing catalyst placed in the heated zone results in a product that is significantly upgraded as compared to either the original oil or a thermally processed oil. 


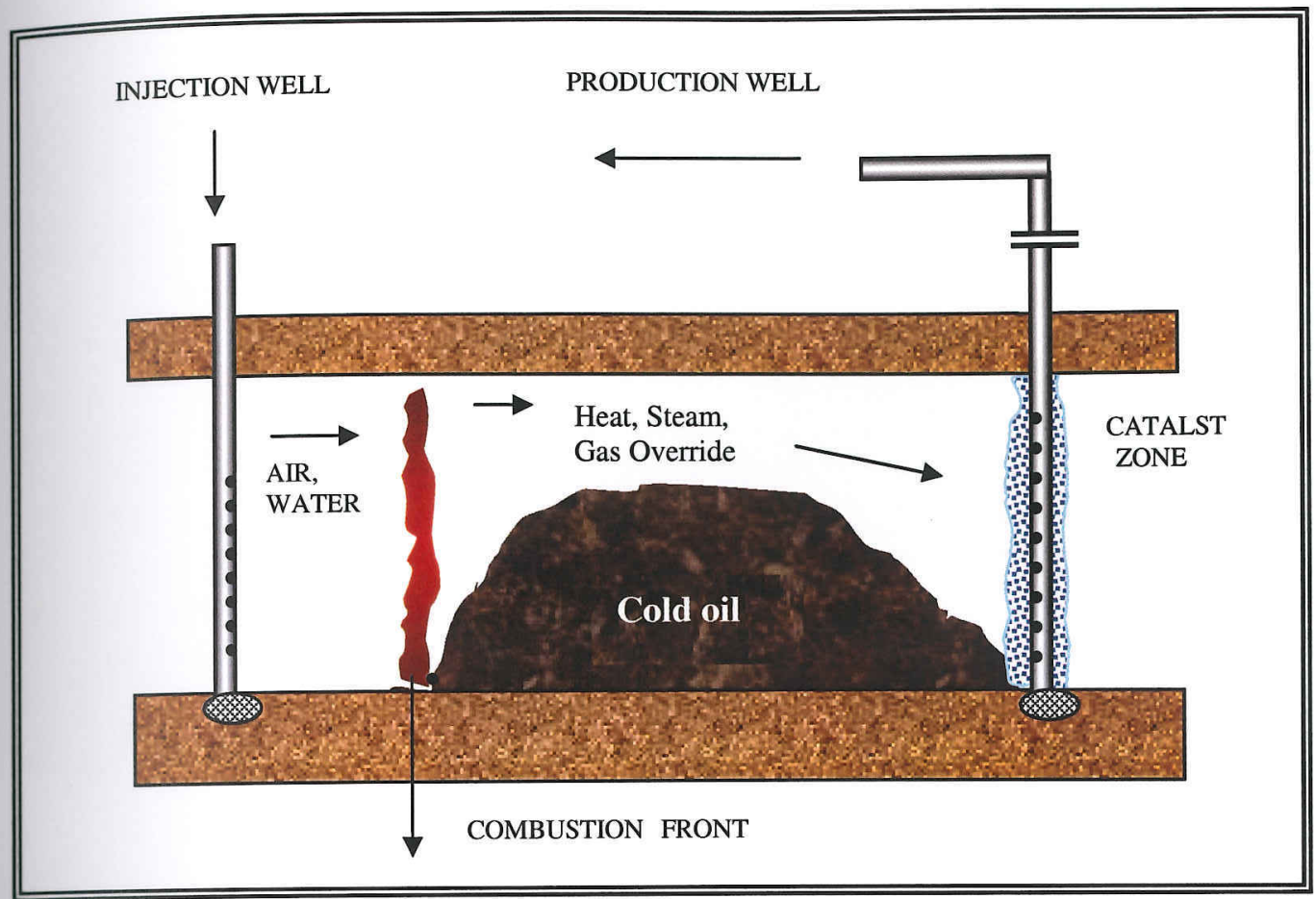

Figure 3.3: Combustion assisted in-situ catalytic upgrading process, (Weissman et al, 1996)

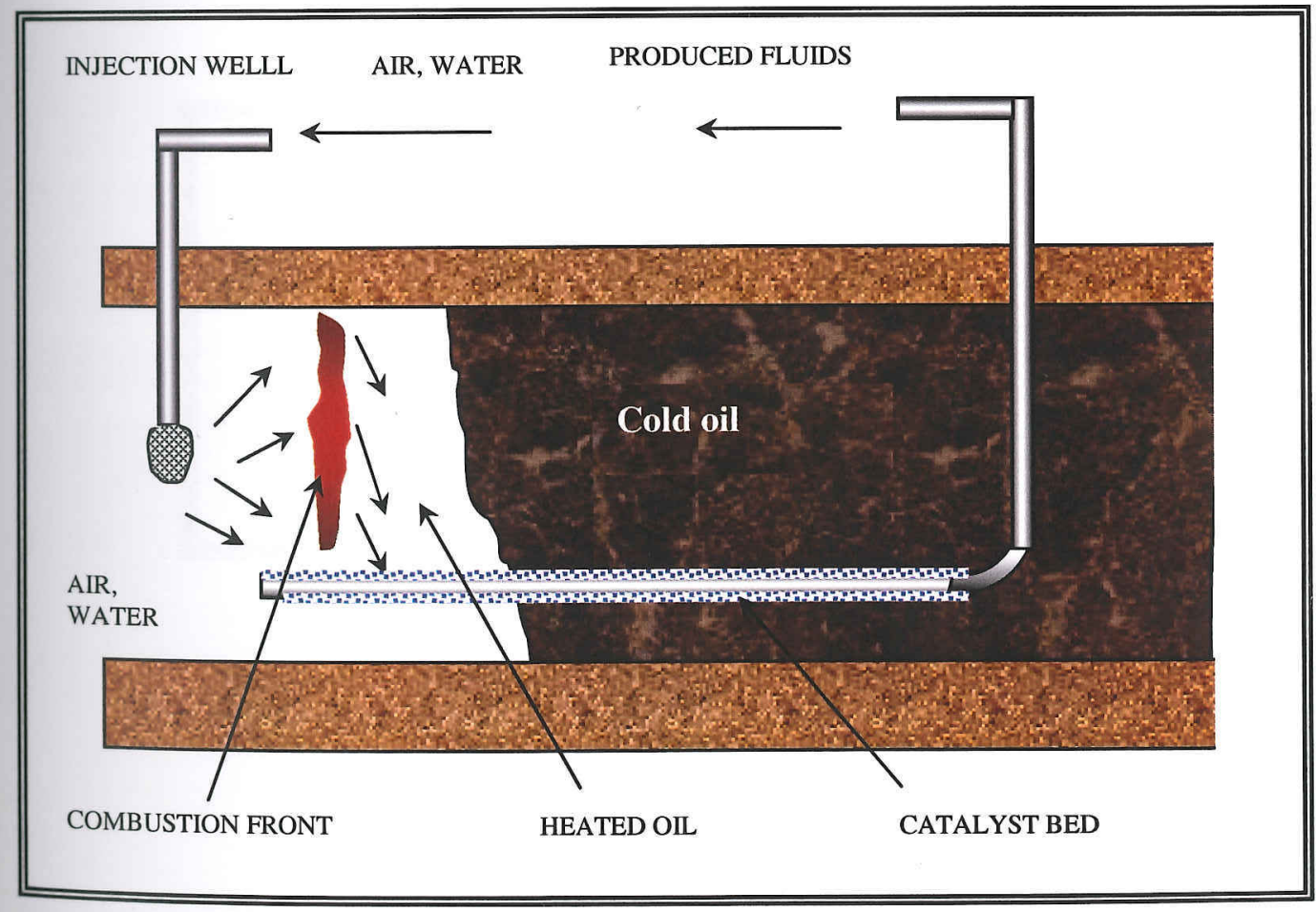

Figure 3.4: "Toe-to-Heel" air injection process with downhole catalyst bed, (Horizontal well),

(Greaves and Xia, 2001) 


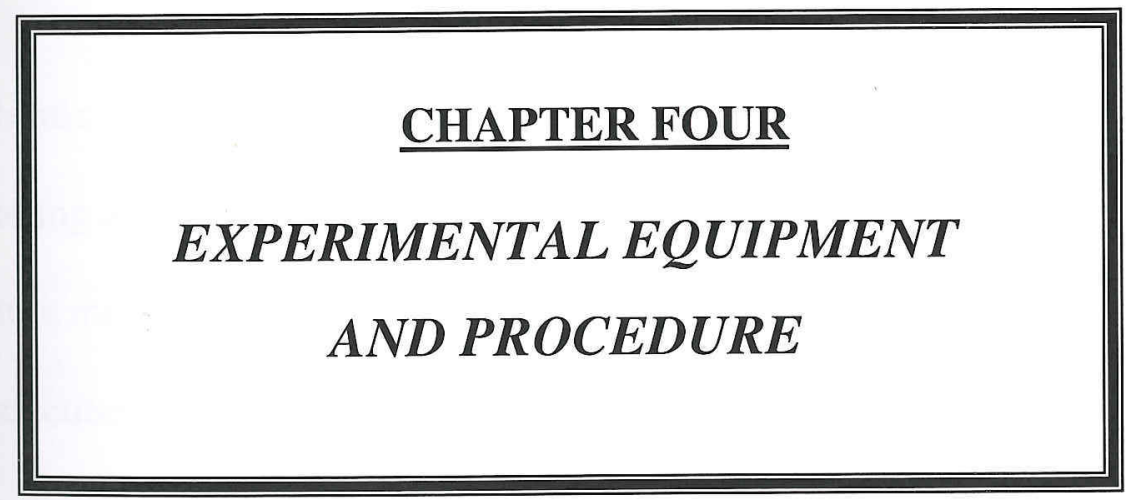




\subsection{INTRODUCTION}

Air injection / in-situ combustion (ISC) experiments were conducted in dry and wet modes, without and with catalyst at low pressure, using unconsolidated sand packs in a combustion cell reactor of tubular form. The experiments were carried out to investigate the feasibility of in-situ catalytic upgrading of medium-heavy crude (Clair) oil of $19.8^{\circ} \mathrm{API}$. For achieving the advantage of using catalyst for upgrading of oil, two modes of experiments were performed with horizontal tube geometry (see subsection 4.2.1)

\subsection{EXPERIMENTAL EQUIPMENT}

The major components of the experimental apparatus used in the experimental set-up are shown schematically in Figure 4.1. The system consisted of the following interrelated parts:

- The combustion cell.

- Flow metering and pressure regulation units.

- Temperature measurement and control.

- Fluid production unit.

- Gas analysis unit.

\subsubsection{Combustion Cell}

The combustion cell, as shown in Figures 4.2 and 4.3, is a cylindrical tube constructed from 316 stainless steel with dimensions $530 \mathrm{~mm}$ in length, $53 \mathrm{~mm}$ inside diameter and $3 \mathrm{~mm}$ wall thickness. It was designed to operate at low pressure and both ends were 


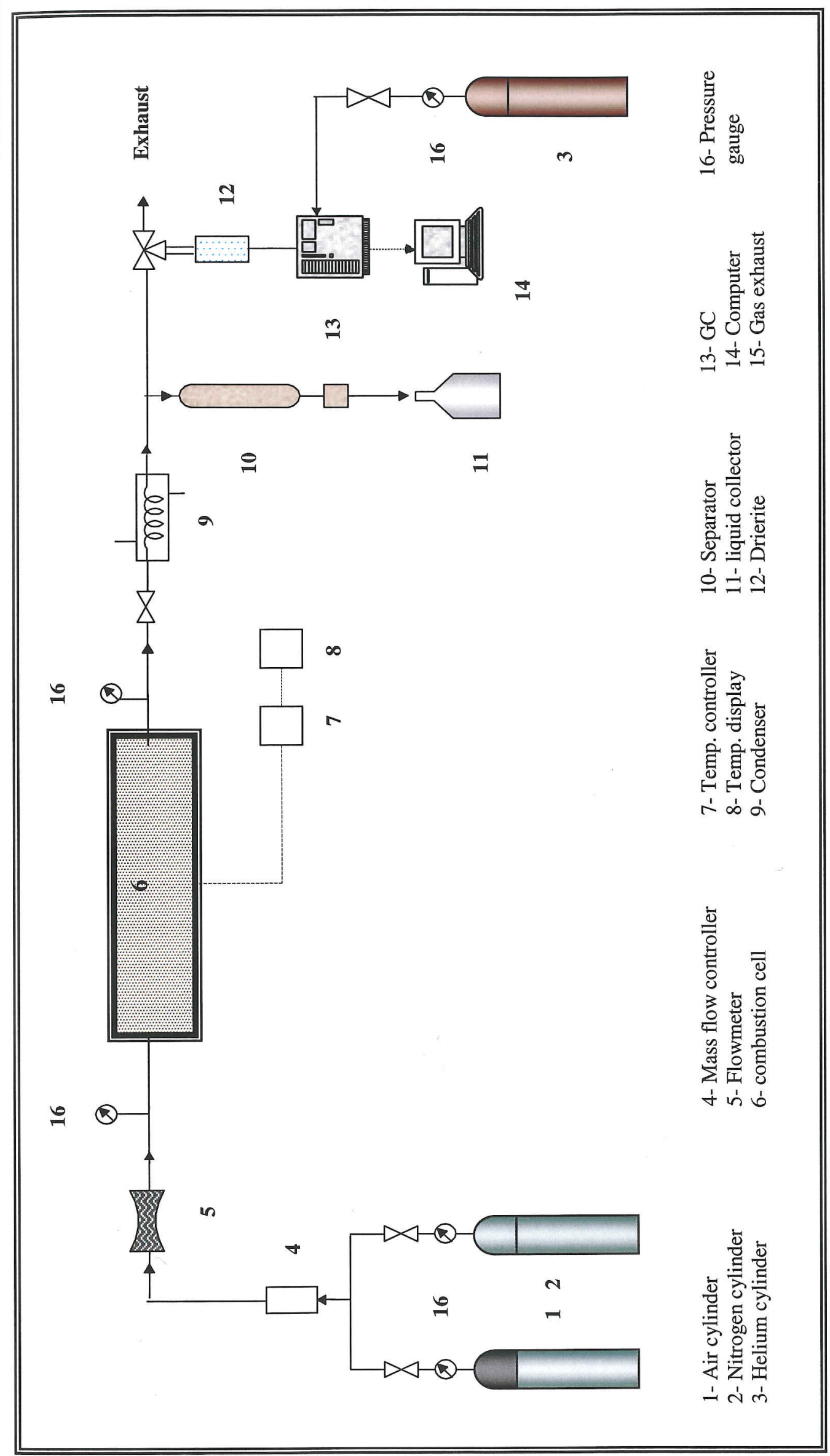

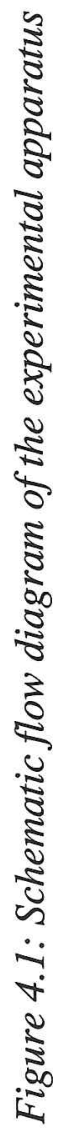


accessible for packing in the oil/sand sample. Also both ends were fitted with large nuts, which were conically threaded to obtain a gas tight seal and additional fireproof copper o-ring gaskets were fixed between the tube ends and their fittings before they were tightly screwed up. As mentioned above, two modes of experiments were performed:

(i) The majority of experiments were performed by packing the sample bed $(100 \mathrm{~mm}$ length) at the middle of the combustion tube, and packing the catalyst at the end of sample bed in the catalytic runs. The rest of the tube (the inlet and the outlet sections of $\sim 215 \mathrm{~mm}$ long each) contained porcelain beads, for preheating the inlet oxidant air and maintaining the temperature of the fluid produced from the combustion to the bed exit. To prevent the sand from coming through the production line or into the porcelain bead zones; two stainless steel wire screens of different mesh, were fitted exactly between each side of the sample bed and the porcelain bead zones; one was of 200 mesh and the other was of 10 mesh to support the 200 mesh screen, as shown in Figure 4.2. An axial centre thermowell was fixed along the centre of the sand pack through which a $0.5 \mathrm{~mm}$ diameter thermocouple could move.

(ii) 4 experiments were performed using a small perforated tube, which serves as horizontal well, fixed in the lower part of an outlet side fitting of the tubular combustion cell. In the catalytic runs, the catalyst was packed around the perforated tube as shown in Figure 4.3. The perforated tube was made of 316 stainless steel of 9.1 $\mathrm{mm}$ O.D with 5 perforations of $1.5 \mathrm{~mm}$ diameter at $10 \mathrm{~mm}$ intervals. They were arranged in a single row of phase angle of $360^{\circ}$. The perforated section was covered with 100-gauge wire mesh to prevent the sand from entering this production line. Also, 


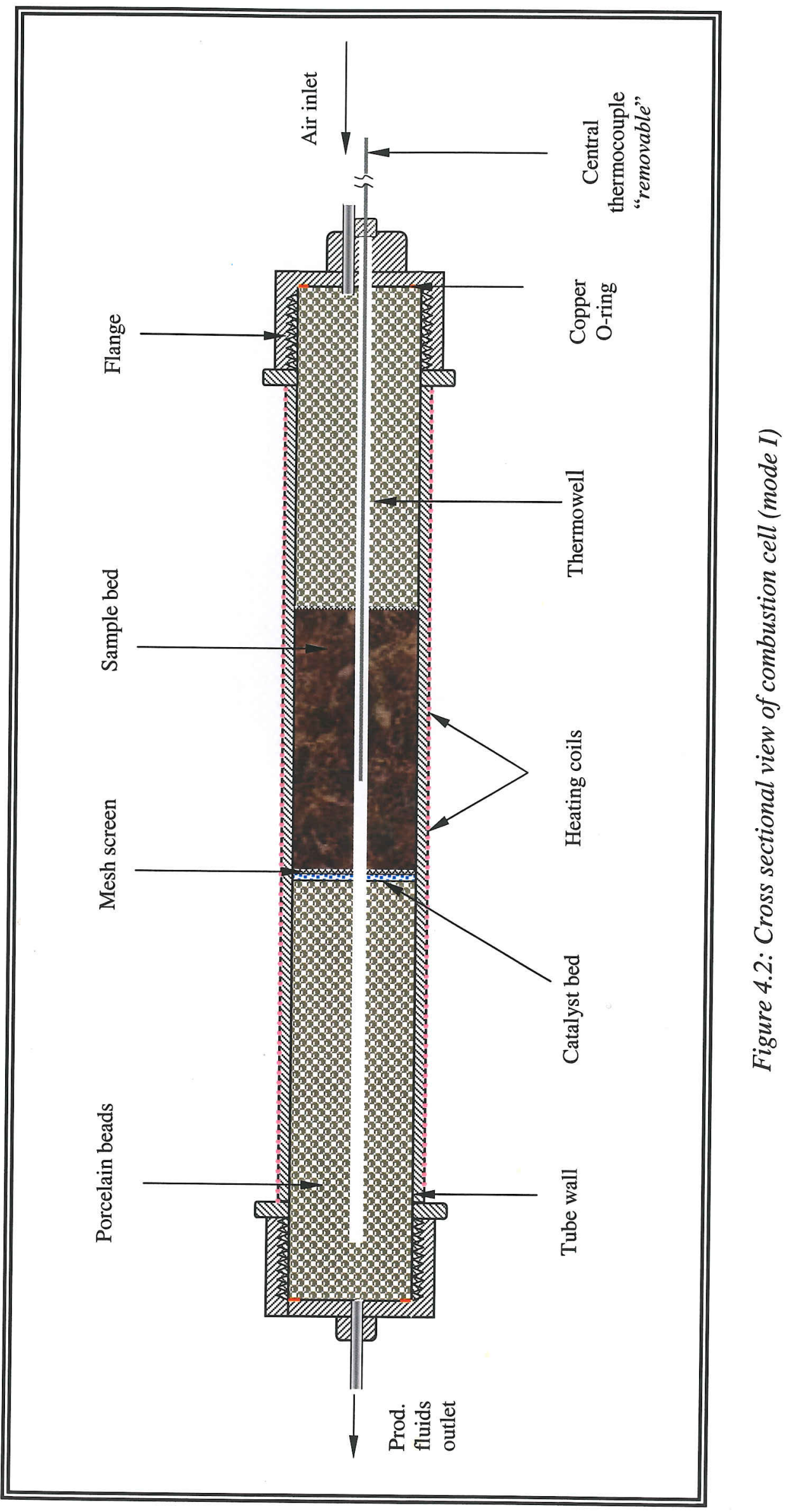




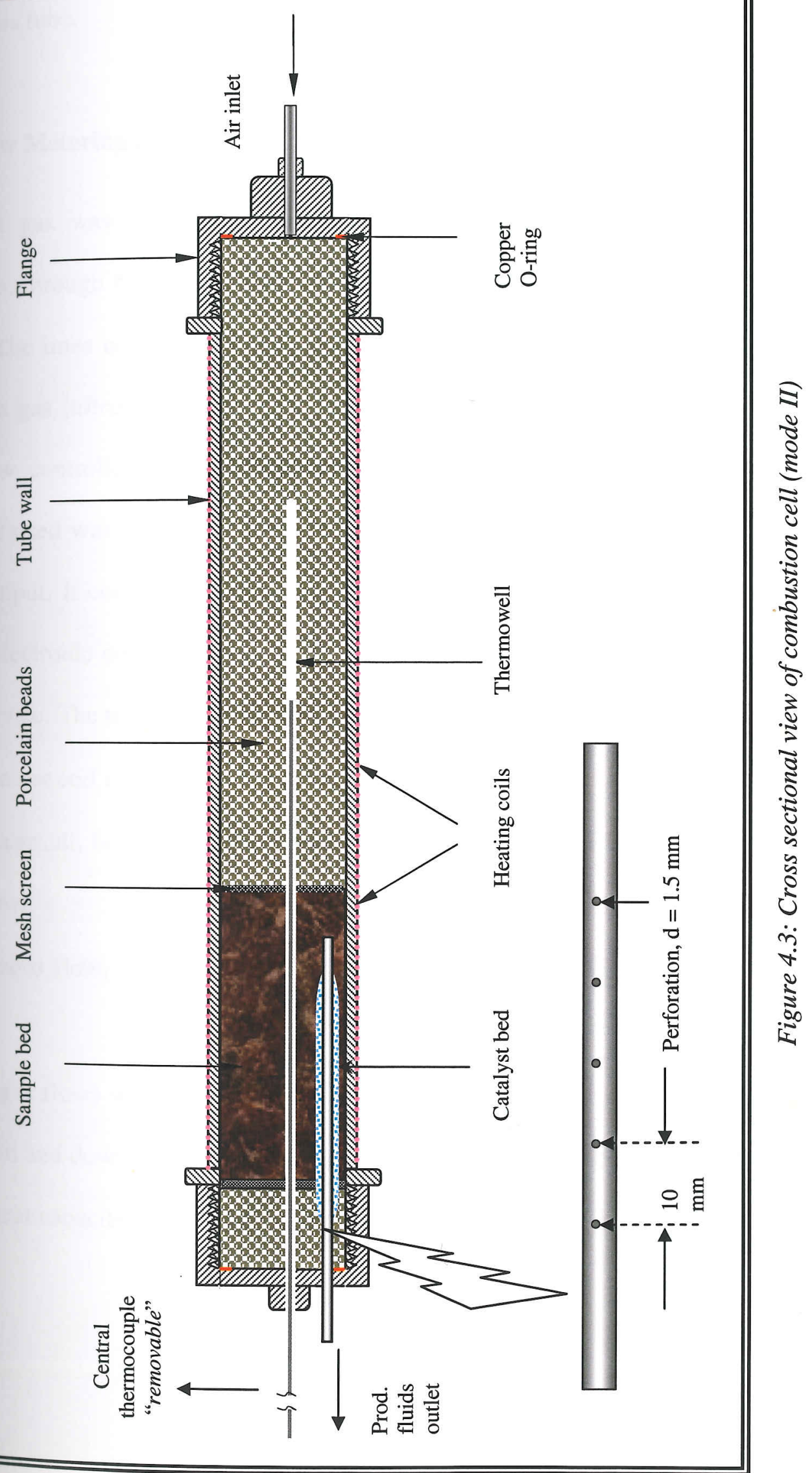


in these catalytic runs, the same sized mesh was used to retain the catalyst packing around this tube.

\subsubsection{Flow Metering and Pressure Regulation}

The inlet gas was fed from a high-pressure gas cylinder via two-stage pressure regulators, through $6.4 \mathrm{~mm}$ O.D. nylon tubing connected with "Enots" solderless brass fittings. The lines near the inlet and outlet of the reactor tube were made of stainless steel. The gas (nitrogen or air) flow through the system was controlled by means of mass flow controllers and measured with a rotameter flow meter. The mass flow controller used was a Brooks 5850 model, with a range of $0-500 \mathrm{ml}^{3} / \mathrm{min}$ air and a digital output. It consisted of three basic units; a flow sensor, a control valve and an integral electronic control system. Figure 4.4 gives an operational diagram of the flow sensor device. The theory of operation is as follows:

- A heater coil uniformly heats the gas flow stream.

- As a result, both the upstream and downstream sensor coils are heated equally at zero flow.

- At zero flow, a balanced bridge circuit is established to provide a zero output signal.

- As gas flows within the sensor, a temperature differential is created between the upstream and downstream sensor coils, which is inversely proportional to the product of the heat capacity of flowing gas and the mass flow rate. 
The resulting voltage differential is applied to the input of the differential amplifier, which generates a DC voltage directly proportional to the mass flow rate and controls the flow.

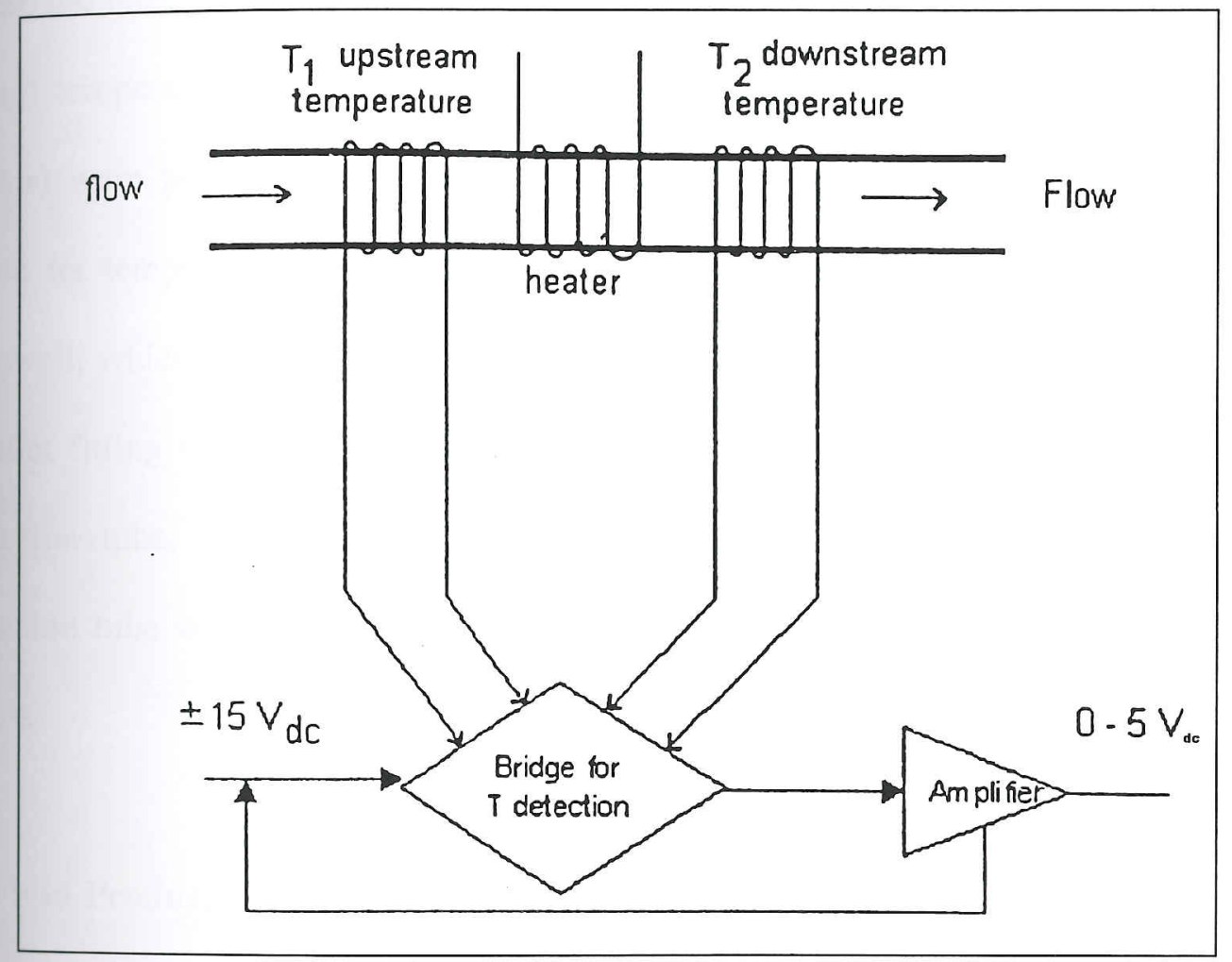

Figure 4.4: Operational diagram of the flow sensor device in mass flow controller

\subsubsection{Temperature Measurement and Control}

In order to have a uniform temperature distribution and to provide supplementary heat for that lost during the run, three separate electrical heating coils (15 ohm and 10 
amperes), each controlled by means of a temperature controller were wrapped around the tube. There were three power regulators, which powered the current to the heating coils separately. One of the regulators was automatically controlled for the maximum set temperature of the central sample bed, which was $400{ }^{\circ} \mathrm{C}$ and with a ramp rate of $5^{\circ} \mathrm{C} / \mathrm{min}$ to achieve this temperature. The other two were manually controlled to maintain the longitudinal temperature of the tube wall within $\pm 10^{\circ} \mathrm{C}$ of the set (central winding) temperature. Three thermocouples (K-type, minerally insulated and $0.5 \mathrm{~mm}$ diameter) were positioned at $100 \mathrm{~mm}$ intervals on the outside wall of the tube to measure its temperatures. Another moveable thermocouple was inserted inside the thermowell, which was fitted on the centre of the inlet fitting (in the first mode) or to the outlet fitting (in the second mode) and positioned along the central axis of the combustion tube, to monitor the sand pack temperature. For all experiments, the combustion tube was wrapped with mineral wool insulation in order to minimize the heat loss.

\subsubsection{Fluid Production Unit}

The fluid production unit separates the fluids produced from the combustion cell after combustion. It consisted of a condenser, separator and a produced liquid collector. In order to release the pressure in an emergency, a pressure regulator was put in the line between the combustion cell outlet and the condenser. The condenser, which was water-cooled, was a glass Leibig type. It was connected from its inlet to the combustion cell outlet at an angle of $45^{\circ}$ and its outlet to the produced liquids collector, which was a $250 \mathrm{ml}$ Erlenmeyer flask, had two exit streams; one was for produced fluids collection 
and the other was for produced gases collection. It was placed in ice path to assist the condensation process. The produced liquids were separated by centrifugation, after collection in special bottles, prior to measuring the oil and water recovered and produced oil's API gravity.

\subsubsection{Gas Analysis Unit}

A gas analysis unit was used to analyse the composition of the produced gases. It consisted of a gas chromatograph $(G C)$ connected to a personal computer through an AD Converter Board. The output from the gas chromatograph was recorded and plotted using Varian Star 4.5 software.

The produced gases from the outlet fluid collector travelled to the analysis unit and exhaust; passing through a dryer (to ensure that no liquid accompanied the gas), through an exit nylon pipe of $3.2 \mathrm{~mm}$ O.D., which was fitted to the flask outlet.

A Varian 3300 gas chromatograph equipped with a "CTR I" column and thermal conductivity detector head was used for analysing of produced gas composition. The carrier gas used was helium, which was supplied from a high-pressure cylinder provided. The CTR I column was calibrated before each experiment (see subsection 4.2.5.2), by using standard calibration gas.

\subsubsection{The GC column (CTR I)}

This column allows the analysis of the fixed gases; nitrogen $\left(\mathrm{N}_{2}\right)$, oxygen $\left(\mathrm{O}_{2}\right)$, methane $\left(\mathrm{CH}_{4}\right)$, carbon dioxide $(\mathrm{CO})$ and carbon monoxide $\left(\mathrm{CO}_{2}\right)$ under isothermal conditions, at room temperature. It is based on concentric columns with one column inserted 
concentrically within the other column; this configuration allows the use of two different packings for the gas analysis. The outer column is a stainless steel tube construction, with an external diameter of $6 \mathrm{~mm}$ and $1.83 \mathrm{~m}$ length. The inner column is the same as the outer column, but its external diameter is $3 \mathrm{~mm}$, and is packed with a porous polymer mixture, while the outer column is packed with activated molecular sieve. Figure 4.5 shows the CTR I column prescription.

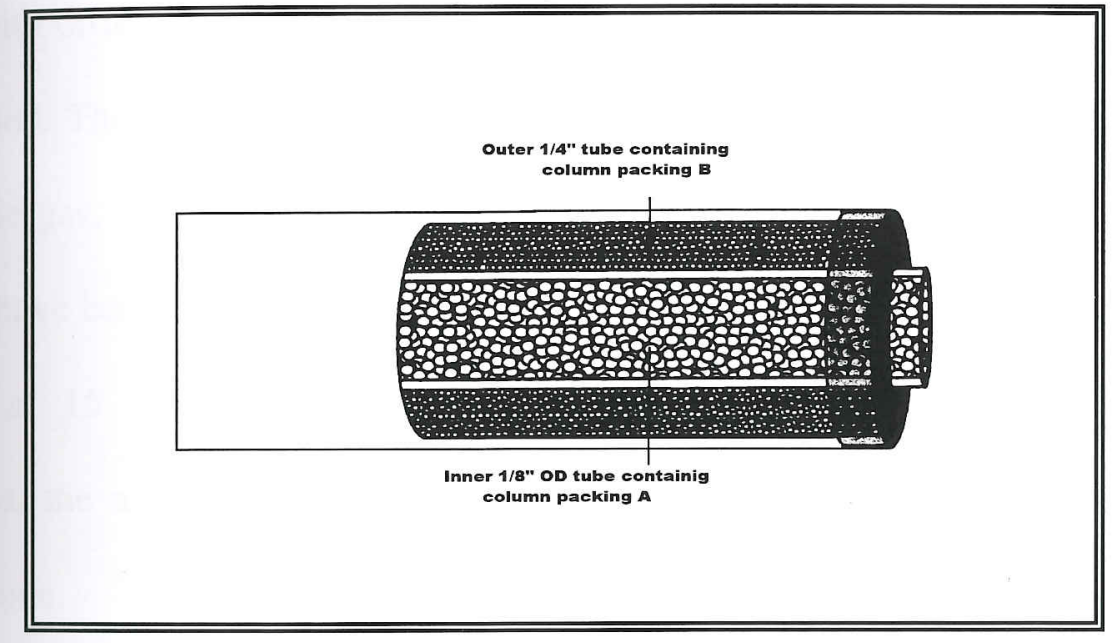

Figure 4.5: Cut-away view of CTR I column

1. Column packing A: Porous polymer mixture.

2. Column packing B: Activated molecular sieve.

\subsubsection{Calibration of the CTR I column}

Before the start of each experiment, the calibration of the CTR I gas chromatograph column for quantitative analysis of the fixed gases is accomplished by the use of a standard calibration gas. This is a special mixture containing approximately $15.0 \%$ $\mathrm{CO}_{2}+7.01 \% \mathrm{CO}+7.0 \mathrm{O}_{2}+4.5 \% \mathrm{CH}_{4}$ with the balance $\mathrm{N}_{2}$. The $\mathrm{GC}$ was allowed to 
warm up while the carrier gas (helium) flowed at a rate of $65 \mathrm{ml} / \mathrm{min}$, for about two hours and a desired volume of calibration gas was injected on to the column through its injection port by a syringe. The corresponding chromatograph report data were recorded as area counts (as shown in Figure 4.6) for every single gas concentration. Then the same volume of the calibration gas, which was used in the first step, was diluted (to $50 \%$ of the original concentration) by adding the same volume of $\mathrm{N}_{2}$, using a scaled syringe and injected on to the column injection port. These procedures were repeated with different calibration gas concentrations to obtain the area counts for each gas separated. These area counts were plotted versus gas concentrations in mole $\%$ for every single gas, to produce straight-line relationships. From the slopes of these lines, equations have been derived to calculate the produced gas concentrations, which were measured at $15 \mathrm{~min}$ intervals during each experiment. Hence, based on these calculations, the measurements of the combustion parameters for every experimental run were done.

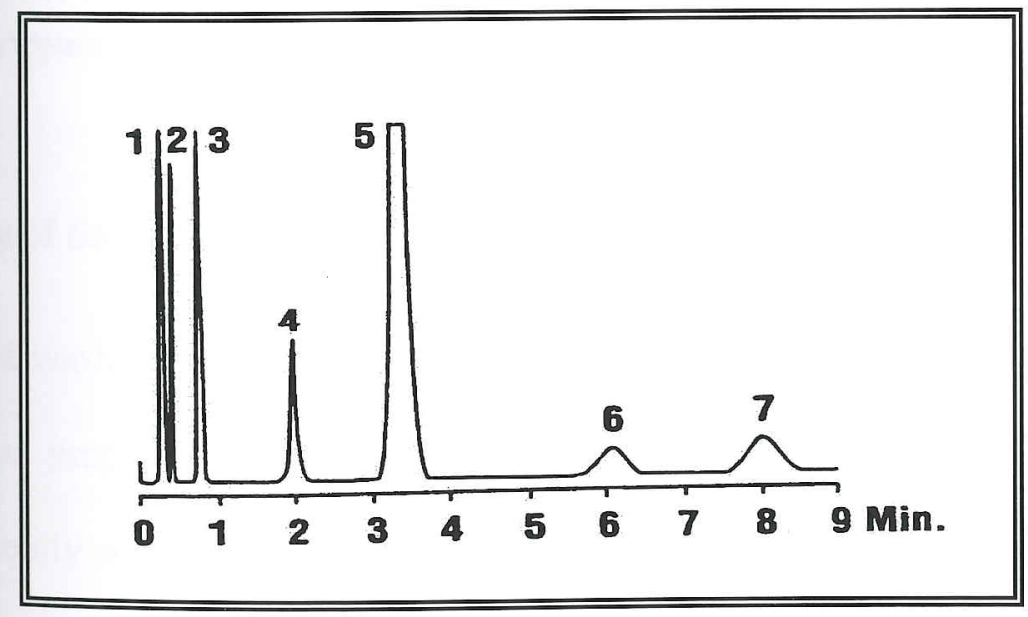

Figure 4.6: CTR I calibration curve 
1. Air and carbon monoxide, (inner column).

2. Methane, (inner column).

3. Carbon dioxide, (inner column).

4. Oxygen, (outer column).

5. Nitrogen, (outer column).

6. Methane, (outer column).

7. Carbon monoxide, (outer column).

\subsection{EXPERIMENTAL PROCEDURE}

The carrier gas (helium) was switched on to the gas chromatograph $(G C)$. The GC was allowed to warm up and calibrated. Mixtures of washed Buckland silica sand ( 355 gm), Clair oil and water (if water saturation was required) were used in the experiments of this work; in addition catalyst was added if it was to be used in the catalytic runs. The properties of sand and crude oil are given in Tables 4.1 and 4.2 respectively, (Al-Saghr, 1998). The sand matrix, oil and water requirement calculations are given in Appendix-A.

\subsubsection{Mixing of Sample Matrix}

A mixture of washed Buckland silica sand, water (if required) and Clair oil, used as received, was prepared in a small plastic container. The mixture was prepared by mixing manually a $\sim 355$ gm of sand with a calculated volume of water (if water saturations were required) and the mixture was mixed until the entire amount of water was added. Then, the calculated volume of oil was added to the mixture in small slugs 
until the total oil amount was complete. Special care was taken to avoid any losses of material throughout the mixing stage and to ensure that a homogeneous mixture is produced. Oil saturations of $20 \%$ to $40 \%$ and $20 \%$ of water saturations (based on the sand pore volume) were used in this work. The catalyst used was a standard HDS catalyst of 1/16-inch CoMo extrudates on an alumina support, pre-sulphided and supplied by Akzo Nobel Netherlands, (Al-Sagher, 1998). It was used as received.

Table 4.1: Sand properties

\begin{tabular}{||l|c||}
\hline Sand & Washed silica sand W50 \\
\hline Type & Coarse \\
\hline Grain volume* $\left(\mathrm{cm}^{3}\right)$ & 61.16 \\
\hline Grain density* $\left(\mathrm{gm} / \mathrm{cm}^{3}\right)$ & 2.546 \\
\hline Bulk volume* $\left(\mathrm{cm}^{3}\right)$ & 96.36 \\
\hline Bulk density* $\left(\mathrm{gm} / \mathrm{cm}^{3}\right)$ & 1.616 \\
\hline Porosity* $(\%)$ & 36.53 \\
\hline Permeability* $(\mathrm{md})$ & 1004 \\
\hline
\end{tabular}

*Measured by AEA Technology, Winfrith

Table 4.2: Crude oil properties

\begin{tabular}{||l|c||}
\hline Crude type & Clair (medium-heavy) \\
\hline Density, $\mathrm{kg} / \mathrm{m}^{3}$ & 935 \\
\hline Viscosity, cp. @ $20^{\circ} \mathrm{C}$ & 200 \\
\hline Gravity, ${ }^{\circ} \mathrm{API}$ & 19.8 \\
\hline
\end{tabular}




\subsubsection{Packing Procedure for the Combustion Cell}

The combustion cell, which had been equipped with heating coils, and wrapped with thermal insulation, to minimise heat loss was ready for packing. Two modes of experiments were performed. The packing procedures were as follows:

\subsubsection{First mode}

The experiments performed in this mode, were made by packing the sample mixture (100mm length) at the middle of the combustion tube and packing the catalyst at the end of sample bed, if catalytic runs were to be adopted. The sequence of the packing procedure is as follows:

- The inlet fitting which contained the axial centre thermowell was smeared with anti seizing compound and placed vertically on the stand provided.

- A copper o-ring fireproof gasket was fixed to the end fitting before it was tightly screwed to the combustion cell.

- The required amount of porcelain beads was introduced into the tube to a depth of $\sim 215 \mathrm{~mm}$ of its length to serve as a preheating zone and two stainless steel wire screens of different mesh (as mentioned in section 4.2.1) were inserted in the tube to separate the sample mixture and the porcelain beads.

- The sample mixture then was packed into the combustion cell by transferring small batches of the mixture into the cell and tamping down firmly by means of a plastic rod until the total mixture was packed to a $\sim 100 \mathrm{~mm}$ tube length positioned at the middle part. 
- Another two stainless steel wire screens of different mesh were inserted into the tube for same purpose and to prevent sand production.

- A known weight of catalyst (CoMo) was packed (in the catalytic run cases) into the tube at the end of sample bed and also two stainless steel wire screens were inserted to cover the catalyst bed and separate it from the porcelain beads zone.

- Then, porcelain beads were introduced to fill the rest of the $\sim 215 \mathrm{~mm}$ tube length at the bed exit in order to heat the fluids produced from combustion.

- Once the combustion tube was filled, another fireproof copper o-ring gasket was fixed in the outlet fitting and both were positioned at the top of the combustion tube and screwed dawn tightly and carefully.

\subsubsection{Second mode}

The experiments were conducted in this mode using a perforated tube, which serves as a horizontal well. It was fixed in the outlet cap of the combustion tube in such a way as to place it close to the bottom of the sample bed. At the same time, the thermowell was fixed in the flange centre as shown in Figure 4.3. In general, the packing procedure sequence follows the same procedure as the first mode with some differences, as follows:

- Before the combustion tube was fitted with the outlet fitting; a 100-gauge wire mesh was wrapped around the perforated section to prevent the sand from entering to the production line. A known weight of catalyst was packed around the perforated section, using the same sized mesh to support the catalyst in its place. The outlet cap, which carried the perforated tube and the thermowell was 
tightly screwed into the combustion cell, (following the first two procedures mentioned in first mode).

- A certain amount of porcelain beads were introduced into the tube to a depth of $\sim 25 \mathrm{~mm}$ of its length and the sample mixture was packed following steps 3 to 5 as mentioned in the first mode.

- Then, porcelain beads were introduced to fill the rest of the tube at the bed inlet in order to serve as preheating zone.

- Once the combustion tube was filled, another fireproof copper o-ring gasket was fixed in the inlet cap and both were positioned at the top of the combustion tube and carefully screwed down tightly.

\subsubsection{Operating Procedure}

The GC was warmed up and calibrated. After the packing procedures were completed, the combustion tube was then removed from the packing stand and placed horizontally on the experimental system stand. Before installing the tube in the system, it was verified that all of the equipment was in good working condition and any damaged wires or tubes were changed. The tube was then pressurised at a pressure of 3 bars for about 30 mins, to check for any leakage using soap liquid. After the leakage check was accomplished, the following steps were carried out:

- The air supply, the production unit and the gas analysis unit were connected to the combustion cell and the water supply to the condenser was started. 
- The heating coils were connected with the power regulators, the thermocouples placed in position and mineral wool insulation was wrapped around the cell in order to minimize the heat loss.

- The pressure regulators on the air supply cylinder were adjusted to the operating working pressure $(3$ bars $)$ of the mass flow meters. Thereafter, the air was introduced to the cell for about 30 minutes, while the combustion cell was still at room temperature to ensure an equilibrated atmosphere.

- The power regulators were plugged in to start the run and a temperature ramp of $5^{\circ} \mathrm{C} / \mathrm{min}$ up to the working temperature of $400{ }^{\circ} \mathrm{C}$ was set.

- Effluent gas analysis and temperature of the sample bed were recorded at 15 min intervals during each experiment.

- Depending on the experiment's goal, the run was terminated (discussed later): a - At the time when the carbon oxides concentrations in the effluent gas started to decrease and that of oxygen started to increase.

b - When no further or very low carbon oxides in the effluent gas were detected.

\subsubsection{Measurement of API Gravity}

One of the more apparent and most easily measured physical features that can be used to classify oil is its gravity measured in degrees API (American Petroleum Institute):

Degrees API $=\left(141.5 / \mathrm{Sp}\right.$. Grav. of oil at $\left.15^{\circ} \mathrm{C}\right)-131.5$

In this study, the recovered oil's API gravity is the most important factor. This was measured, after the oil-water separation, to observe any changes after each experiment and compared with that of the native oil and oils from other experiments. All the 
measurements were done at room temperature, which ranged between 17 and $19^{\circ} \mathrm{C}$. The API measurement procedure is as follow:

- Special small-scale bottles of 2 and $5 \mathrm{ml}$ were used for weighing a known volume of oil samples using a sensitive balance. Then, the density of the produced oil was calculated as a mass per unit volume:

Density $\left(\rho_{o}\right)=$ weight of oil sample $/$ its volume $\left(\mathrm{gm} / \mathrm{cm}^{3}\right)$

- The same volume of water was weighed to find its density as mass per unit volume.

- The specific gravity was calculated as a ratio of oil density to that of water.

- Then API gravity was calculated using Equation 4.1.

\subsubsection{Shut Down Procedure}

As mentioned in the previous section, step 6; depending on the experiment's goal, the shut down procedures were started by switching the gas supply to the system to nitrogen, which was kept flowing to cool down the cell until the temperature reached $-50{ }^{\circ} \mathrm{C}$; the produced gas was then vented to the exhaust. At the same time, the heating coils and the GC were switched off. The combustion cell was then disconnected from the system and removed for unpacking and cleaning after cooling down. The produced liquids were collected for separation and measurements and the combustion tube contents were collected with care during unpacking, for measuring and calculating the combustion parameters. 


\section{CHAPTER FIVE}

RESULTS AND DISCUSSIONS 


\subsection{INTRODUCTION}

This Chapter deals with the results, analysis and discussions of the combustion parameters for the in-situ combustion experiments, which were carried out to investigate the feasibility of thermo-catalytic oxidation of medium-heavy Clair crude oil having an API gravity of $19.8^{\circ}$, using a low-pressure ( 3 bar) combustion cell. The subjected crude oil was mixed with an unconsolidated formation of washed Buckland silica sand, having a grain size of 50 mesh and water (if water saturation was required) and combusted in an air feed stream containing $21 \%$ oxygen, with an operating pressure of 3 bar and temperature ramp of $5^{\circ} \mathrm{C} / \mathrm{min}$, over the range from room temperature to $400^{\circ} \mathrm{C}$. The analysis is based on the effluent gas data obtained for different runs. This was carried out intermittently at 15 minutes intervals during each experiment. The carbon dioxide, carbon monoxide and oxygen concentrations in the effluent gas stream and temperature were determined as a function of time, for each combustion run. The produced oil was separated from water and collected for recovery, density and API gravity measurements.

As mentioned in the previous Chapter, two modes of experiments were performed using a horizontal tube position. Most of the experiments in this study were conducted in the first mode, by packing the sample bed at the middle part of the combustion tube in the non-catalytic runs and packing the catalyst at the outlet end of a similarly placed sample bed in the catalytic runs. In the second mode, a small-perforated tube was fixed in the outlet fitting of the same combustion tube, which served as a horizontal well. Four experiments were conducted in this second mode. In the catalytic runs, the catalyst was packed at the perforated section around the perforated tube (the procedure for this was discussed in detail in the previous Chapter). The common operating conditions of all 
experiments are listed in Table-5.1 and the calculations of the experimental parameters are given in Appendix-A. The experimental data of each run are given in Appendix-C.

Table - 5.1: Common operating conditions

\begin{tabular}{||l|c||}
\hline \hline Sand type & W50 Coarse silica sand \\
\hline Sand wt., $\mathrm{kg}$ & 0.355 \\
\hline Sand grain density, $\mathrm{kg} / \mathrm{m}^{3}$ & 2546 \\
\hline Sand porosity, $\%$ & 36.53 \\
\hline Crude oil & Clair \\
\hline Density, $\mathrm{kg} / \mathrm{m}^{3}$ & 935 \\
\hline API gravity, ${ }^{\circ} \mathrm{API}$ & 19.8 \\
\hline Temperature,${ }^{\circ} \mathrm{C}$ & 400 \\
\hline Heating rate, ${ }^{\circ} \mathrm{C} / \mathrm{min}$ & 5 \\
\hline Pressure, $\mathrm{bar}$ & 3 \\
\hline Air flow rate, $\mathrm{ml} / \mathrm{min}$ & 250 \\
\hline Air flux, $\mathrm{sm}^{3} / \mathrm{m}^{2} \mathrm{~h}$ & 6.80 \\
\hline $\mathrm{N}_{2}$ flux, $\mathrm{sm}^{3} / \mathrm{m}^{2} \mathrm{~h}$ & 5.37 \\
\hline $\mathrm{O}_{2}$ flux, $\mathrm{sm}^{3} / \mathrm{m}^{2} \mathrm{~h}$ & 1.43 \\
\hline
\end{tabular}

The experiments were carried out for both dry and wet forward combustion and for catalytic combustion. In wet combustion runs, the samples were prepared by first wetting the sand with a specified amount of water and then, adding the required amount of oil. The water was then trapped between the oil and sand. In the catalytic combustion runs, the catalyst used was a standard HDS catalyst of 1/16-inch CoMo extrudates on an alumina support. 


\subsection{FIRST MODE EXPERIMENTS}

Three sets of experiments were performed using the first mode (see section 5.1). In the first set, a series of non-catalytic experiments were performed, at different oil and water saturations. In the second set, a series of catalytic experiments were carried out to investigate the feasibility of thermo-catalytic oxidation of the subjected crude oil for this study. Two weights ( 1 and 5 grams) of CoMo catalyst were used as different experimental parameters, to test the catalyst loading. The catalyst was located at the outlet end of the sample bed. All the experiments in these two sets were terminated at the point when the carbon oxides concentrations in the effluent gas stream decreased towards zero and the $\mathrm{O}_{2}$ content approaches that of air.

The third set (4 experiments) was performed to investigate the activity of catalyst usage with time. In this set, the same catalyst (5 $\mathrm{gm}$ of CoMo) was used in all four experiments and this was collected and weighed after each experiment and reused in the next experiment under the same conditions. All experiments were terminated at the point when the carbon oxides concentrations in the effluent gas started to decrease and that of oxygen started to increase, i.e. before the combustion front reached the catalyst bed.

Partial oxidation or low temperature oxidation (LTO) occurs in zones where the temperature is lower than $\sim 300{ }^{\circ} \mathrm{C}$. These partial oxidation reactions produce primarily water and oxygenated hydrocarbons such as carboxylic acids, aldehydes, ketones and alcohols, (Burger and Sauquoit, 1972). Also, the combustion processes were very similar, because the sample bed in all experiments was identical and the same 
Chapter -5

processing parameters were used. Due to this, the analysis of the results was based on the stabilised period of the combustion run (HTO region).

\subsubsection{In-Situ Combustion (ISC) Experiments}

All runs in this set were conducted both as dry and wet in-situ combustion experiments without catalyst (WOC). Run-1 to Run-3 were conducted at different oil and water saturations, with an air flow rate of $250 \mathrm{ml} / \mathrm{min}$, while Run-4 was performed as a dry combustion run, with an oil saturation of $40 \%$ and an air flow rate of $375 \mathrm{ml} / \mathrm{min}$ to investigate this effect on the oxidation of the crude oil. This set of experiments are designated as:

Run-1: WOC, $\mathrm{S}_{\mathrm{o}}=20 \%, \mathrm{~S}_{\mathrm{w}}=0$.

Run-2: WOC, $S_{0}=40 \%, S_{w}=0$.

Run-3: WOC, $\mathrm{S}_{\mathrm{o}}=40 \%, \mathrm{~S}_{\mathrm{w}}=20 \%$.

Run-4: WOC, $\mathrm{S}_{\mathrm{o}}=40 \%, \mathrm{~S}_{\mathrm{w}}=0$.

Where;

WOC $=$ without catalyst

$\mathrm{S}_{0}=$ oil saturation as a percentage of pore volume.

$\mathrm{S}_{\mathrm{w}}=$ water saturation as a percentage of pore volume.

\subsubsection{Produced gas composition}

The effluent gases from the combustion cell are the result of different chemical reactions occurring in the in-situ combustion process. Carbon oxides $\left(\mathrm{CO}_{2}\right.$ and $\left.\mathrm{CO}\right)$ are the major uncondensed products that are produced by these reactions; together with any 
unreacted oxygen, they can provide a good indication of the performance of the in-situ combustion process. Generally, the outlet gases $\left(\mathrm{CO}_{2}, \mathrm{CO}\right.$ and $\left.\mathrm{O}_{2}\right)$ in the individual composition profiles tend to exhibit approximately similar trends.

Figures 5.1 to 5.4 illustrate the composition of the outlet gases $\mathrm{CO}_{2}, \mathrm{CO}$ and $\mathrm{O}_{2}$ and the maximum combustion temperature as a function of time. They represent the general behavior of the combustion. Table 5.2 summaries the outlet gas composition and the maximum temperature during the stabilised period of combustion for each experiment.

Run-1 was performed as a dry forward combustion run, with an oil saturation of $20 \%$. From Figure 5.1, the carbon oxides $\left(\mathrm{CO}_{2}\right.$ and $\left.\mathrm{CO}\right)$ started production at about 1 hour from the beginning of the experiment, while at the same time most of oxygen supplied has been consumed. The $\mathrm{CO}_{2}$ and $\mathrm{CO}$ concentrations during the stabilised period of combustion averaged 15.02 and $3.87 \%$ respectively, while the $\mathrm{O}_{2}$ concentration was stable at about $0.93 \%$, which indicates that most of oxygen has been consumed by combustion reactions.

Run-2 was carried out as same conditions as Run-1, but with a higher oil saturation, which was $40 \%$. Figure 5.2 shows that the values of the $\mathrm{CO}_{2}$ and $\mathrm{CO}$ concentrations at the stabilised period of combustion averaged 15.59 and $4.47 \%$ respectively, and the $\mathrm{O}_{2}$ level at about $1.20 \%$. Comparing with Run-1, the duration of reaction time and that of stabilised period of carbon oxides and oxygen production were slightly longer in Run-2 than those in Run-1, also the levels of carbon oxides production were a slightly higher. This is due to a higher oil content that was used in Run-2. 
In order to investigate the effect of water on the oxidation of the Clair crude oil, Run-3 was performed at the same conditions as Run-2, but with the addition of $20 \%$ (based on sand pore volume) water saturation. From Figure 5.3, the same behavior was observed compared with the previous runs. The results were compared with that of Run- 2 . The $\mathrm{CO}_{2}$ and $\mathrm{CO}$ produced levels averaged at $15.91 \%$ and $3.91 \%$ respectively, which were slightly higher and lower respectively than those in Run-2. The slight increase in the $\mathrm{CO}_{2}$ produced level may be attributed to the reaction between the water and carbon monoxide (the conversion of $\mathrm{CO}$ to $\mathrm{CO}_{2}$ ) via the water-gas shift reaction and this could also explain why less $\mathrm{CO}$ is observed in the outlet gas composition in Run-3. Another effect observed was a decrease in the peak temperature, which was $447^{\circ} \mathrm{C}$, compared with $464{ }^{\circ} \mathrm{C}$ in Run-2. The presence of water results in an increase in steam production. The decrease in peak temperature in wet combustion is due to the combined effect of the external heat losses and increases in the steam zone size.

All experiments in this set were carried out with an airflow rate of $250 \mathrm{ml} / \mathrm{min}$, except Run-4, which was conducted, with an airflow rate of $50 \%$ higher than that of the other experiments. It was performed with an airflow rate of $375 \mathrm{ml} / \mathrm{min}$ to investigate the effect of increase in airflow rate on the oxidation of the crude oil. Changes in the range of flow rate were limited due to of the specifications of the gas analyzer used. Run-4 was conducted with the same conditions of Run-2, but at this higher airflow rate. The results from Figures 5.2 and 5.4, which present the compositions of produced gases and temperature, show that the produced gas profiles have a similar trend. At the higher airflow rate (Figure 5.4) the reaction starts earlier and the duration of reaction time was shorter, this is attributed to the higher combustion front velocity. Also, the $\mathrm{CO}_{2}$ and $\mathrm{CO}$ 
levels at the stabilised period were higher in Run-4 than those in Run- 2 due to the higher airflow rate effect. There was a significant increase in oxygen outlet concentration, due to a decrease in oxygen consumption compared to that at the lower airflow rate (Figure 5.2). Also, as can be seen, from both figures and Table 5.2, there was an increase in peak temperature at the higher flow rate and levels of carbon oxides production were higher.

Table 5.2: Produced gas composition: first set (first mode)

\begin{tabular}{|c|c|c|c|c|}
\hline Experiment & Run - 1 & Run - 2 & Run - 3 & Run - 4 \\
\hline Oil saturation, $\mathrm{S}_{\mathrm{o}} \%$ & 20 & 40 & 40 & 40 \\
\hline $\mathrm{H}_{2} \mathrm{O}$ saturation, $\mathrm{S}_{\mathrm{w}} \%$ & 0 & 0 & 20 & 0 \\
\hline Air inj. rate, $\mathrm{ml} / \mathrm{min}$ & 250 & 250 & 250 & 375 \\
\hline $\mathrm{CO}_{2}$, mole $\%$ & 15.02 & 15.59 & 15.91 & 16.50 \\
\hline $\mathrm{CO}, \mathrm{mole} \%$ & 3.87 & 4.47 & 3.91 & 5.56 \\
\hline $\mathrm{O}_{2}, \mathrm{~mole} \%$ & 0.93 & 1.20 & 1.21 & 1.62 \\
\hline Max. temp. ${ }^{\circ} \mathrm{C}$ & 460 & 464 & 447 & 474 \\
\hline Combustion time, $\mathrm{hr}$ & 4.25 & 5 & 5.25 & 3.5 \\
\hline Stabilised period, hr & 1.75 & 2.5 & 2.5 & 1.75 \\
\hline
\end{tabular}

\subsubsection{H/C and carbon molar ratios}

The apparent $\mathrm{H} / \mathrm{C}$ and $\mathrm{CO} /\left(\mathrm{CO}+\mathrm{CO}_{2}\right)$ ratios are important parameters for determining the combustion performance of a combustion project. A low ratio for each is indicative of efficient combustion, low oxygen requirement and a well-established high temperature combustion regime (Moore et al, 1995). These ratios were calculated from the analysis of the outlet gases for each combustion run. The H/C calculations were 

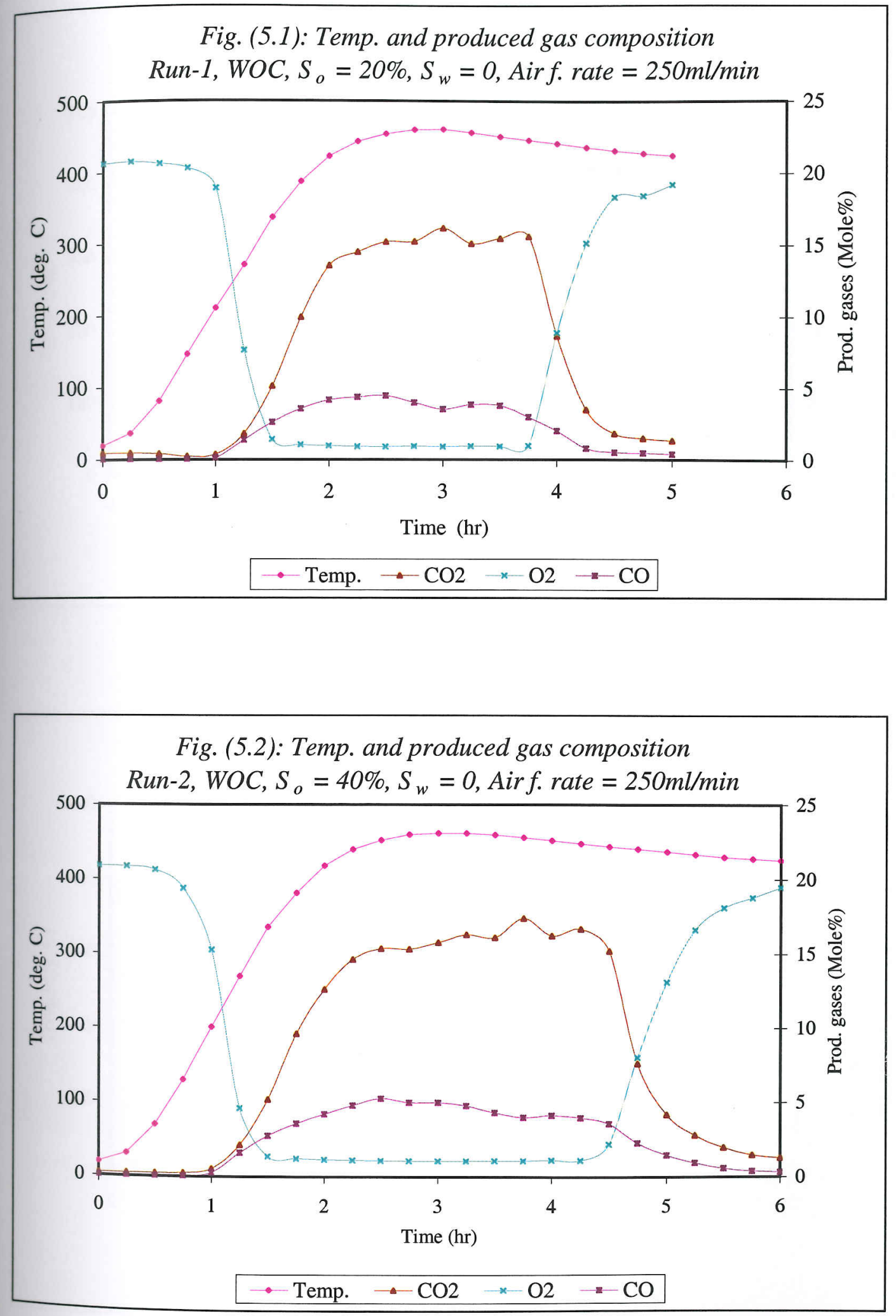
Fig. (5.3): Temp. and produced gas composition

Run-3, WOC, $S_{o}=40 \%, S_{w}=20 \%$, air f. rate $=250 \mathrm{ml} / \mathrm{min}$

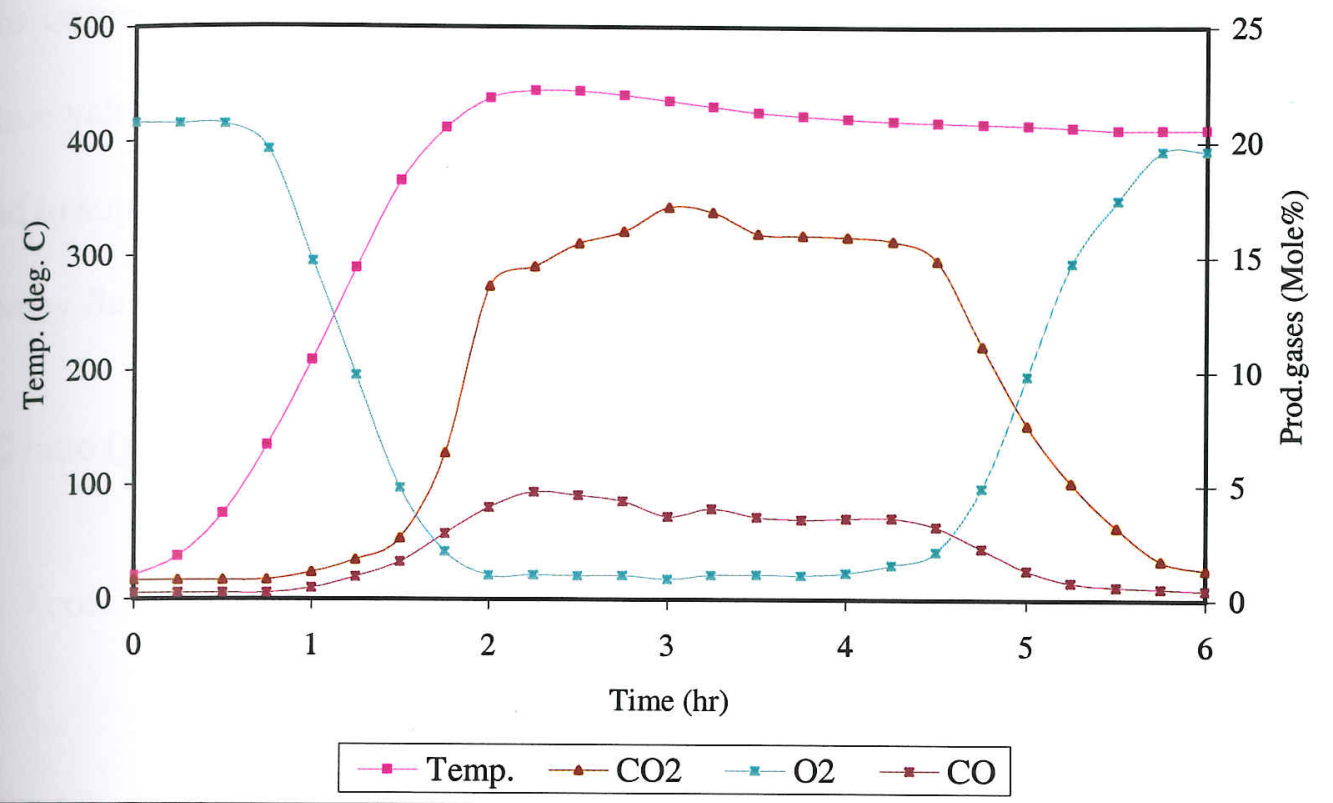

Fig. (5.4): Temp. And produced gas composition

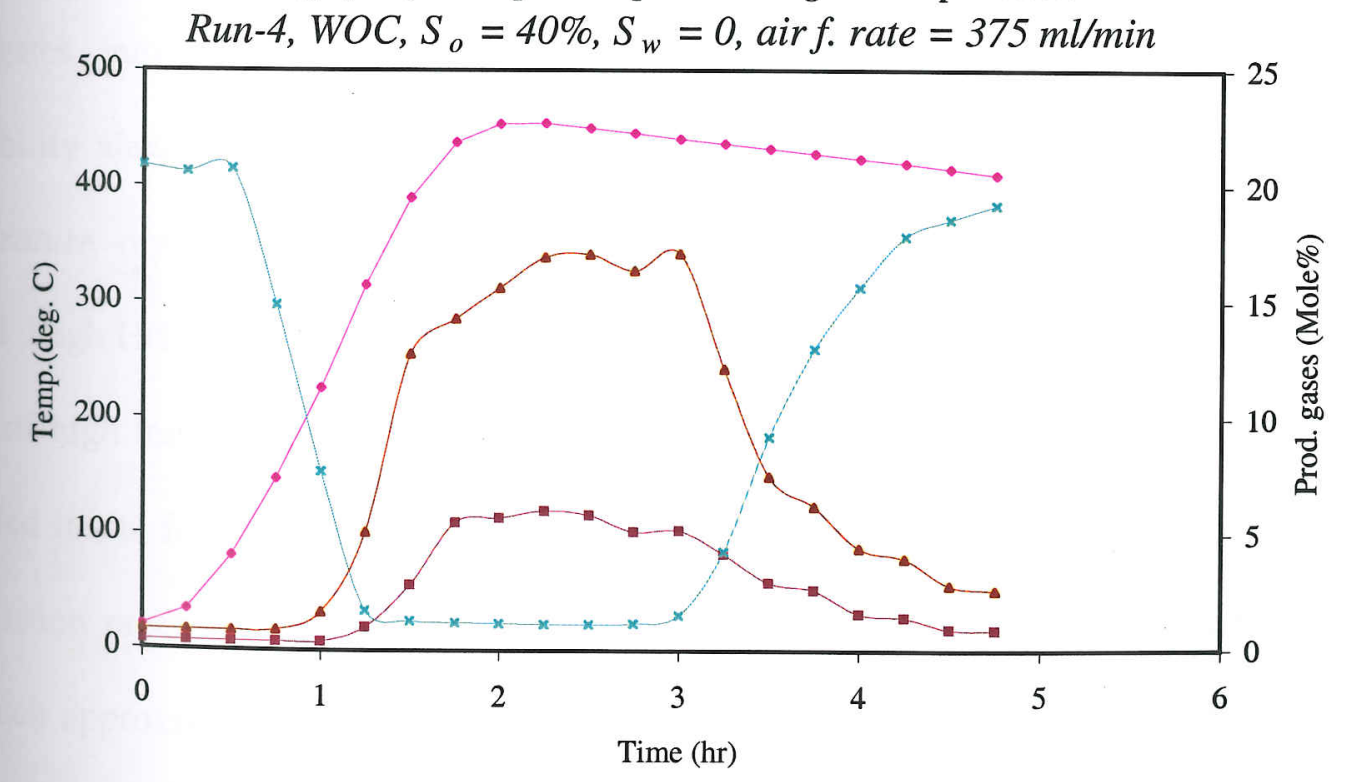

- Temp. $\rightarrow \mathrm{CO} \rightarrow$ O2 $\rightarrow \mathrm{CO} 2$ 
based on the assumption that all the oxygen, which did not appear in the exit gases had reacted to form water. This is not strictly true, because of the possibility of LTO reactions occurring. For this reason, the $\mathrm{H} / \mathrm{C}$ ratio is considered as an apparent rather than a true value. A low level of carbon oxides in the produced gas and a high $\mathrm{H} / \mathrm{C}$ ratio will tend to support this assumption. The atomic $\mathrm{H} / \mathrm{C}$ ratio is calculated by the following equation by Burger et al (1985):

$$
\mathrm{H} / \mathrm{C} \text { ratio }(\mathrm{x})=\left[1.06-3.06 \mathrm{Y}_{\mathrm{CO}}-5.06\left(\mathrm{Y}_{\mathrm{CO} 2}+\mathrm{Y}_{\mathrm{O} 2}\right)\right] /\left(\mathrm{Y}_{\mathrm{CO} 2}+\mathrm{Y}_{\mathrm{CO}}\right)
$$

Where, $\mathrm{Y}_{\mathrm{CO} 2}, \mathrm{Y}_{\mathrm{CO}}$ and $\mathrm{Y}_{\mathrm{O} 2}$ are the molar fractions of $\mathrm{CO}_{2}, \mathrm{CO}$ and $\mathrm{O}_{2}$ in the outlet gases.

Figures 5.5 to 5.8 show the plots of $\mathrm{H} / \mathrm{C}$ and $\mathrm{CO} /\left(\mathrm{CO}+\mathrm{CO}_{2}\right)$ ratios. These values were tabulated for the four ISC experiments with the other parameters in Table 5.3. These Figures show that the $\mathrm{H} / \mathrm{C}$ ratio is not constant, but varies as the combustion zone propagates into the downstream due to the variations in composition and fuel availability ahead of the combustion front. At the beginning of the experiment (low temperature region), the values of $\mathrm{H} / \mathrm{C}$ ratio are unrealistically high and randomly spread. High $\mathrm{H} / \mathrm{C}$ ratios also reflect that low temperature oxidation reactions precede the onset of high temperature reactions. However, these initial high values should not be included in the final calculation, as they don't represent the actual performance of the combustion process. The $\mathrm{H} / \mathrm{C}$ values decrease as the temperature increases and finally approach approximately constant value between 0.3 and 0.5 . This is consistent with the results reported by Fassihi and Brigham (1981). They found that at temperatures below $287^{\circ} \mathrm{C}$, the $\mathrm{H} / \mathrm{C}$ ratio was higher than that of original oil, and as the temperature was 
Fig. (5.5): Atomic H/C \& carbon molar ratios VS time Run-1, WOC, So $=20 \%, S w=0$

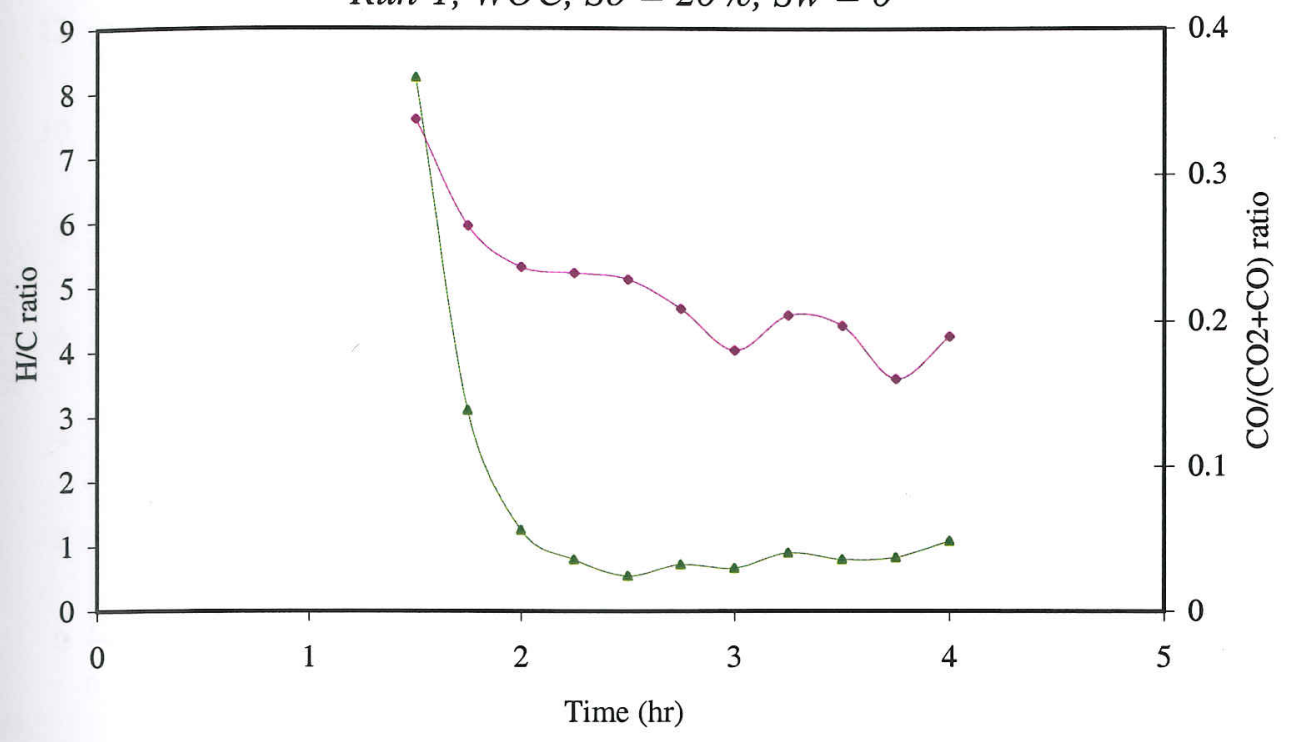

Fig. (5.6): Atomic H/C and carbon molar ratios

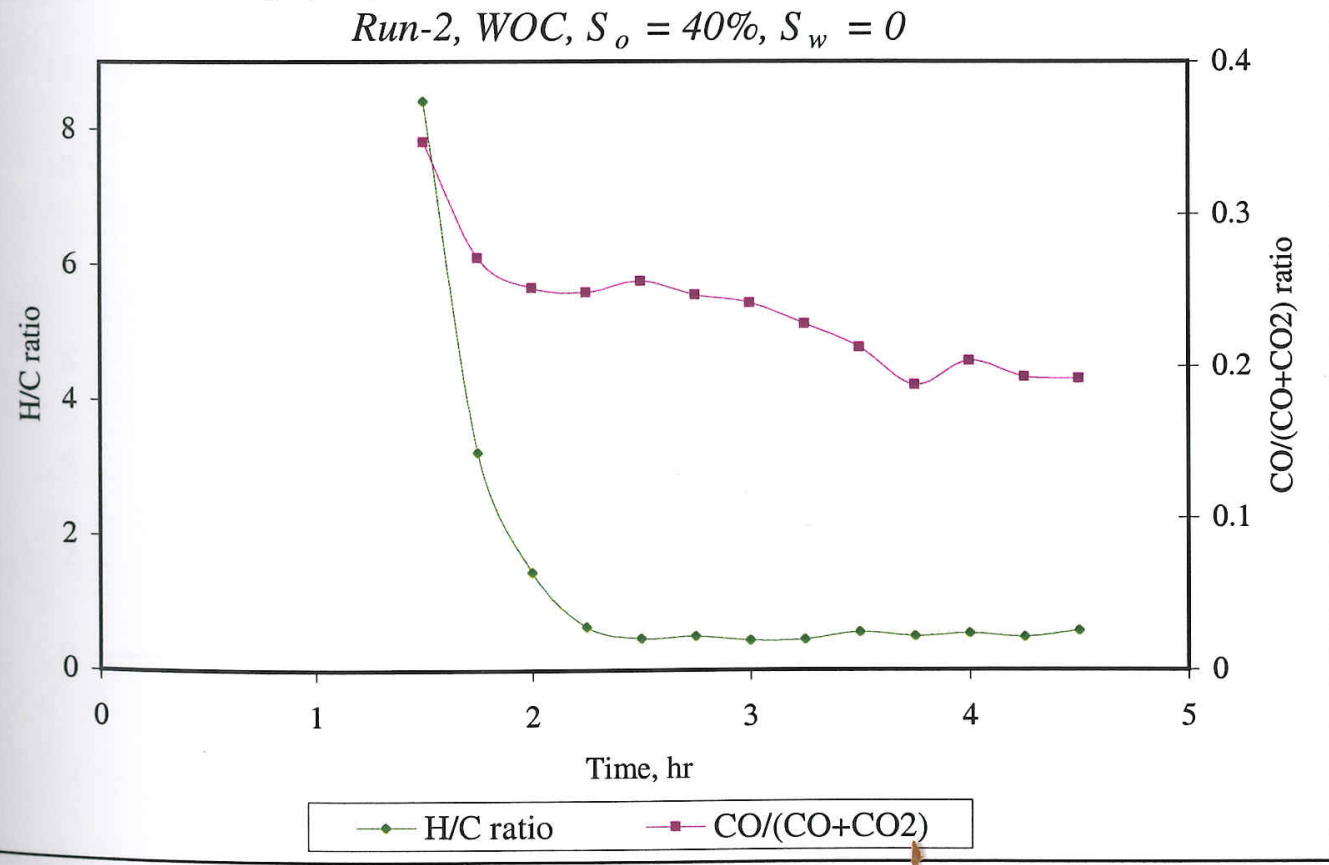




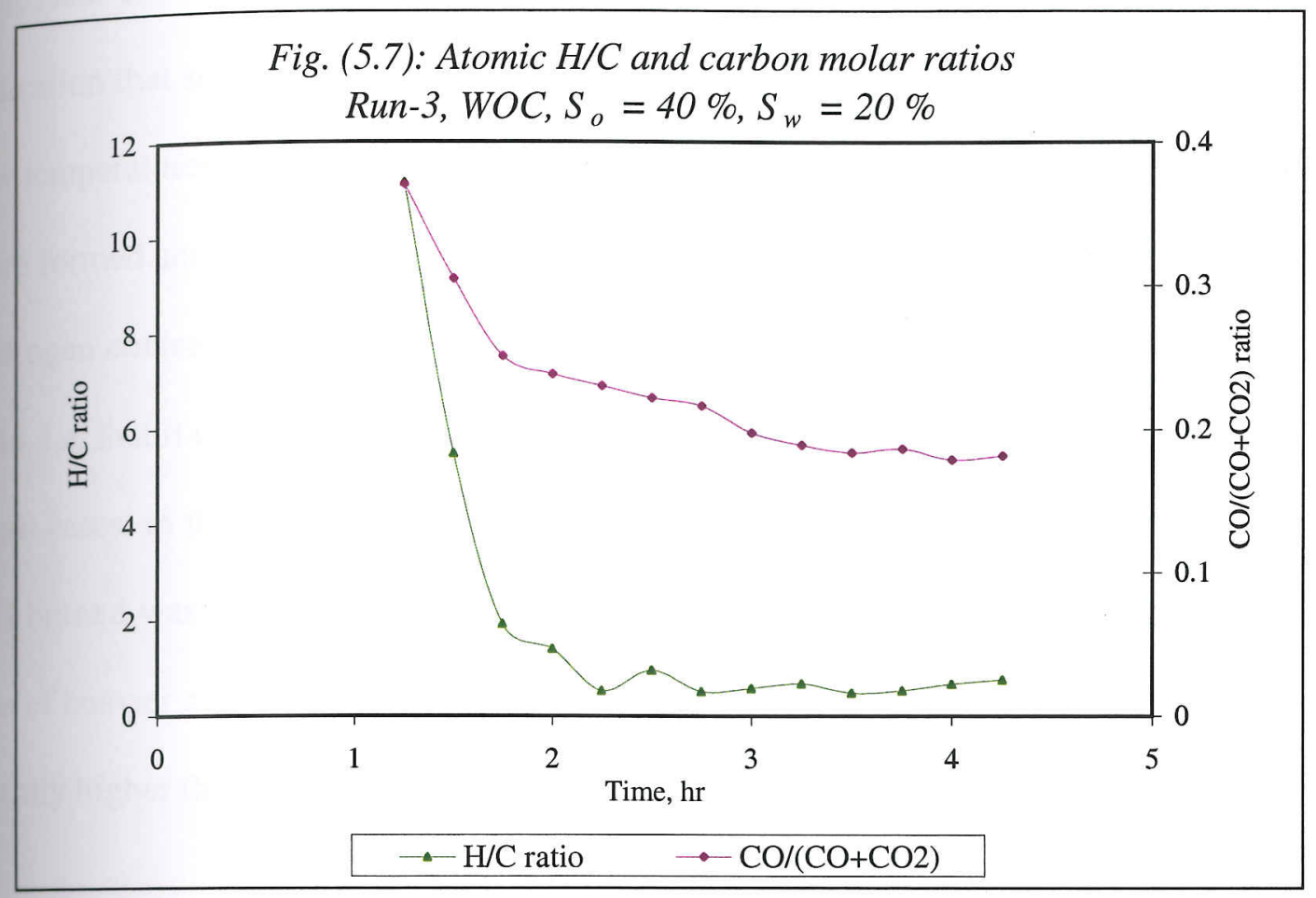

Fig. (5.8): Atomic H/C \& carbon molar ratios

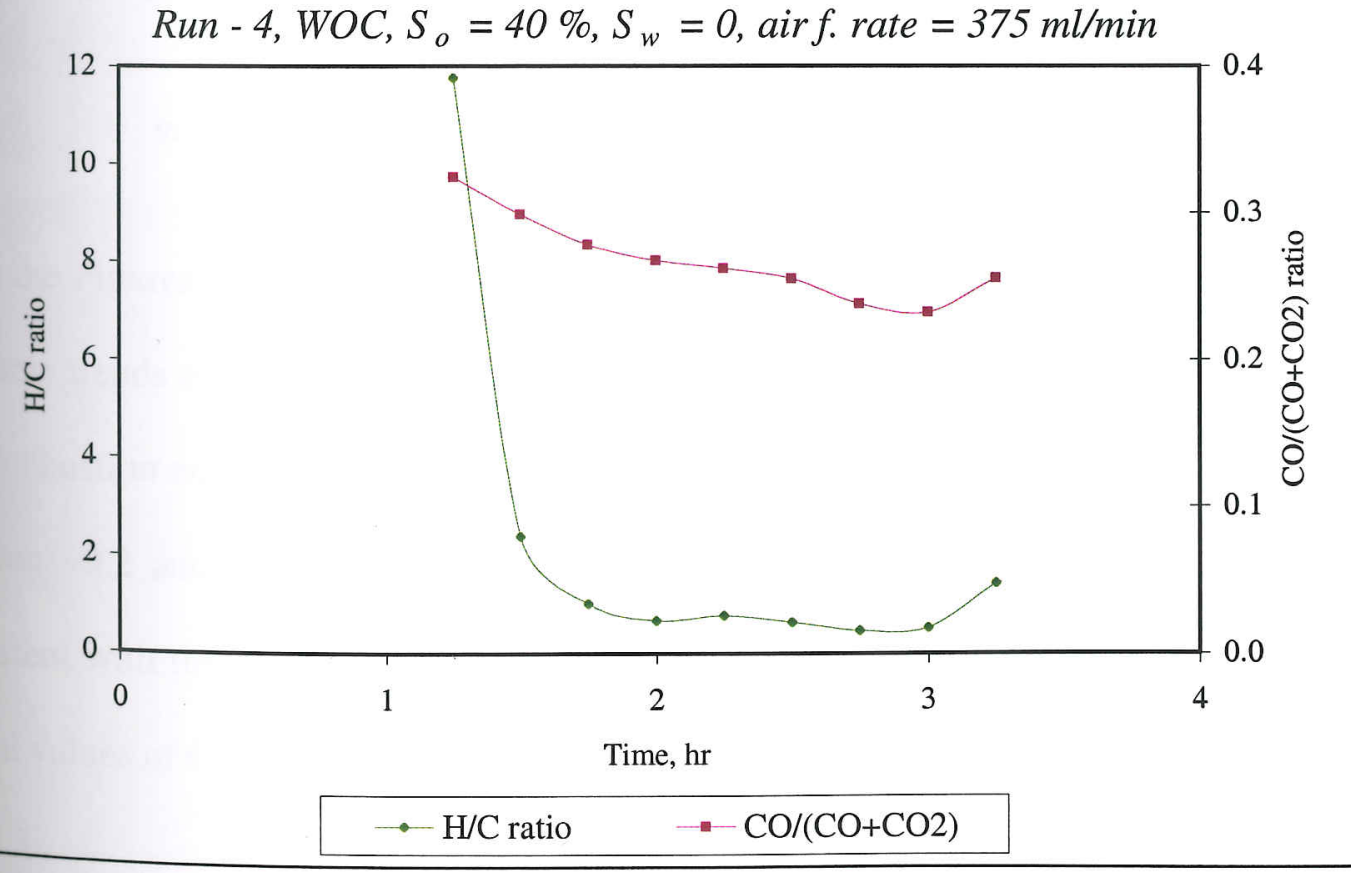


increased, it decreased until it reached a minimum of at around 0.5. This is a clear indication that some LTO and possibly, combustion of light hydrocarbons took place at low temperatures, but at high temperatures mainly carbon dioxide and carbon monoxide were formed and little water was produced, which indicate that the fuel had a very small hydrogen content. Also, Bagci (1986) observed the same effect on the hydrogen-carbon ratio, i.e. that it decreases with increase in temperature for both dry and wet combustion. In all cases, in the present work for both dry and wet combustion, the $\mathrm{H} / \mathrm{C}$ ratio for the fuel burned was lower than that of the native Clair oil $(\mathrm{H} / \mathrm{C}=1.8)$, i.e. the fuel burned was of heavier composition than the original oil. In Run-3 the H/C was 0.66 , which was slightly higher than that of Run-2 $(\mathrm{H} / \mathrm{C}=0.587)$, due to the $\mathrm{H}_{2} \mathrm{O}$ present in feed in Run3.

The molar ratio $\mathrm{CO} /\left(\mathrm{CO}+\mathrm{CO}_{2}\right)$ is defined as the ratio of carbon monoxide to that of all carbon oxides present in the effluent gas i.e.:

$$
m=\mathrm{CO} /\left(\mathrm{CO}+\mathrm{CO}_{2}\right)
$$

From the Figures 5.5 to 5.8 and Table 5.3 , it also seen that $\mathrm{CO} /\left(\mathrm{CO}+\mathrm{CO}_{2}\right)$ ratios have the same trends as the $\mathrm{H} / \mathrm{C}$ ratio in that high values were obtained at the beginning of the combustion and then decreased as temperature increased. The average values ranged between $\sim 0.2$ and 0.25 . The values of the molar ratios were in the same range and consistent with the results obtained by Vossoughi et al (1982) who concluded that the typical values of $\mathrm{CO} /\left(\mathrm{CO}+\mathrm{CO}_{2}\right)$ for stable high temperature combustion are between 0.2 and 0.3 . 


\subsubsection{Oxygen utilization}

Oxygen utilization provides a measure of the combustion efficiency. In general, the lowest values occurred in the period just after ignition, thereafter it reached higher values as the combustion front is established and stabilised. The oxygen utilization for each run is calculated from the exit gas analysis, at the stabilised period of combustion according to equation 5.4 , and is plotted alongside with combustion temperature as a function of the operating time in Figures 5.9 to 5.12 .

$$
\text { Oxygen utilization }(\%)=\left[\left(\mathrm{O}_{2 \text { inlet }}-\mathrm{O}_{2 \text { outlet }}\right) / \mathrm{O}_{2 \text { inlet }}\right] \times 100
$$

Where, $\mathrm{O}_{2 \text { inlet }}$ and $\mathrm{O}_{2 \text { outlet }}$ are the mole $\%$ of oxygen in the injected gas and oxygen concentration in the flue gases respectively.

The results show that the oxygen utilization profiles tend to follow the same behavior. The average oxygen utilization at the stabilised period was very high and ranged between $94-96 \%$. This is an indication that most of oxygen was consumed in the high temperature zone to produce $\mathrm{CO}$ and $\mathrm{CO}_{2}$.

\subsubsection{Air requirement}

Air compression represents the major operating cost for an in-situ combustion project.

Air/fuel ratio (AFR) is the air consumed per kg of fuel. The air requirement for each run is given in Table-5.3, with the other combustion parameters. As can be seen from this Table, the lowest value was for Run-1 at $206 \mathrm{sm}^{3} / \mathrm{m}^{3}$, while it was higher for Run-2 at $247.3 \mathrm{sm}^{3} / \mathrm{m}^{3}$, which was conducted with a higher oil saturation. The comparison between runs "Run-2 and Run-3" (dry and wet respectively) shows that the presence of 

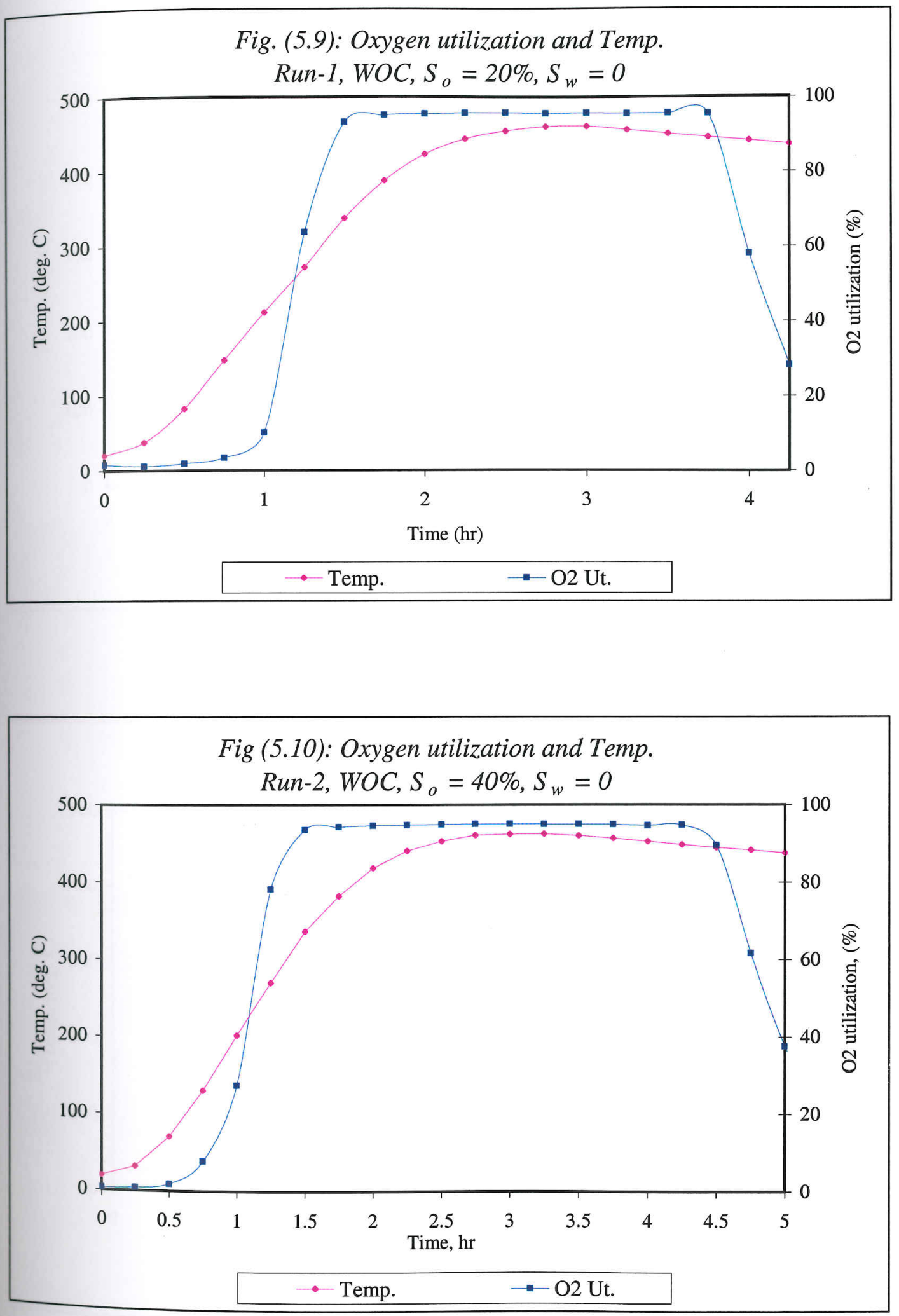

$\sim 02 U t .=$ Oxygen utilization 


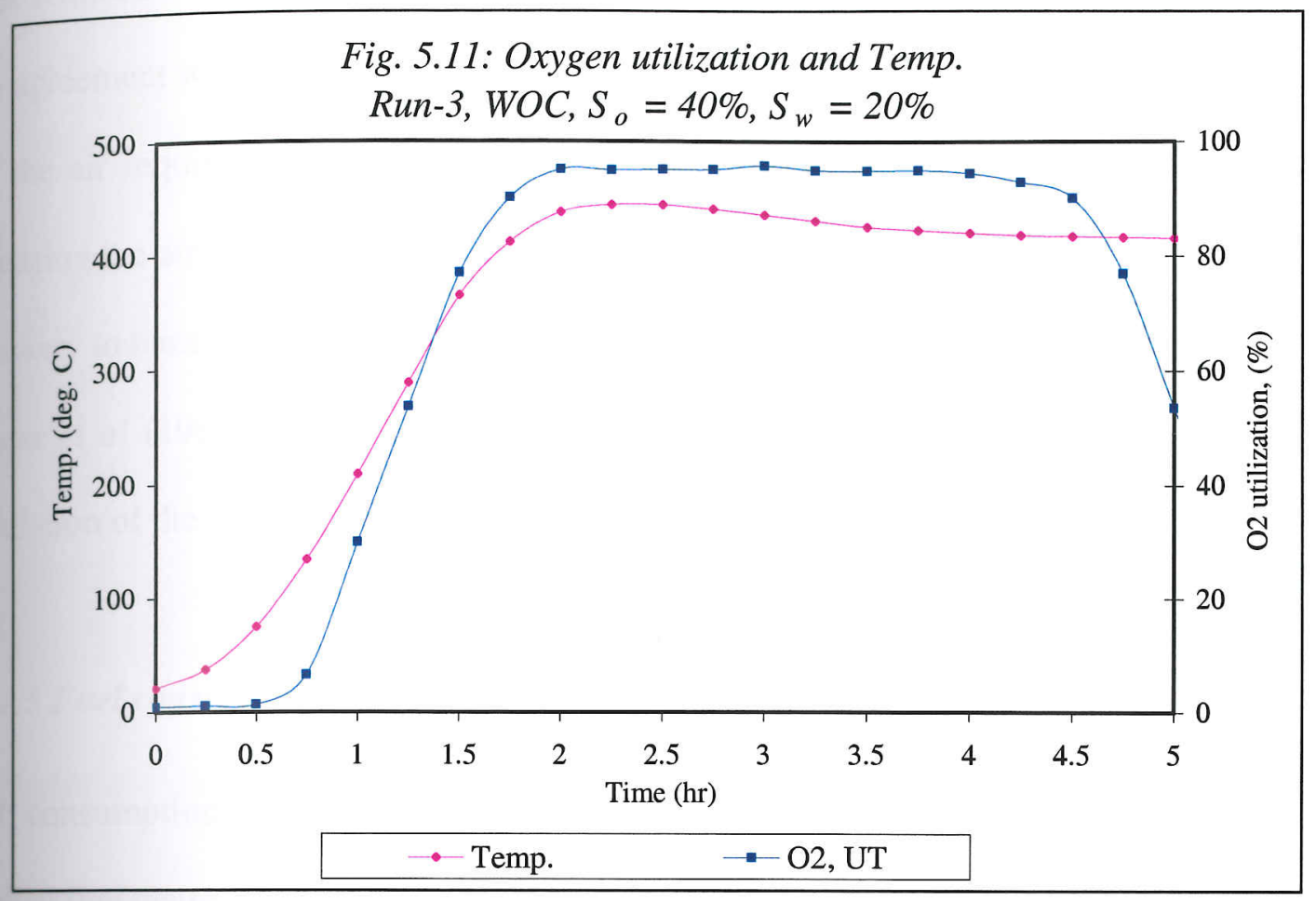

Fig. (5.12): Oxygen utilization and Temp.

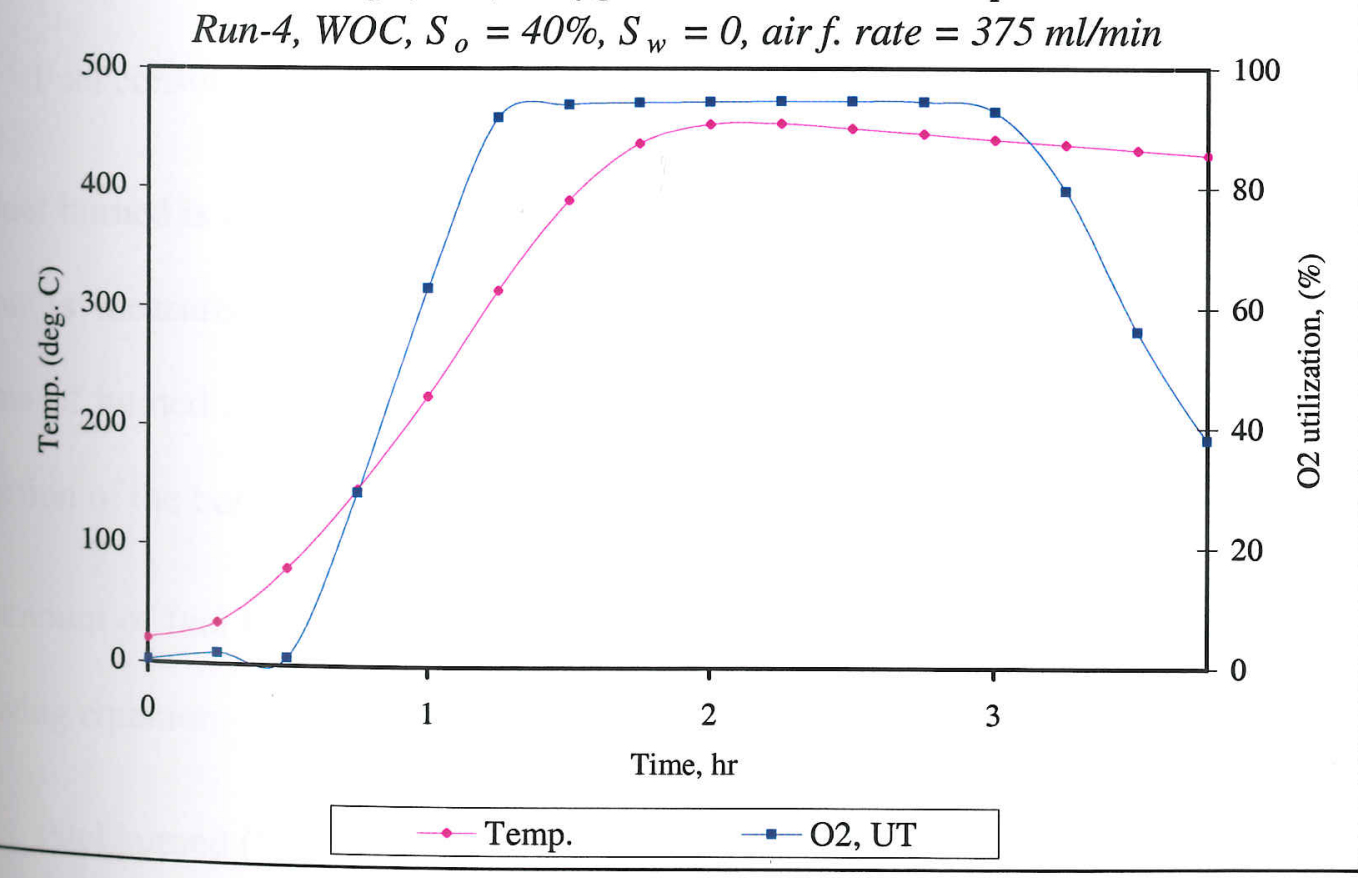


water reduced the air requirement to $226.7 \mathrm{sm}^{3} / \mathrm{m}^{3}$ because less fuel is consumed. This is in agreement with Smith and Perkins (1973) and Greaves et al (1987) who confirmed that the air requirement is reduced with water injection. From Run-4, it is clear that increasing the airflow rate increases the air requirement. The air requirement and the air necessary to burn $1 \mathrm{~kg}$ of fuel, for all of the experiments lie within the range reported by Burger et al (1985), of 150 to $600 \mathrm{sm}^{3} / \mathrm{m}^{3}$, and 10 to $12 \mathrm{sm}^{3}$ respectively. A sample calculation of the combustion parameters is given in Appendix-B.

\subsubsection{Fuel consumption}

Fuel consumption is an important factor because the combustion reactions of the residual fuel generate the necessary energy to sustain the combustion process. The fuel consumption in kilograms of fuel per cubic meter of reservoir matrix, is calculated from the following equation:

Fuel consumption $\left(\mathrm{kg} / \mathrm{m}^{3}\right)=$ Fuel burned / volume of burned section

The fuel burned is calculated from flue gas composition, whereas the volume of burned section is measured from post-mortem inspection. In the present experiments, the volume of burned section was assumed equal to the volume of sample pack; because inspection of the burned sand after use shows that the sand was clean.

The amount of fuel burned as percentage of original oil in place is calculated using the following equation:

Fuel burned $(\%$ of OOIP $)=100\left\{\mathrm{O}_{2 \mathrm{c}}\right.$ /oxygen fuel requirement $\} /$ OOIP 
Where, $\mathrm{O}_{2 \mathrm{c}}$ is the oxygen consumed in the combustion reaction, $(l)$.

Table 5.3: Combustion performance: first set (first mode)

\begin{tabular}{|c|c|c|c|c|}
\hline Experiment & Run-1 & Run-2 & Run-3 & Run-4 \\
\hline Oil saturation, $\mathrm{S}_{\mathrm{o}} \%$ & 20 & 40 & 40 & 40 \\
\hline $\mathrm{H}_{2} \mathrm{O}$ saturation, $\mathrm{S}_{\mathrm{w}} \%$ & 0 & 0 & 20 & 0 \\
\hline $\mathrm{H} / \mathrm{C}$ ratio & 0.81 & 0.587 & 0.66 & 0.55 \\
\hline $\mathrm{CO} /\left(\mathrm{CO}+\mathrm{CO}_{2}\right)$ ratio & 0.20 & 0.22 & 0.197 & 0.25 \\
\hline Air - fuel ratio, $\left(\mathrm{sm}^{3} / \mathrm{kg}\right)$ & 9.69 & 9.27 & 9.46 & 9.1 \\
\hline $\mathrm{O}_{2}$ - fuel ratio, $\left(\mathrm{sm}^{3} / \mathrm{kg}\right)$ & 2.03 & 1.95 & 2 & 1.91 \\
\hline Fuel burnt, (\%OOIP) & 16.04 & 12.73 & 12.30 & 13.37 \\
\hline Oxygen utilization, (\%) & 95.6 & 94.3 & 94.3 & 94.2 \\
\hline Fuel consumption, $\left(\mathrm{kg} / \mathrm{m}^{3}\right)$ & 10.86 & 17.24 & 16.79 & 18.1 \\
\hline Air flux, $\left(\mathrm{sm}^{3} / \mathrm{m}^{2} \mathrm{hr}\right)$ & 6.8 & 6.8 & 6.8 & 10.2 \\
\hline Combust. front velocity, $(\mathrm{m} / \mathrm{hr})$ & 0.033 & 0.0275 & 0.03 & 0.033 \\
\hline Air requirement, $\left(\mathrm{sm}^{3} / \mathrm{m}^{3}\right)$ & 206 & 247.3 & 226.7 & 309 \\
\hline $\mathrm{O}_{2}$ requirement, $\left(\mathrm{sm}^{3} / \mathrm{m}^{3}\right)$ & 43.26 & 51.93 & 47.61 & 64.89 \\
\hline Oil recovery, (\%OOIP) & 56.3 & 67 & 70.50 & 69.2 \\
\hline API gravity, ( $\left.{ }^{\circ} \mathrm{API}\right)$ & 21.9 & 22.87 & 24.80 & 24.5 \\
\hline
\end{tabular}

According to Table 5.3, an increase in oil saturation from $20 \%$ (Run-1) to $40 \%$ (Run-2) leads to a high fuel consumption value for the latter. It seems that the fuel consumption for the in-situ combustion process depends on oil saturation. Alexander et al (1962) also found that the fuel consumption increases as the oil saturation increases. The presence of water slightly reduces the fuel consumption, as can be noted in Run-3 compared to Run-2. As a result, less coke residue is left in the sand ahead of the combustion zone with wet combustion. Also, increasing the air flux from $250 \mathrm{ml} / \mathrm{min}$ (Run-2) to 375 
$\mathrm{ml} / \mathrm{min}($ Run-4) increased the fuel consumption, due to higher levels of thermal cracking at the high temperature achieved.

\subsubsection{Produced oil}

The physical properties of the produced oil from in-situ combustion experiments changed according to the experimental conditions. The specific gravity of the produced oil was measured by weighing portions of it to calculate its API gravity (see the previous Chapter). In all the experiments, a substantial oil upgrading was obtained as evidenced by an increase in oil's API gravity by $\sim 2$ to $5^{\circ}$ API, compared to original Clair crude oil $\left(19.8^{\circ} A P I\right)$.

Table 5.3 gives the total oil recovery as a percentage of the original volume of original oil-in-place $(O O I P)$ and the produced oil's API gravity for each experiment with other combustion parameters.

The only difference between Run- 1 and Run- 2 is that the oil saturation was higher in Run-2 than it was in Run-1. Because of this difference, the recovered oil, as a percentage of original oil in place (\%OOIP), in Run-2 was higher than that in Run-1. This is due to higher oil saturation used in Run-2. This is consistent with the studies of Satman et al (1978), which concluded that higher oil saturation causes higher oil recoveries. Another effect observed was that the produced oil had a slightly higher API gravity.

The presence of water gave a higher yield and a lighter oil production. The oil recovered in Run-3 (wet) was higher than that of Run-2 (dry), at 70.50 and $67 \%$ OOIP, 
respectively. Also the produced oil in Run-3 had a slightly higher API gravity than that in Run-2. This is may attributed to the increased hydrogen generation due to coke gasification and water-gas shift reactions as the water vaporises and contacts the residual coke ahead of combustion front.

Run-4 was conducted with a higher air flux, compared with same operating conditions run (Run-2), and it was found that the produced oil showed a slightly higher recovery and API gravity. 


\subsubsection{Catalytic In-Situ Combustion (CISC) Experiments (first mode)}

All runs in this set were performed both as dry and wet in-situ combustion experiments with catalyst $(W C)$, in which the catalyst is packed at the outlet part of the sample bed. The heated oil and hot gases, generated by combustion reactions, are passed over the catalyst bed and hydrogenation takes place to produce upgraded oil. All runs follow the same operating conditions of non-catalyst runs that were given in Table-5.1. These runs are designated as:

Run-5: WC $(1 \mathrm{gm}), \mathrm{S}_{\mathrm{o}}=20 \%, \mathrm{~S}_{\mathrm{w}}=0$.

Run-6: WC $(1 \mathrm{gm}), \mathrm{S}_{\mathrm{o}}=40 \%, \mathrm{~S}_{\mathrm{w}}=0$.

Run-7: WC (5 gm), $\mathrm{S}_{\mathrm{o}}=40 \%, \mathrm{~S}_{\mathrm{w}}=0$.

Run-8: WC (5 gm), $\mathrm{S}_{\mathrm{o}}=40 \%, \mathrm{~S}_{\mathrm{w}}=20 \%$.

Where;

$\mathrm{WC}=$ with catalyst.

( 1 and $5 \mathrm{gm})=$ weights of catalyst used.

$\mathrm{S}_{\mathrm{0}}=$ oil saturation as a percentage of pore volume.

$\mathrm{S}_{\mathrm{w}}=$ water saturation as a percentage of pore volume.

\subsubsection{Produced gas composition}

The measured composition of the produced gas and the maximum combustion temperature as a function of time for each run are shown in Figures 5.13 to 5.16. Table 5.4 summarises the values of $\mathrm{CO}_{2}, \mathrm{CO}$ and $\mathrm{O}_{2}$ and the maximum temperature during the stabilised period of combustion reaction. 
Generally, as mentioned previously, the carbon oxides started production at about one hour from the beginning of the experiment, while at the same time most of oxygen supplied had been consumed; also, the produced gas profiles tend to exhibit similar trends. From close inspection of the Figures and comparing with the non-catalytic experiments, which were discussed previously (subsection 5.2.1.1), the main findings in this set was that the $\mathrm{CO}$ declines more rapidly with time compared with runs, Run-1 to Run-4, especially with 5 gm catalyst. Also, the $\mathrm{CO}_{2}$ level is significantly higher mirrored by a lower level of $\mathrm{CO}$. This reduction in the $\mathrm{CO}$ level suggests that some conversion of $\mathrm{CO}$ to $\mathrm{CO}_{2}$ has occurred, giving a rise to a higher value of $\mathrm{CO}_{2}$ than that produced in non-catalytic runs. Similar results have been reported by Moore et al (1999), who attributed it to the effectiveness of the heated catalyst zone in converting $\mathrm{CO}$ and $\mathrm{H}_{2} \mathrm{O}$ into $\mathrm{CO}_{2}$ and $\mathrm{H}_{2}$ via the water-gas shift reaction (WGS), due to the presence of this heated catalyst zone.

Figure 5.13 shows the temperature and the composition of the produced combustion gas of Run-5, which was conducted as a dry combustion run with an oil saturation of $20 \%$ and $1 \mathrm{gm}$ of CoMo catalyst. The $\mathrm{CO}_{2}$ and $\mathrm{CO}$ levels during the stabilised period averaged 15.76 and $3 \%$ respectively. Comparing with the non-catalyst run; Run-1 (Figure 5.1), the $\mathrm{CO}_{2}$ level is significantly higher and this produces a lower value of $\mathrm{CO}$, due do the catalytic reaction effect.

Run- 6 was conducted with the same conditions of Run-5, but with oil saturation of 40\%. The temperature and the produced gases composition profiles are shown in Figure 5.14. This run follows the same behavior of the previous run (Run-5), but the $\mathrm{CO}_{2}$ and $\mathrm{CO}$ levels were higher and also the duration of reaction time was longer. This is due to 
the higher oil saturation, which was used in Run-6. The catalytic runs, Run-5 and Run6, have almost the same duration of combustion time compared with the same conditions as for the non-catalytic runs, Run-1 and Run-2 respectively, because a very small amount $(1 \mathrm{gm})$ of catalyst was used and it wasn't spread over the whole sample outlet section in these catalytic runs.

Table 5.4: Produced gas composition: second set, (first mode)

\begin{tabular}{||l|c|c|c|c||}
\hline Experiment & Run-5 & Run-6 & Run-7 & Run-8 \\
\hline Oil saturation, $\mathrm{S}_{\mathrm{o}} \%$ & 20 & 40 & 40 & 40 \\
\hline $\mathrm{H}_{2}$ O saturation, $\mathrm{S}_{\mathrm{w}} \%$ & 0 & 0 & 0 & 20 \\
\hline Catalyst wt., gm & 1 & 1 & 5 & 5 \\
\hline $\mathrm{CO}_{2}$, mole\% & 15.76 & 16.10 & 16.73 & 16.85 \\
\hline $\mathrm{CO}$, mole\% & 3.0 & 3.63 & 3.09 & 2.87 \\
\hline $\mathrm{O}_{2}$, mole\% $^{\circ}$ & 1.08 & 1.09 & 1.11 & 1.29 \\
\hline $\mathrm{Max}^{\circ}$ temp. ${ }^{\circ} \mathrm{C}$ & 460 & 464 & 461 & 436 \\
\hline Combustion time, $\mathrm{hr}$ & 4.25 & 5 & 5.75 & 5.75 \\
\hline Stabilised period $\left(\mathrm{O}_{2}\right), \mathrm{hr}$ & 1.75 & 2.5 & 3.25 & 3.25 \\
\hline
\end{tabular}

Run-7 and Run-8 were performed as a dry and wet catalytic combustion runs respectively, with the same conditions of Run-6, but with 5 grams of catalyst instead of 1 gram; in addition $20 \%$ water saturation was used in Run-8. Figures 5.15 and 5.16 show the temperature and produced gas composition profiles for both runs respectively. They have almost the same period of combustion time, which means that the presence of water gives no significant effect on combustion time. Comparing with the non- 

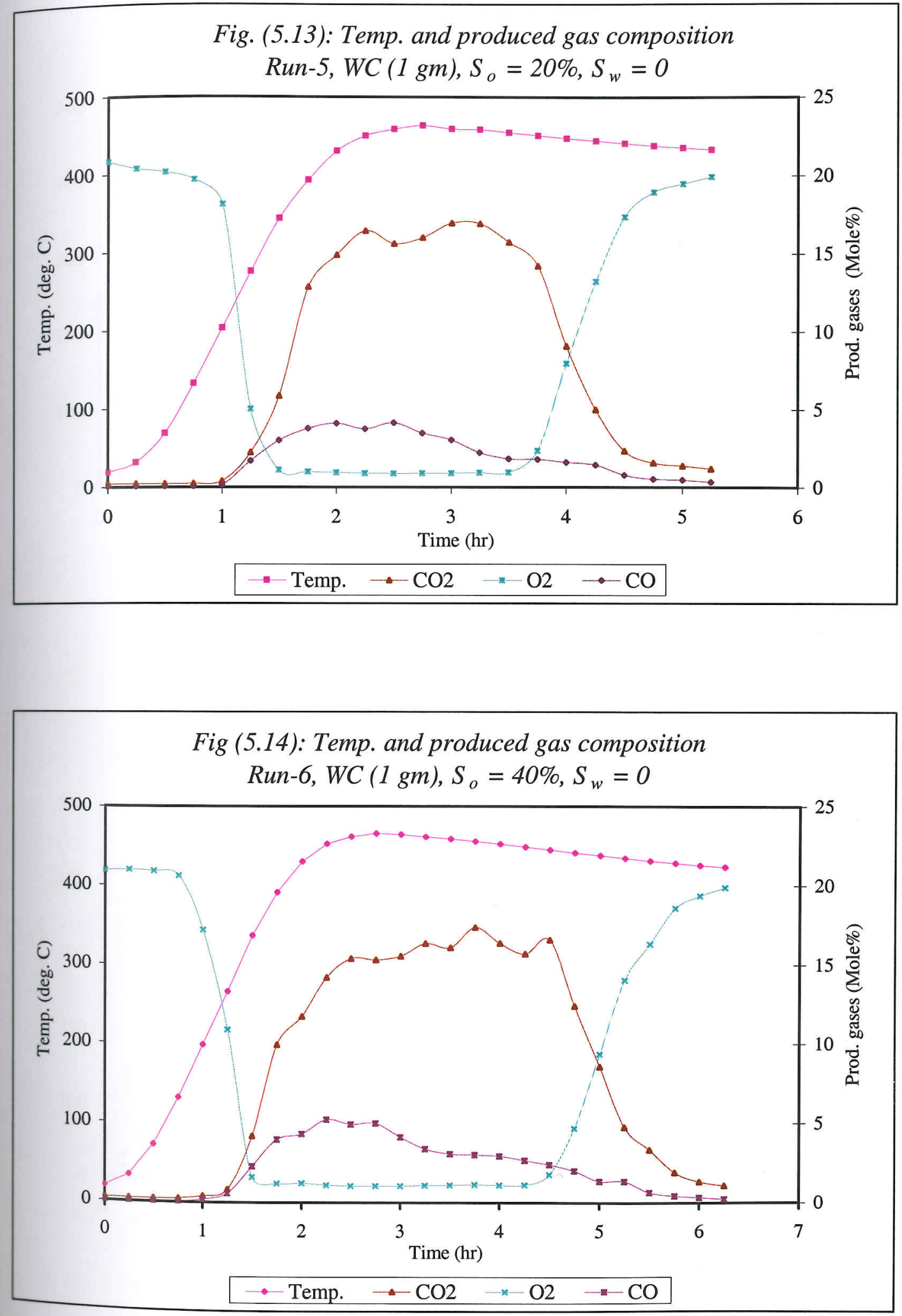

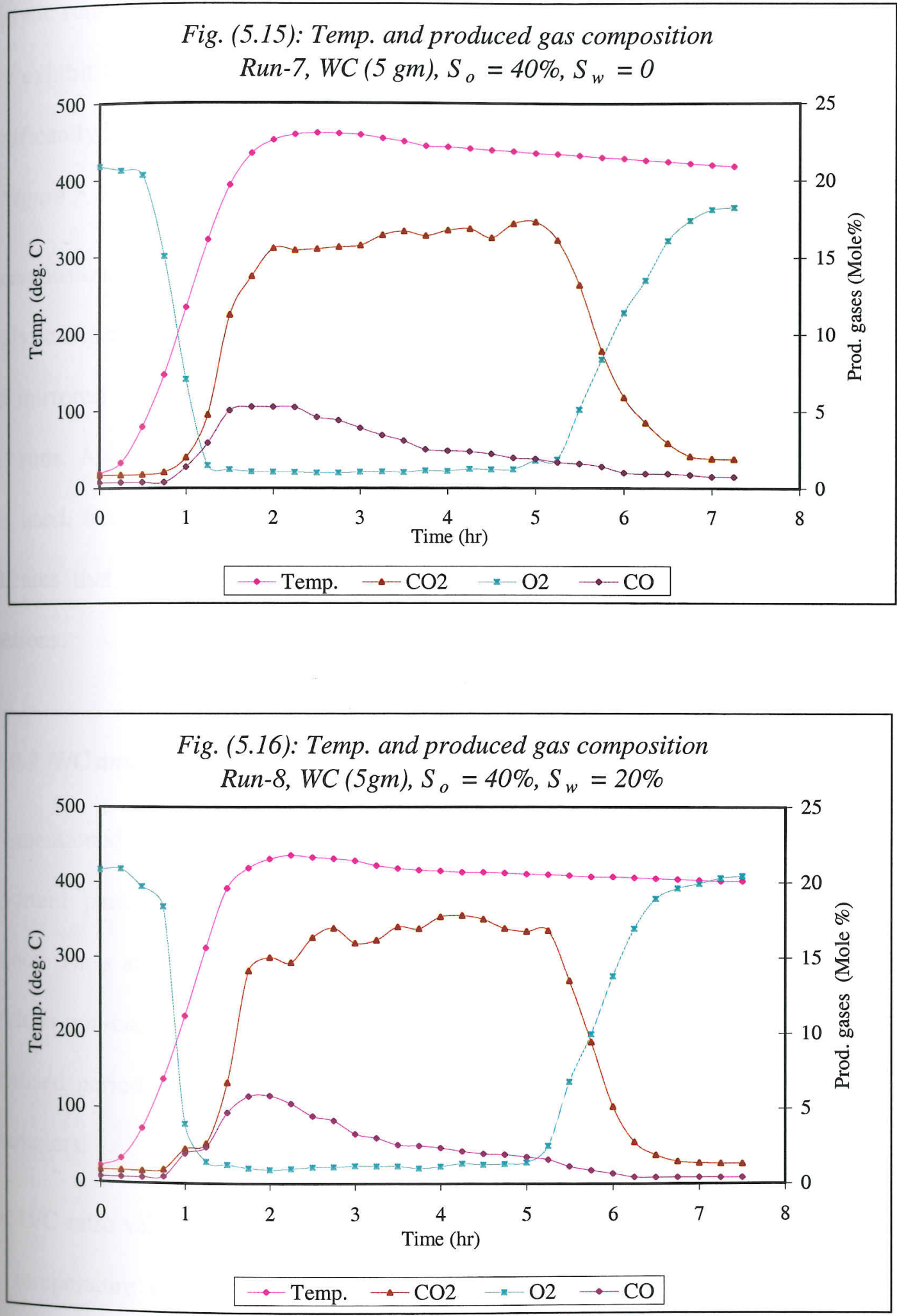
catalytic runs for the same conditions runs, Run-2 (Figure 5.2) and Run-3 (Figure 5.3), they exhibit the same behavior as the two runs, (Run-2 and Run-3). Also, they have a significantly longer period of combustion duration than both the 1 gm catalytic run Run5 (Figure 5.14) and non-catalytic runs, Run-2 and Run-3.

In conclusion, the most interesting observation in comparison between non-catalytic and catalytic experiments was that in the catalytic runs, the $\mathrm{CO}_{2}$ production level was higher and mirrored by a reduction in CO level especially for the heavier catalyst weight ( 5 $\mathrm{gm}$ ) runs. Also, the combustion duration was almost the same when $1 \mathrm{gm}$ of catalyst was used, but the duration was longer when more catalyst $(5 \mathrm{gm})$ was loaded. This indicates that both the presence and loading of catalyst promotes the combustion reactions.

\subsubsection{H/C and carbon molar ratios}

As mentioned previously, the apparent $\mathrm{H} / \mathrm{C}$ ratio and $\mathrm{CO} /\left(\mathrm{CO}+\mathrm{CO}_{2}\right)$ ratios are important parameters for determining the combustion performance of combustion project. They are calculated following Equations 5.1 and 5.2 respectively, as in the previous non-catalytic experiments. Figures 5.17 to 5.20 show their trends, while their stabilised period values are tabulated in Table 5.5, along with the other combustion parameters.

The $\mathrm{H} / \mathrm{C}$ ratio values are very high in the early period of combustion and decreased as the temperature increased and then have a constant value of about 0.4 during the stabilised period of combustion. In all runs, the $\mathrm{H} / \mathrm{C}$ ratio for the fuel burned was lower 
than that of original Clair crude oil $(\mathrm{H} / \mathrm{C}=1.8)$. The $\mathrm{H} / \mathrm{C}$ values of the catalytic runs were slightly lower than those of non-catalytic runs.

Table 5.5: Combustion performance: second set, (first mode)

\begin{tabular}{|c|c|c|c|c|}
\hline Experiment & Run-5 & Run-6 & Run-7 & Run-8 \\
\hline Oil saturation, $\mathrm{S}_{\mathrm{o}} \%$ & 20 & 40 & 40 & 40 \\
\hline $\mathrm{H}_{2} \mathrm{O}$ saturation, $\mathrm{S}_{\mathrm{w}} \%$ & 0 & 0 & 0 & 20 \\
\hline Catalyst wt., gm & 1 & 1 & 5 & 5 \\
\hline $\mathrm{H} / \mathrm{C}$ ratio & 0.787 & 0.68 & 0.51 & 0.505 \\
\hline $\mathrm{CO} /\left(\mathrm{CO}+\mathrm{CO}_{2}\right)$ ratio & 0.16 & 0.18 & 0.156 & 0.146 \\
\hline Air - fuel ratio, $\left(\mathrm{sm}^{3} / \mathrm{kg}\right)$ & 9.834 & 9.59 & 9.55 & 9.46 \\
\hline $\mathrm{O}_{2}$ - fuel ratio, $\left(\mathrm{sm}^{3} / \mathrm{kg}\right)$ & 2.065 & 2.014 & 2.006 & 1.987 \\
\hline Fuel burnt, (\%OOIP) & 16.91 & 11.16 & 17.41 & 16.14 \\
\hline Oxygen utilization, (\%) & 94.86 & 94.81 & 94.71 & 93.86 \\
\hline Fuel consumption, $\left(\mathrm{kg} / \mathrm{m}^{3}\right)$ & 11.45 & 15.11 & 23.57 & 21.85 \\
\hline Air flux, $\left(\mathrm{sm}^{3} / \mathrm{m}^{2} \mathrm{hr}\right)$ & 6.8 & 6.8 & 6.8 & 6.8 \\
\hline Combust. front velocity, $(\mathrm{m} / \mathrm{hr})$ & 0.03 & 0.025 & 0.022 & 0.024 \\
\hline Air requirement, $\left(\mathrm{sm}^{3} / \mathrm{m}^{3}\right)$ & 226.7 & 272 & 309 & 283.3 \\
\hline $\mathrm{O}_{2}$ requirement, $\left(\mathrm{sm}^{3} / \mathrm{m}^{3}\right)$ & 47.61 & 57.12 & 64.89 & 59.49 \\
\hline Oil recovery, (\% OOIP) & 53.13 & 65.3 & 61.32 & 67.15 \\
\hline API gravity, $\left({ }^{\circ} \mathrm{API}\right)$ & 23.87 & 23.38 & 27.13 & 29.21 \\
\hline
\end{tabular}

The $\mathrm{CO} /\left(\mathrm{CO}+\mathrm{CO}_{2}\right)$ ratio is calculated following Equation 5.2, and its values are tabulated in Table 5.5. In all runs, the molar ratio follows the same trend as in the previous experiments, but has lower values when compared with the non-catalytic experiments. Also, its values were slightly lower in Run-7 and Run-8 (5 gm of catalyst), compared with Run-6 (1 gm of catalyst). This is due to the low CO level in the higher 

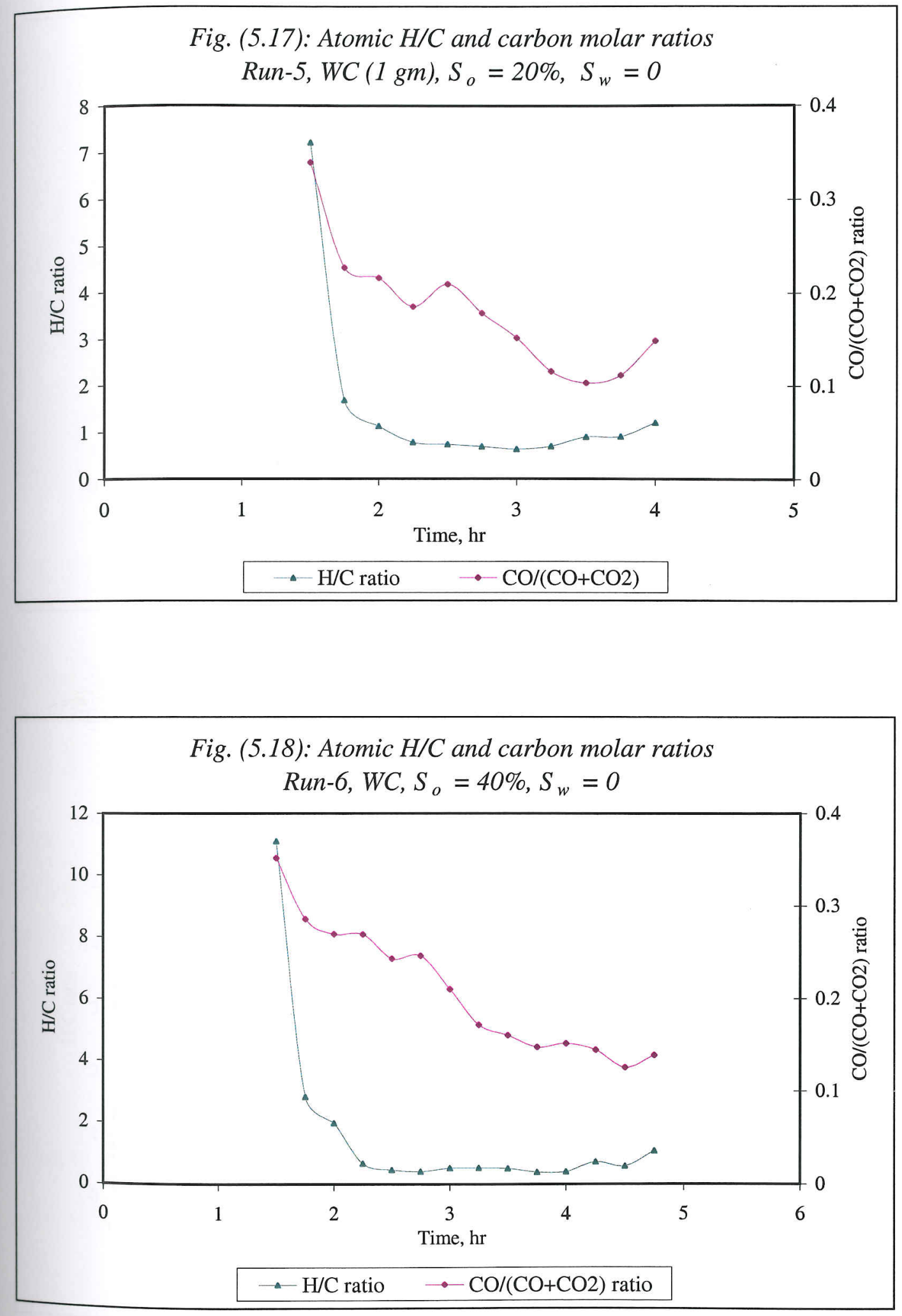

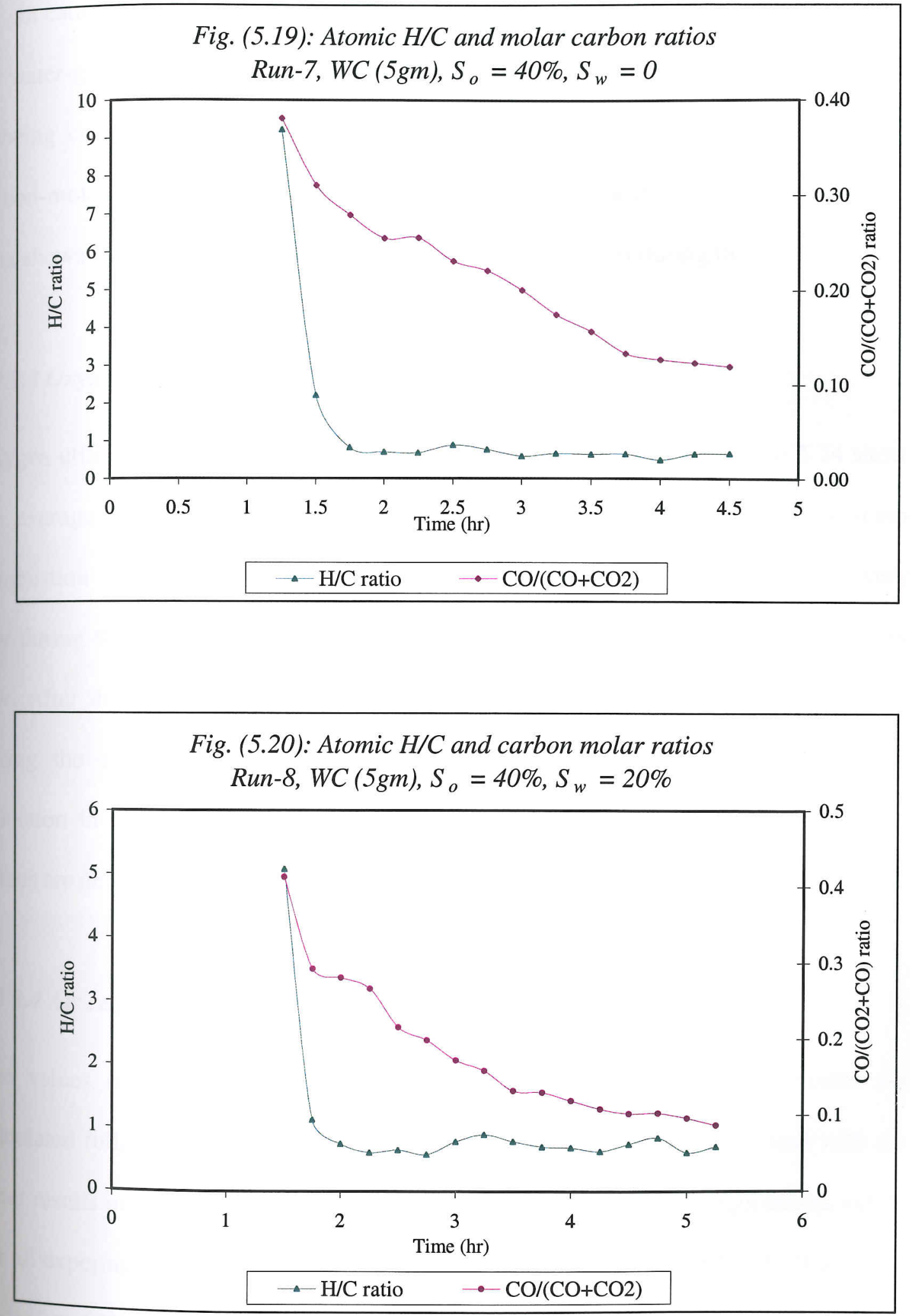
weight catalyst runs, (Run-7 and Run-8), which is clear evidence for CO consumption in the water-gas shift reaction. From this, it is clear that in the presence of catalyst, oxygen is being consumed efficiently to produce carbon dioxide. The lowest value of the carbon-molar ratio for catalytic runs is 0.146 compared with 0.20 in non-catalyst runs. This shows that the combustion reactions have been facilitated during the catalyst runs.

\subsubsection{Oxygen utilization}

Oxygen utilization is calculated following Equation 5.3 and Figures 5.21 to 5.24 show the average stabilised oxygen utilization of all runs alongside with the maximum combustion temperature. As it is seen from the results, the oxygen utilization is very low during the start period of every experiment, because the temperature is still very low. After that, it increased as the temperature increased and reached a higher value during the stabilised period (HTO region), typically greater than 95\%. A slight reduction in $\mathrm{O}_{2}$ utilization was noticed during wet combustion (Run-8). These high values are an indication that very satisfactory combustion was achieved.

\subsubsection{Air requirement}

The values of air-fuel ratio $(A F R)$ and air requirement for each experiment are calculated following an example given in Appendix-B and they are tabulated with the other results in Table 5.5. Again, the air fuel ratio $(A F R)$ and the air requirement values for all experiments lie within the range reported by Burger et al (1985), of 10 to $12 \mathrm{~m}^{3}$ and 150 to $600 \mathrm{~m}^{3} / \mathrm{m}^{3}$. 

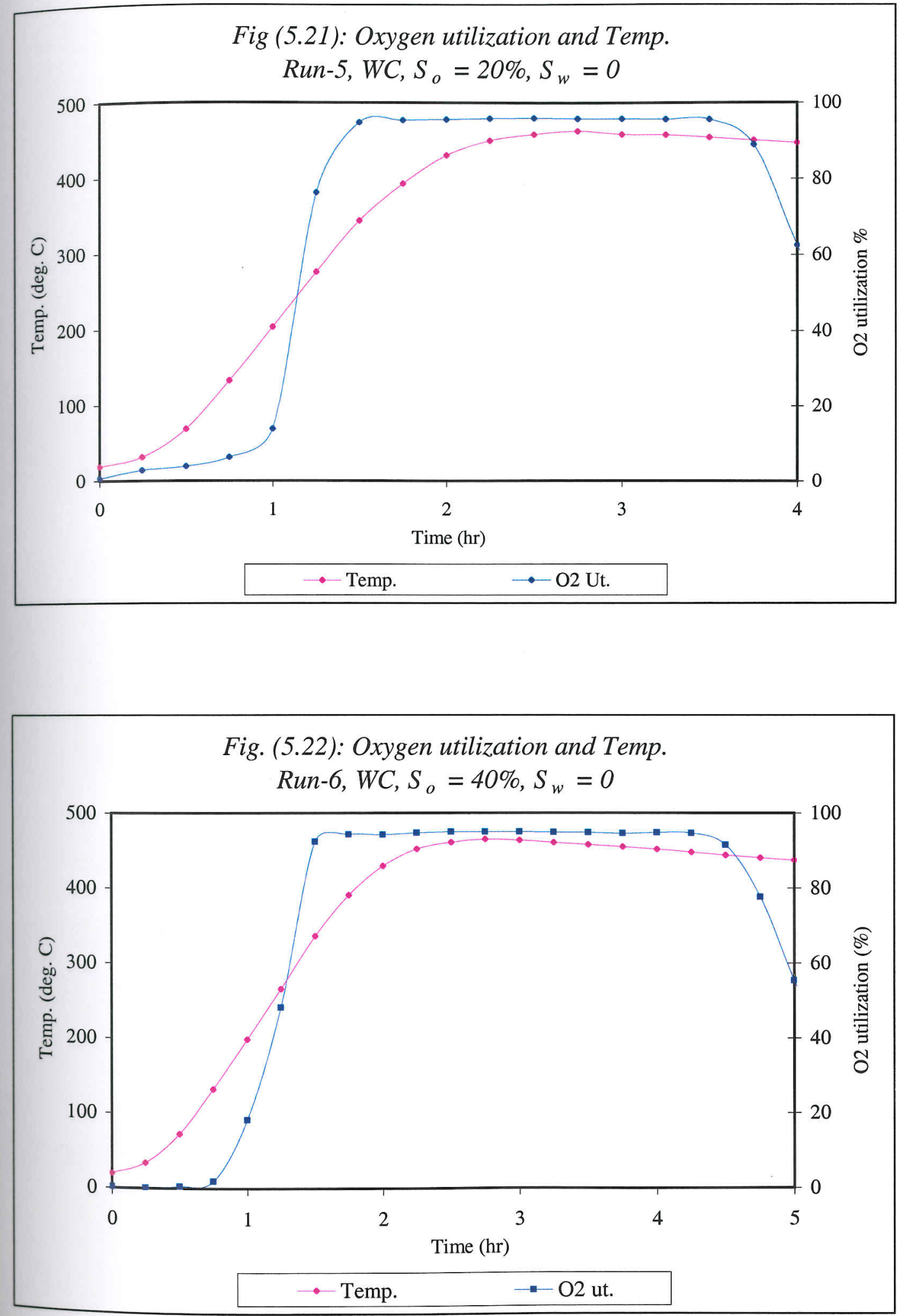

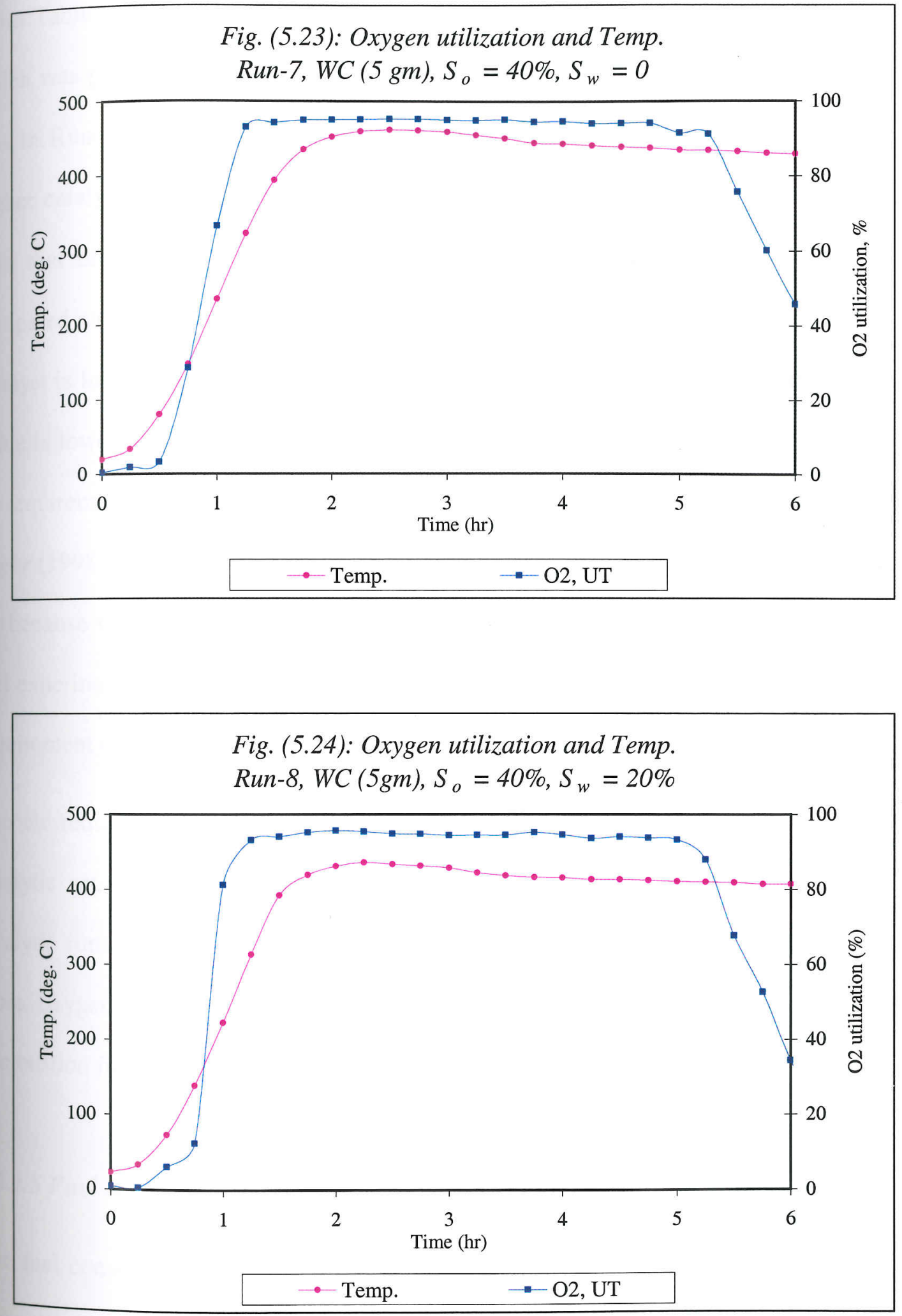
From Table 5.5, the lowest value of the air requirement was in Run-5 $\left(226.7 \mathrm{~m}^{3} / \mathrm{m}^{3}\right)$, which was performed as a dry run with lowest oil saturation (20\%). The highest value was in Run-7 $\left(309 \mathrm{~m}^{3} / \mathrm{m}^{3}\right)$, which was conducted with higher oil content $(40 \%)$ and higher catalyst weight. The air requirement in Run-6 was $272 \mathrm{~m}^{3} / \mathrm{m}^{3}$, which is lower than that of Run-7. This is due to heavier catalyst weight used in Run-7 (5 $\mathrm{gm}$ ) compared with Run-6 (1 gm). This is an indication for more air being required as more catalyst is loaded, because more oxygen is needed. In Run-8 (wet), the air requirement value is lower than that of Run-7; this indicates that the presence of water reduces the air requirement. This is in agreement with the results reported by Bagci (1986) and AlSaghr (1998), who confirmed that wet experiments consumed less fuel and required less air because the high displacement efficiency provided by steam generated during the wet experiments. Also Greaves et al (1987) stated that a considerable reduction in air requirement occurs with wet combustion, because less fuel is consumed.

The air requirement values of this catalytic set were compared with those of noncatalytic set. From Tables 5.3 and 5.5, it can be seen that the air requirement for catalytic runs is observed to be higher than that of non-catalytic runs. This is due to more oxygen being needed in the catalytic runs, and also due to a reduction in combustion front velocity caused by its higher fuel consumption

\subsubsection{Fuel consumption}

The fuel consumption and the fuel burned are calculated using Equations 5.4 and 5.5 respectively, following an example given in Appendix-B and the calculation procedure as mentioned in sub-section 5.2.1.5. Their values are given in Table 5.5. 
The oil consumed as fuel for Run-5 was about $11.45 \mathrm{~kg} / \mathrm{m}^{3}$ while that for Run- 6 was higher, which was $15.11 \mathrm{~kg} / \mathrm{m}^{3}$. This is due to the higher oil content used in Run-6. This result is in good agreement with Shallcross et al, (1991) who revealed that more fuel was consumed as the oil content increased. Both runs were performed with $1 \mathrm{gm}$ of CoMo catalyst. In Run-7, where 5 gm of catalyst was loaded; the fuel consumption was much higher compared with the run at the same conditions (Run-6), but with only $1 \mathrm{gm}$ of catalyst, which was $23.57 \mathrm{~kg} / \mathrm{m}^{3}$. Run- 8 was conducted with the same conditions of Run-7, but with water saturation of $20 \%$. The fuel consumption was $21.85 \mathrm{~kg} / \mathrm{m}^{3}$, which is a slightly lower than that of Run-7. This indicates that the presence of water reduces the fuel consumption.

Comparing both catalytic and non-catalytic experiments, it is clear that the non-catalytic experiments consumed less fuel than catalytic experiments. Also more fuel was consumed as more catalyst was loaded. This is a proof of why less oil is recovered from the catalytic runs. The literature on catalytic cracking shows that increasing catalyst-site density and acid strength favors increased rate of coke formation, (Tanabe, 1970). Vossoughi et al (1983) investigated the effect of clay on dry ISC process. They found that more fuel was deposited as the clay content of the mixture was increased.

\subsubsection{Produced oil}

The produced oil from in-situ combustion (ISC) experiments is a result of several processes such as, pyrolysis, distillation and cracking which are governed by temperature. Weissman et al (1996) passed the oil over a hydroprocessing catalyst bed 
located in the heated zone, which resulted in a product that was significantly upgraded as compared to either the original crude oil or thermally processed oil (non-catalytic). In the present set of experiments, the catalyst bed was packed at the outlet end of the sample bed, in order for the produced oil to flow over it at high temperature facilitating the catalytic reaction to take place; as a result an upgraded oil is produced. The procedure of measuring API gravity was as described previously in subsection 5.2.1.6.

According to Table 5.5, which includes the results of this set of catalytic experiments, the produced oil had a gravity increase that varies upon the experimental conditions. For all of the four runs the gravity increased by $\sim 4$ to $10^{\circ} \mathrm{API}$ as compared by the original Clair crude oil of $19.8^{\circ} \mathrm{API}$. This was due the combined effect of thermal and catalytic reactions. On the other hand, the oil recovery as a percent of original volume of oil-inplace varies from about 53.13 to 67.15 volume $\%$ of the OOIP.

From Table 5.5, it is seen that the oil production was affected by experimental conditions. The API gravity of the produced oil for Run-5, which was done with $20 \%$ of oil saturation and $1 \mathrm{gm}$ of catalyst, was $23.87^{\circ} \mathrm{API}$ which is almost same as that obtained at the higher oil saturation run (40\%). Run- 6 gave a value of $23.38^{\circ} \mathrm{API}$, which is higher than that of the original oil by $\sim 4{ }^{\circ} \mathrm{API}$. When the catalyst weight was increased to 5 gm, in Run-7 (dry) and Run-8 (wet), the produced oil was more highly upgraded by about 3 to $5^{\circ} \mathrm{API}$ respectively, (27.13 and $\left.29.21^{\circ} \mathrm{API}\right)$ as compared with Run-6, and about 7 and $9^{\circ} \mathrm{API}$ respectively, as compared with the original Clair oil. This indicates that the presence of water promotes the catalytic combustion performance. Also, it is clear that the catalyst loading promotes the crude oil combustion performance by producing a higher oil API gravity. This upgrading is due the presence of the 
catalytic bed at the outlet part of sample bed. This finding is in agreement with results reported by Xia and Greaves (2001, a) who stated that when the total catalyst loading was reduced, the level of oil upgrading decreased.

Oil recovery increased from 53.13 to 65.30 volume $\%$ of OOIP as oil saturation increased from $20 \%$ (Run-5) to $40 \%$ (Run-O). These two runs were performed with catalyst weight of $1 \mathrm{gm}$. Using a $5 \mathrm{gm}$ of the catalyst instead of $1 \mathrm{gm}$ in Run-7 reduces the oil recovery to 61.32 volume $\%$ of OOIP compared with the run at the same conditions (Run-6), due to more oil burned when more catalyst loaded. More oil was produced in Run- 8 when $20 \%$ of water saturation was used, compared with the dry run, Run-7. This might be due to the high displacement efficiency provided by the steam generated.

The API gravity of the produced oil and oil recovery were compared for catalytic with non-catalytic runs. As can be seen in Tables 5.3 and 5.5, oil produced by non-catalytic in-situ combustion is upgraded by about 2 to $5^{\circ} \mathrm{API}$ depending on the experimental conditions, compared with original crude oil. While, in catalytic in-situ combustion runs, the oil produced is upgraded by about 4 to $10^{\circ} \mathrm{API}$, depending on the experimental conditions, and especially on the catalyst weight used. It is clear that the API of the oil produced catalytically is significantly higher than the oil processed non-catalytically. Greaves and Xia, (2001) reported similar findings. Also, in the presence of water, a slight increase in API gravity was noticed in both catalytic and non-catalytic in-situ combustion tests. This is may be due to the increased generation of hydrogen by the water-gas shift reaction. 
Johnson and Bright (1985) and Stapp (1989) demonstrated the importance of water in upgrading, reporting successful upgrading of heavy oil in the presence of water and brine, with either $\mathrm{H}_{2}$ or $\mathrm{CO}$, using heterogeneous or homogeneous catalysts.

Also, the oil recovered as a percentage of the volume of original oil in place (OOIP) from catalytic runs was less than that from non-catalytic runs. This is due to more oil being burnt during the catalyst runs.

The above results are consistent with those reported by Al-Saghr (1998). He concluded that the oil produced by ISC (non-catalytic) experiments was upgraded by 2 to 3 points, while that produced by CISC (catalytic) was upgraded by 7 to 10 points for both dry and wet ISC experiments respectively, compared with the original crude oil. It was also stated that less oil was recovered from the catalytic runs compared with non-catalyst runs. Another finding reported in his study was that water injection is beneficial in improving the quality of produced oil by promoting the hydrogen generation by watergas shift reaction and the possibility of restoration of catalyst activity by the presence of steam. 


\subsection{SECOND MODE EXPERIMENTS (perforated tube experiments)}

\subsubsection{General Introduction}

Four forward in-situ combustion experiments were performed using a small-perforated tube (described in the previous Chapter), which serves as a horizontal well. This perforated tube was inserted in the same combustion cell used in previous experiments, at the outlet fitting and was placed close to the bottom of the sample bed. In this mode, the sample bed was shifted towards the outlet of the combustion cell. This was done after some trial and error tests to find the best location for the sample bed (reaction zone) using this small-perforated tube. The experiments were conducted for both dry and wet conditions and with and without catalyst. $5 \mathrm{gm}$ of catalyst was used in these catalytic experiments. The main purpose of these experiments was to investigate the effect of in-situ combustion process on the catalytic upgrading of medium-heavy Clair oil $\left(19.8^{\circ} \mathrm{API}\right)$, by using a catalyst bed surrounding the perforated tube, which acted as a horizontal producer well.

All runs were made with the same experimental conditions as tabulated in Table 5.1 and the same procedure was followed as in previous experiments. These experiments are designated as:

Run-9: $\mathrm{PWOC}, \quad \mathrm{S}_{\mathrm{o}}=40 \%, \mathrm{~S}_{\mathrm{w}}=0$.

Run-10: PWC (5 gm), $\mathrm{S}_{\mathrm{o}}=40 \%, \mathrm{~S}_{\mathrm{w}}=0$.

Run-11: PWOC, $\quad \mathrm{S}_{\mathrm{o}}=40 \%, \mathrm{~S}_{\mathrm{w}}=20 \%$.

Run-12: PWC (5 gm), $\mathrm{S}_{\mathrm{o}}=40 \%, \mathrm{~S}_{\mathrm{W}}=20 \%$.

Where; 
PWOC $=$ Perforated tube, without catalyst.

PWC $=$ Perforated tube, with catalyst.

$\mathrm{S}_{0}=$ oil saturation as a percentage of sand pore volume.

$\mathrm{S}_{\mathrm{W}}=$ water saturation as a percentage of sand pore volume.

The results of these experiments are analysed and discussed in the following sections.

\subsubsection{Produced gas composition}

Figures 5.25 to 5.28 show the measured composition of the produced gas and the maximum combustion temperature as a function of time for each run. The average values of $\mathrm{CO}_{2}, \mathrm{CO}$ and $\mathrm{O}_{2}$ and the maximum temperature during the stabilised period of the combustion reaction are summarised Table 5.6.

Table 5.6: produced gas composition (second mode runs)

\begin{tabular}{|c|c|c|c|c|}
\hline Experiment & Run -9 & Run-10 & Run-11 & Run-12 \\
\hline Oil saturation, $\mathrm{S}_{\mathrm{o}} \%$ & 40 & 40 & 40 & 40 \\
\hline $\mathrm{H}_{2} \mathrm{O}$ saturation, $\mathrm{S}_{\mathrm{w}} \%$ & 0 & 0 & 20 & 20 \\
\hline Catalyst wt., gm & 0 & 5 & 0 & 5 \\
\hline $\mathrm{CO}_{2}$, mole $\%$ & 14.52 & 16.13 & 15.05 & 17.33 \\
\hline $\mathrm{CO}, \mathrm{mole} \%$ & 4.45 & 2.68 & 3.84 & 2.18 \\
\hline $\mathrm{O}_{2}$, mole $\%$ & 1.36 & 1.13 & 2.27 & 1.92 \\
\hline Max. temp. ${ }^{\circ} \mathrm{C}$ & 458 & 468 & 445 & 457 \\
\hline Combustion time, $\mathrm{hr}$ & 5.5 & 5.75 & 5.5 & 5.75 \\
\hline Stabilised period, hr & 2.25 & 2.5 & 2.25 & 2.5 \\
\hline
\end{tabular}


In general, the behavior during these experiments was similar, with some differences in produced gas levels, depending on the experimental conditions. From Figures 5.25 to 5.28 and Table 5.6, it is clear that from wet experiments (Run-11 and Run-12) as compared with dry ones (Run-9 and Run-10), the presence of water promotes the combustion reaction, as represented by the slightly higher $\mathrm{CO}_{2}$ and lower $\mathrm{CO}$ levels. Also, the presence of catalyst around the perforated tube (horizontal well) promotes the combustion reaction. Comparing the dry and wet catalytic runs (Run-10 and Run-12) with those of the non-catalytic runs (Run-9 and Run-11), the level of $\mathrm{CO}_{2}$ is slightly higher; while that of $\mathrm{CO}$ is lower in the catalytic runs. These higher values of $\mathrm{CO}_{2}$ suggest that some conversion of $\mathrm{CO}$ to $\mathrm{CO}_{2}$ may have occurred giving rise to higher values of $\mathrm{CO}_{2}$ than those produced in non-catalytic runs. Al-Saghr (1998) has reported similar results. Also, Moore et al (1999) have reported similar trends of gas composition. They attributed this to the effectiveness of the heated catalyst zone in converting $\mathrm{CO}$ and $\mathrm{H}_{2} \mathrm{O}$ into $\mathrm{CO}_{2}$ and $\mathrm{H}_{2}$ via the water-gas shift reaction.

\subsubsection{H/C and carbon molar ratios}

The detailed results for the $\mathrm{H} / \mathrm{C}$ and $\mathrm{CO} /\left(\mathrm{CO}_{2}+\mathrm{CO}\right)$ ratios are presented graphically in Figures 5.29 to 5.32 and their calculated stabilised period average values are included in Table 5.7. As observed in previous experiments, a general decrease in the atomic $\mathrm{H} / \mathrm{C}$ ratio with an increase in temperature was observed for all runs. In all experiments, the $\mathrm{H} / \mathrm{C}$ ratio for the fuel burned was lower than that of original Clair crude oil $(H / C=1.8)$, and is an indication that the fuel was of heavier composition. As can be seen from Table 5.7, the $\mathrm{H} / \mathrm{C}$ values during the stabilised period for the catalytic tests (Run-10 and Run- 

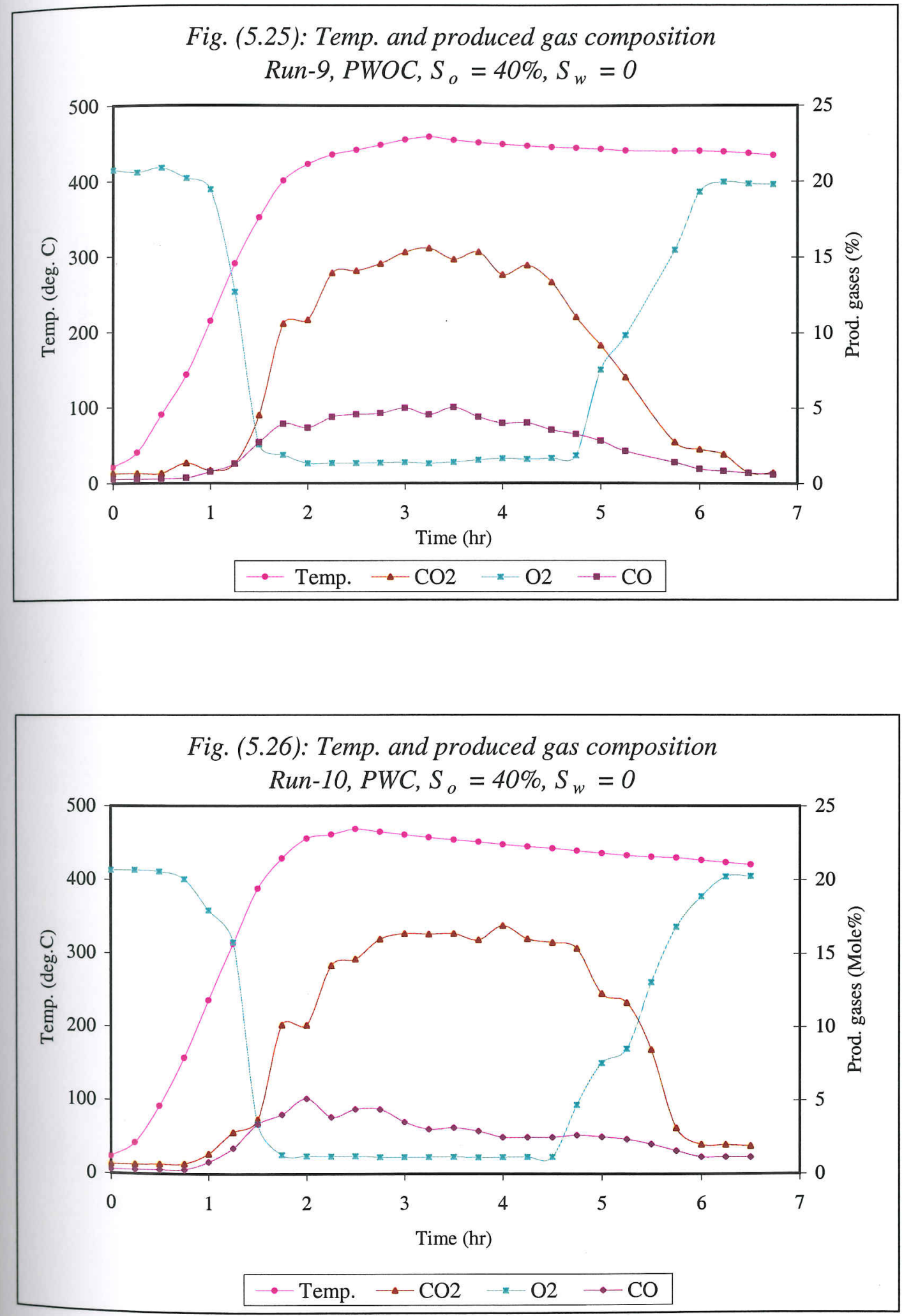

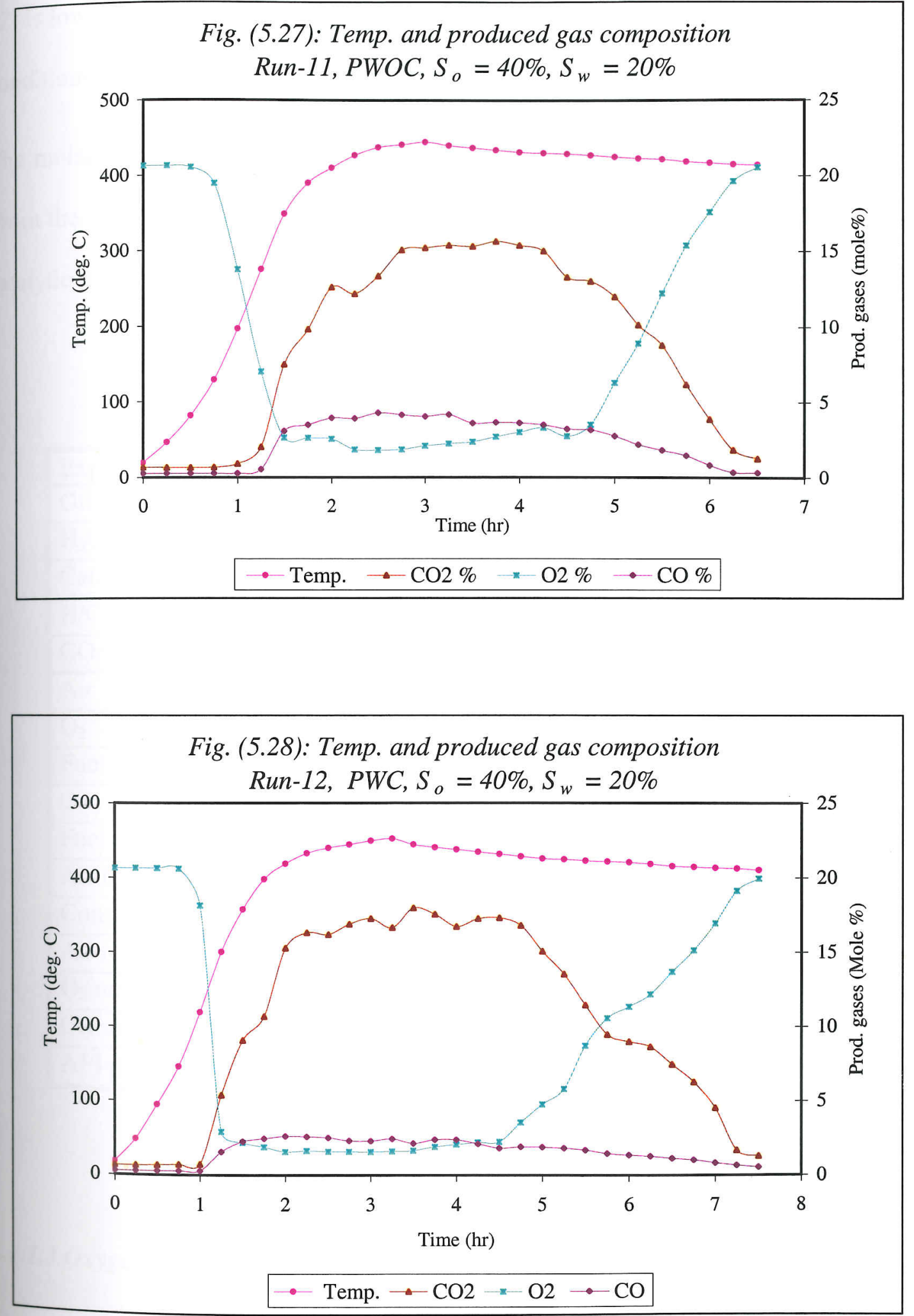
12) is lower than that of the non-catalytic tests (Run-9 and Run-11) for both dry and wet conditions.

The molar carbon ratio $\mathrm{CO} /\left(\mathrm{CO}+\mathrm{CO}_{2}\right)$ followed the same behavior as the $\mathrm{H} / \mathrm{C}$ ratio. From the results, its value is lower in both of the catalytic runs compared with the noncatalytic runs, due to a low CO level, especially in the wet combustion test.

Table 5.7: Combustion performance (second mode runs)

\begin{tabular}{|c|c|c|c|c|}
\hline Experiment & Run-9 & Run-10 & Run-11 & Run-12 \\
\hline Oil saturation, $\mathrm{S}_{\mathrm{o}} \%$ & 40 & 40 & 40 & 40 \\
\hline $\mathrm{H}_{2} \mathrm{O}$ saturation, $\mathrm{S}_{\mathrm{w}} \%$ & 0 & 0 & 20 & 20 \\
\hline Catalyst wt., gm & 0 & 5 & 0 & 5 \\
\hline $\mathrm{H} / \mathrm{C}$ ratio & 0.96 & 0.74 & 0.69 & 0.52 \\
\hline $\mathrm{CO} /\left(\mathrm{CO}+\mathrm{CO}_{2}\right)$ ratio & 0.23 & 0.14 & 0.20 & 0.116 \\
\hline Air - fuel ratio, $\left(\mathrm{sm}^{3} / \mathrm{kg}\right)$ & 9.754 & 9.855 & 9.526 & 9.641 \\
\hline $\mathrm{O}_{2}$ - fuel ratio, $\left(\mathrm{sm}^{3} / \mathrm{kg}\right)$ & 2.048 & 2.070 & 2.0 & 2.025 \\
\hline Fuel burnt, (\%OOIP) & 10.96 & 12.03 & 10.52 & 11.70 \\
\hline Oxygen utilization, (\%) & 93.43 & 94.62 & 89.2 & 90.86 \\
\hline Fuel consumption, $\left(\mathrm{kg} / \mathrm{m}^{3}\right)$ & 14.84 & 16.29 & 14.25 & 15.83 \\
\hline Air flux, $\left(\mathrm{sm}^{3} / \mathrm{m}^{2} \mathrm{hr}\right)$ & 6.8 & 6.8 & 6.8 & 6.8 \\
\hline Combust. front velocity, $(\mathrm{m} / \mathrm{hr})$ & 0.018 & 0.016 & 0.020 & 0.019 \\
\hline Air requirement, $\left(\mathrm{sm}^{3} / \mathrm{m}^{3}\right)$ & 377.8 & 425 & 340 & 357.9 \\
\hline $\mathrm{O}_{2}$ requirement, $\left(\mathrm{sm}^{3} / \mathrm{m}^{3}\right)$ & 79.34 & 89.25 & 71.40 & 75.16 \\
\hline Oil recovery, (\%OOIP) & 71.30 & 64.50 & 74.33 & 69.65 \\
\hline API gravity, $\left({ }^{\circ} \mathrm{API}\right)$ & 23.12 & 27.9 & 25.32 & 30.76 \\
\hline
\end{tabular}

\subsubsection{Oxygen utilization}

Figures 5.33 to 5.36 show the oxygen utilization together with the combustion temperature. As can be seen, oxygen utilization was very low during the start period of 

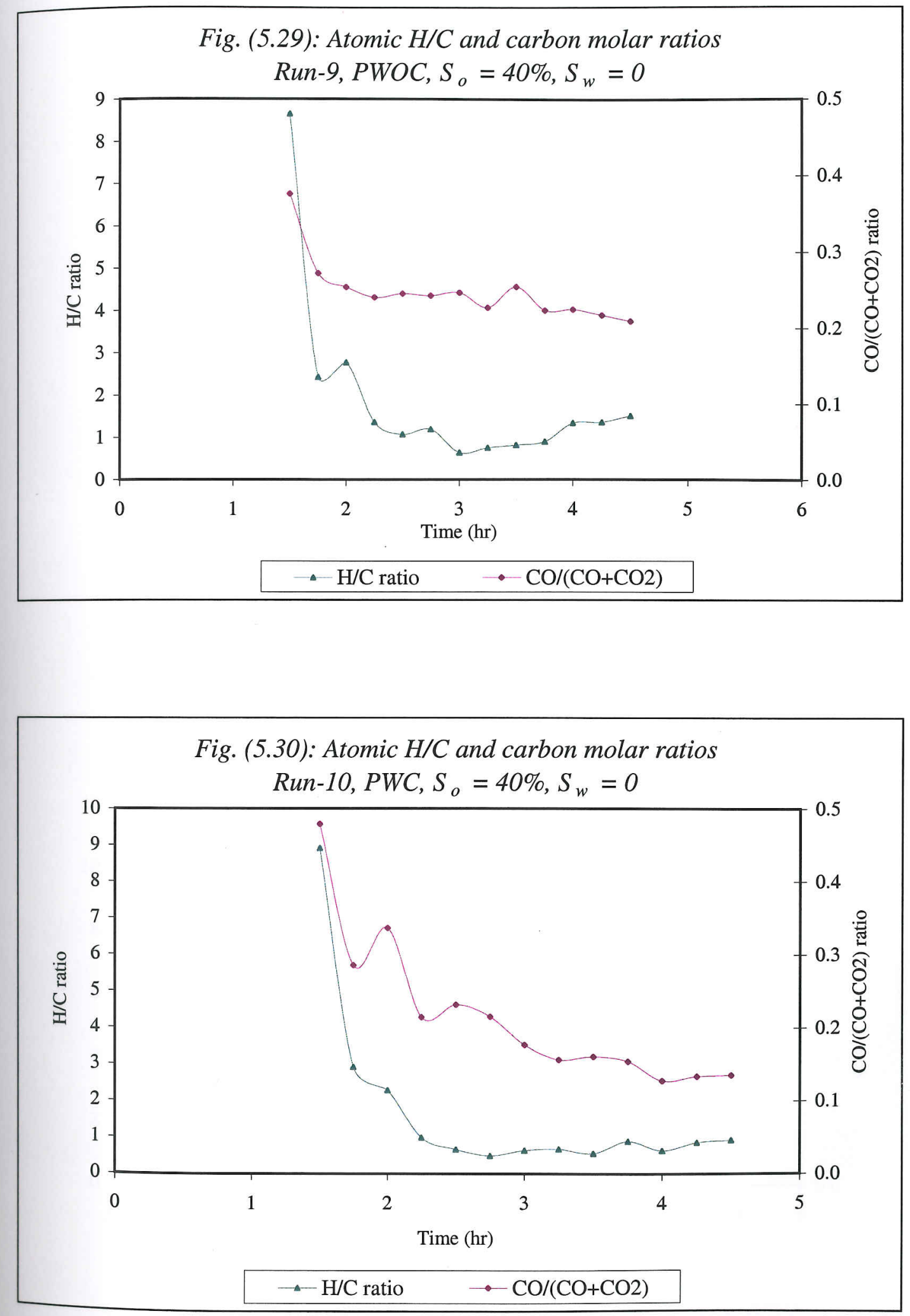

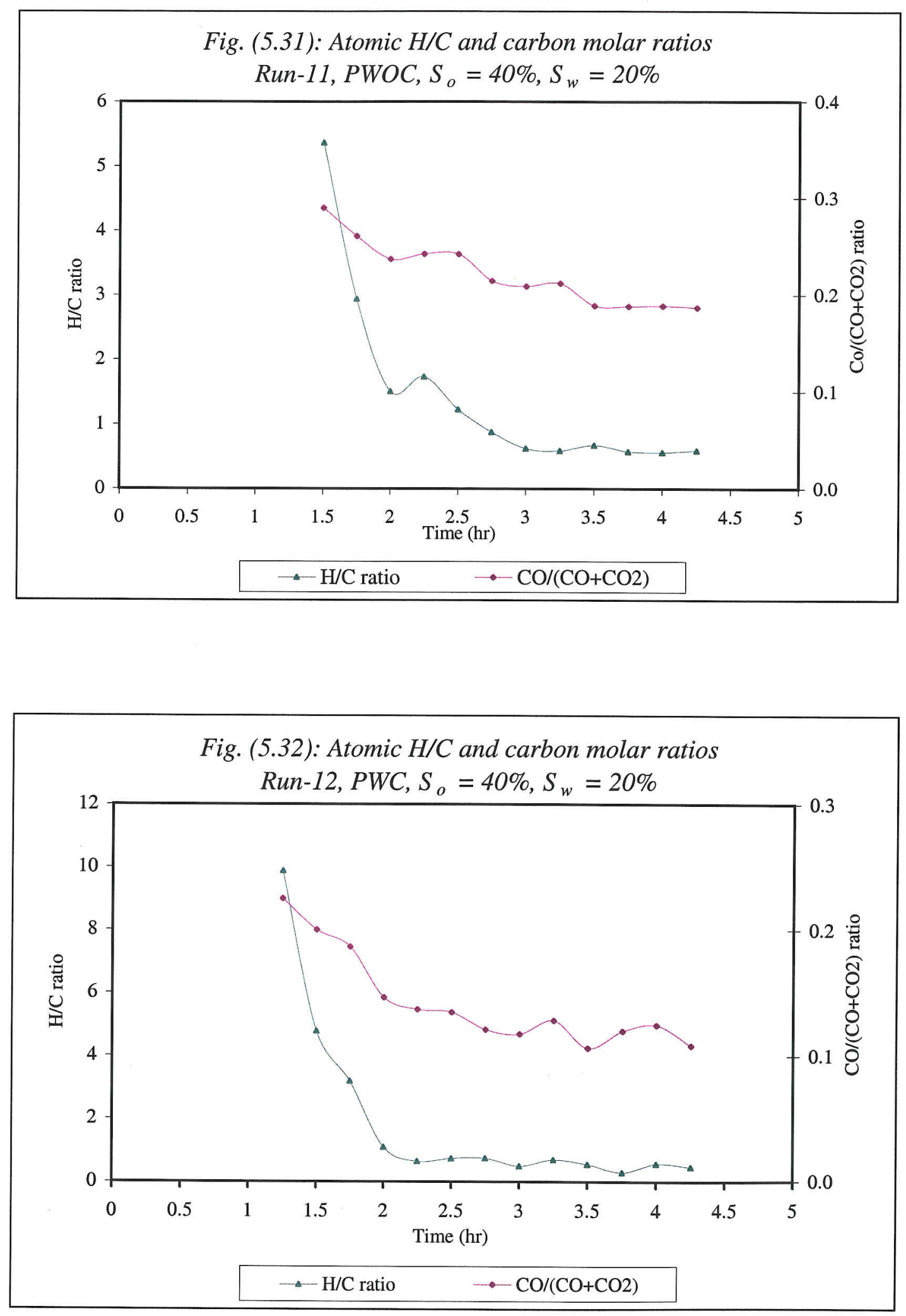

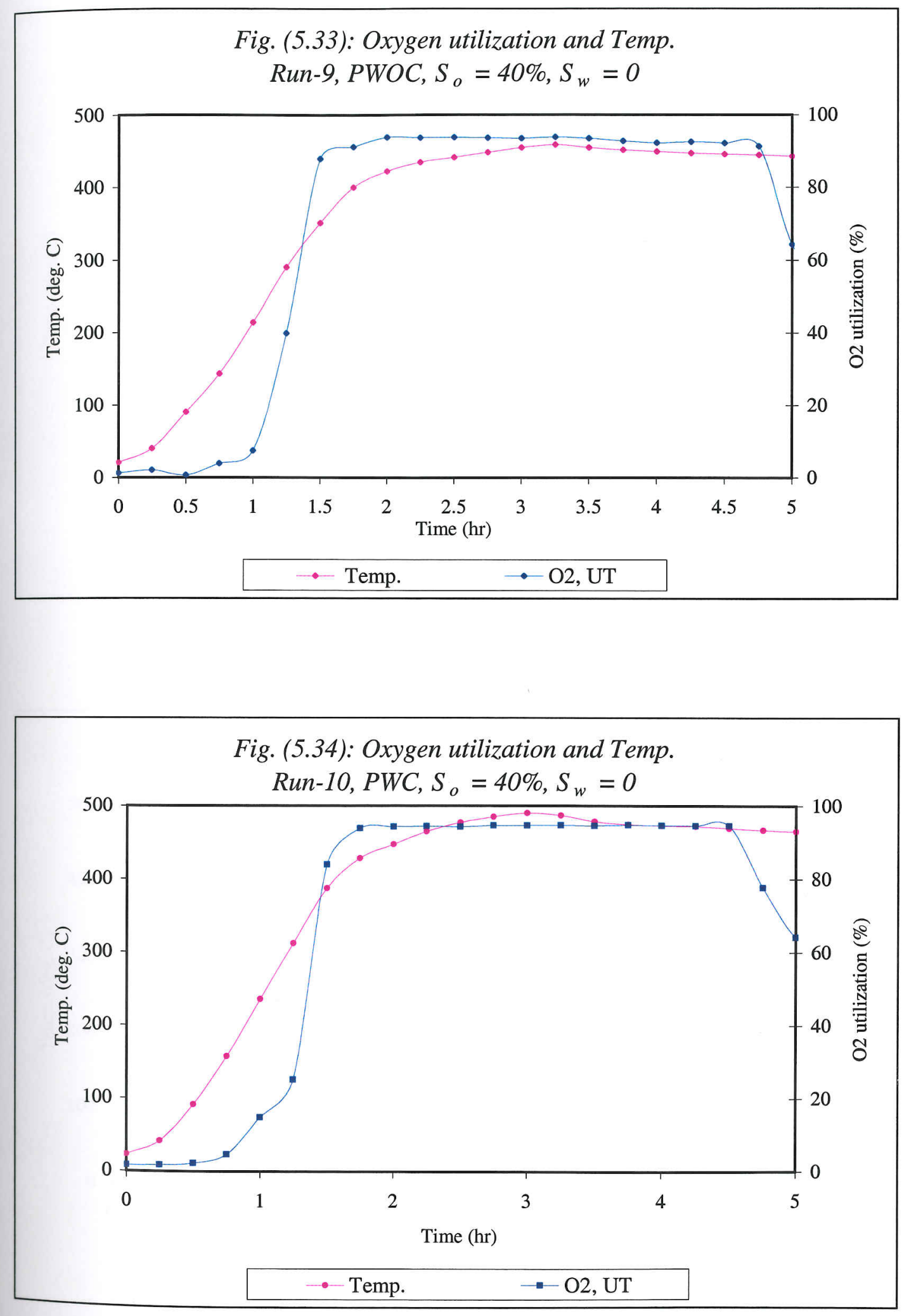

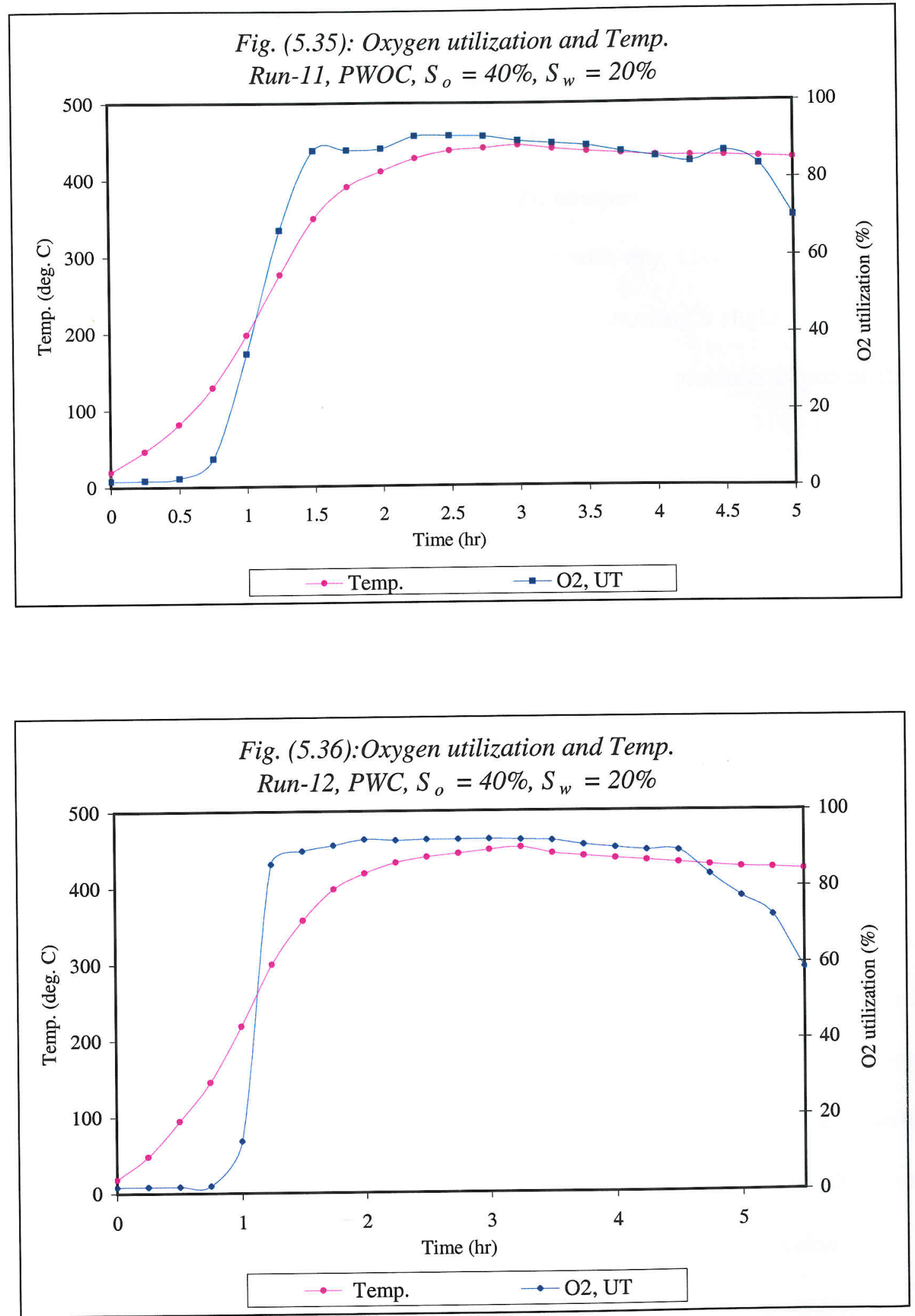
each experiment, but it reached much higher values as the combustion temperature increased. These values were almost constant during the stab:lised period (HTO region). The take-off of oxygen utilization was very rapid in both catalytic runs, especially for the combination of catalyst and water run (Run-12), compared with the non-catalytic experiments and started earlier in wet runs compared with dry. Oxygen utilization is high during dry combustion experiments, averaging 94\%, showing a slight decrease of about $4 \%$ during wet runs. Similar findings were observed in previous experiments, discussed in this Chapter.

\subsubsection{Air requirement}

The air requirement value for each experiment is included in Table 5.6. From this table, the air requirement of catalytic tests, Run-10 and Run-12 were 425 and $357.9 \mathrm{~m}^{3} / \mathrm{m}^{3}$, for dry and wet experiments respectively, while those for the non-catalytic tests, Run-9 and Run-10, were lower at 377.8 and $340 \mathrm{~m}^{3} / \mathrm{m}^{3}$ respectively. All these values are consistent with those reported in the literature, which range from 150 to $600 \mathrm{~m}^{3} / \mathrm{m}^{3}$ when air is the injecting gas, (Burger et al, 1985). It is clear that the air requirement of the catalytic runs is higher than that of the non-catalytic runs. This is due to the increase in fuel deposition, which needs a greater air requirement to consume it. Another finding observed was that less air was required during the wet combustion runs compared with dry ones, in both catalytic and non-catalytic runs. This may be because the high displacement efficiency provided by steam generated during the wet combustion. 


\subsubsection{Fuel consumption}

From Table 5.7, it can be noted that the fuel consumption values followed the same behavior as the air requirement values, as mentioned in the previous subsection. For catalytic runs, both dry and wet, the oil consumed as fuel was 16.29 and $15.83 \mathrm{~kg} / \mathrm{m}^{3}$ respectively, while that for non-catalytic runs was 14.84 and $14.25 \mathrm{~kg} / \mathrm{m}^{3}$ respectively. As can be noted; the fuel consumption values of catalytic runs are a little higher than those of non-catalytic runs. This is probably due to more coke deposits being present during the catalytic tests, i.e. the catalyst promotes coke formation. Also, slightly less fuel was consumed during wet experiments compared with dry experiments. That less fuel is consumed, in both non-catalytic and wet tests compared with catalytic and dry tests respectively, is confirmed by the higher oil recoveries achieved in the non-catalytic and wet tests.

\subsubsection{Produced oil}

The oil produced after each combustion run was collected for measuring its density and recovery factor. The oil production by in-situ combustion is a result of several processes such as pyrolysis, distillation and cracking that are governed by temperature. The combustion reaction commenced when the appropriate temperature was achieved.

In the catalytic experiments of this set, the produced oil was forced through the catalyst bed, which surrounded the perforated tube at high temperature, facilitating catalytic reactions to take place. As a result upgraded oil is produced due to the increase in the 
light products and decrease in heavy fractions. Heavy components such as asphaltenes are converted to coke, which is consumed in the combustion processes.

In this set of experiments, as can be seen from Table 5.7; the produced oil from noncatalytic tests (Run-9 and Run-11) was upgraded by $\sim 3$ and $5^{\circ} \mathrm{API}$, for dry and wet runs respectively due to thermal effects, as compared with original Clair crude oil (19.8 $\left.{ }^{\circ} A P I\right)$, while that produced from catalytic tests (Run-10 and Run-12) was upgraded much more by $\sim 8$ and $11^{\circ} \mathrm{API}$ for dry and wet runs respectively, due to both thermal and catalytic effects. From these results it is clear that the catalyst used does provide a quality improvement of the produced oil. Also, the presence of water is beneficial in improving the quality of the produced oil. The recovered oil for each combustion run was higher in the non-catalytic experiments because they consumed less fuel compared with that of catalytic, as can be seen in Table 5.7. Also, in the wet runs, the recovered oil was higher compared with dry runs. Similar behavior has been observed from the previous first mode experiments as noted earlier in this Chapter (see subsection 5.2.1.6).

\subsubsection{Comparison between first and second mode experiments}

Generally, in comparing the runs of second mode with the runs of first mode under the same conditions, for both catalytic and non-catalytic experiments and dry and wet conditions, similar behavior was observed. In the second mode (perforated tube) experiments, slightly higher oil was recovered from these experiments compared with the first mode. This slight increase in recovered oil might be due the placement of sample bed near the outlet of the tube compared with that in the first mode, which was placed at the middle part of combustion tube. On the other hand, almost the same degree 
of upgrading of the produced oil from both modes was observed, as can be seen in Table 5.8.

The oxygen utilization was high in both modes and averaged $\sim 89$ to $95 \%$, but it was slightly lower in the second mode.

Table 5.8: Comparison between mode I and mode II

\begin{tabular}{|c|c|c|c|c|c|c|c|c|}
\hline Mode & \multicolumn{4}{|c|}{ First mode } & \multicolumn{4}{|c|}{ Second mode } \\
\hline Experiment & Run-2 & Run-3 & Run-7 & Run-8 & Run-9 & Run-10 & Run-11 & Run-12 \\
\hline Oil saturation, $\mathrm{S}_{0} \%$ & 40 & 40 & 40 & 40 & 40 & 40 & 40 & 40 \\
\hline $\mathrm{H}_{2} \mathrm{O}$ saturation, $\mathrm{S}_{\mathrm{w}} \%$ & 0 & 20 & 0 & 20 & 0 & 0 & 20 & 20 \\
\hline Catalyst loading, gm & 0 & 0 & 5 & 5 & 0 & 5 & 0 & 5 \\
\hline Fuel consum., $\left(\left(\mathrm{kg} / \mathrm{m}^{3}\right)\right.$ & 17.2 & 16.7 & 23.57 & 21.85 & 14.84 & 16.29 & 14.25 & 15.83 \\
\hline Oxygen utilization, (\%) & 94.3 & 94.3 & 94.71 & 93.8 & 93.43 & 94.622 & 89.2 & 90.86 \\
\hline Oil recovery, (\%OOIP) & 67 & 70.5 & 61.32 & 67.15 & 71.30 & 64.50 & 74.33 & 69.65 \\
\hline API gravity, $\left({ }^{\circ} \mathrm{API}\right)$ & 22.8 & 24.8 & 27.13 & 29.21 & 23.12 & 27.9 & 25.32 & 30.76 \\
\hline
\end{tabular}




\subsection{Catalytic Life Tests (first mode, third set)}

In this set of experiments, four in-situ combustion catalytic runs were performed to investigate the activity of catalyst with time.

All four runs were conducted under the same experimental conditions as in previous runs, with the catalyst placed at the tube exit, but the same catalyst $(5 \mathrm{gm})$ was used in all four runs. After each experimental run, the catalyst was collected with care and weighed; it was then replaced and reused in the next run. All runs were conducted under dry conditions with an oil saturation of $40 \%$, and are designated as:

Run-13: WFC, $S_{\mathrm{o}} \quad=40 \%, S_{\mathrm{W}}=0$.

Run-14: WUC, $S_{\mathrm{o}}=40 \%, \mathrm{~S}_{\mathrm{w}}=0$.

Run-15: WRUC, $S_{o}=40 \%, S_{w}=0$.

Run-16: WRRUC, $S_{\mathrm{o}}=40 \%, \mathrm{~S}_{\mathrm{w}}=0$.

Where;

WFC $=$ with fresh catalyst.

WUC $=$ with used catalyst.

WRUC $=$ with reused catalyst.

WRRUC $=$ with re-reused catalyst.

The discussion of this set is focused on the coke deposition on the catalyst and the degree of produced oil upgrading.

Generally, the produced gas composition profiles tend to exhibit similar trends, as can be seen from close inspection of Figures 5.37 to 5.40 , in which the maximum temperature and the produced gas compositions are presented for Run-13 to Run-16. 
The duration of the combustion time was almost the same in all runs, due to the same common combustion parameters. Also, the CO level was a slightly higher, while that of $\mathrm{CO}_{2}$ was a slightly lower in Run-15 and Run-16 compared with Run-13 and Run-14. This might be due to a decrease of catalyst activity with time as can be seen in Figure 5.41

Figure 5.41 shows the results of coke deposition weight increase, based on the $5 \mathrm{gm}$ fresh catalyst used for first time in Run-13 (reused in the next runs as collected), alongside with the produced oil's API gravity, both for each run. From this Figure, it is clear that the coke deposition increased during the first two runs (Run-13 and Run-14) as expected at 16 and $20 \%$ by weight of the catalyst, after combustion times of 4.5 and 9 hrs respectively. This coke deposition was mirrored by a significant increase in the produced oil's API gravity as compared with the original Clair crude oil, which averaged $\sim 8^{\circ} \mathrm{API}$. This is a clear indication that the catalyst still retains a good activity after a total of 9 hrs combustion time. After 13.5 hrs (Run-15), a slight decline of both coke deposition and the produced oil's API gravity occurred. The same behavior was noted after 17.5 hrs (Run-16) with almost the same degree of decrease, as in Run-15. This is probably due to coke accumulated on the catalyst surface, from the first two runs (Run-13 and Run-14), which may limit the active sites of the catalyst, when used in the second two runs (Run-15 and Run-16). From these results, it is clear that the catalyst activity decreased with time, as can be observed in the slight reduction of API gravity for both the last runs. Another factor is that the catalyst used was initially pre-sulphided, which is a requirement for hydrogenation activity. In the absence of sufficient sulphur in the feed stream, it is possible that with time the carbon oxides produced and any 

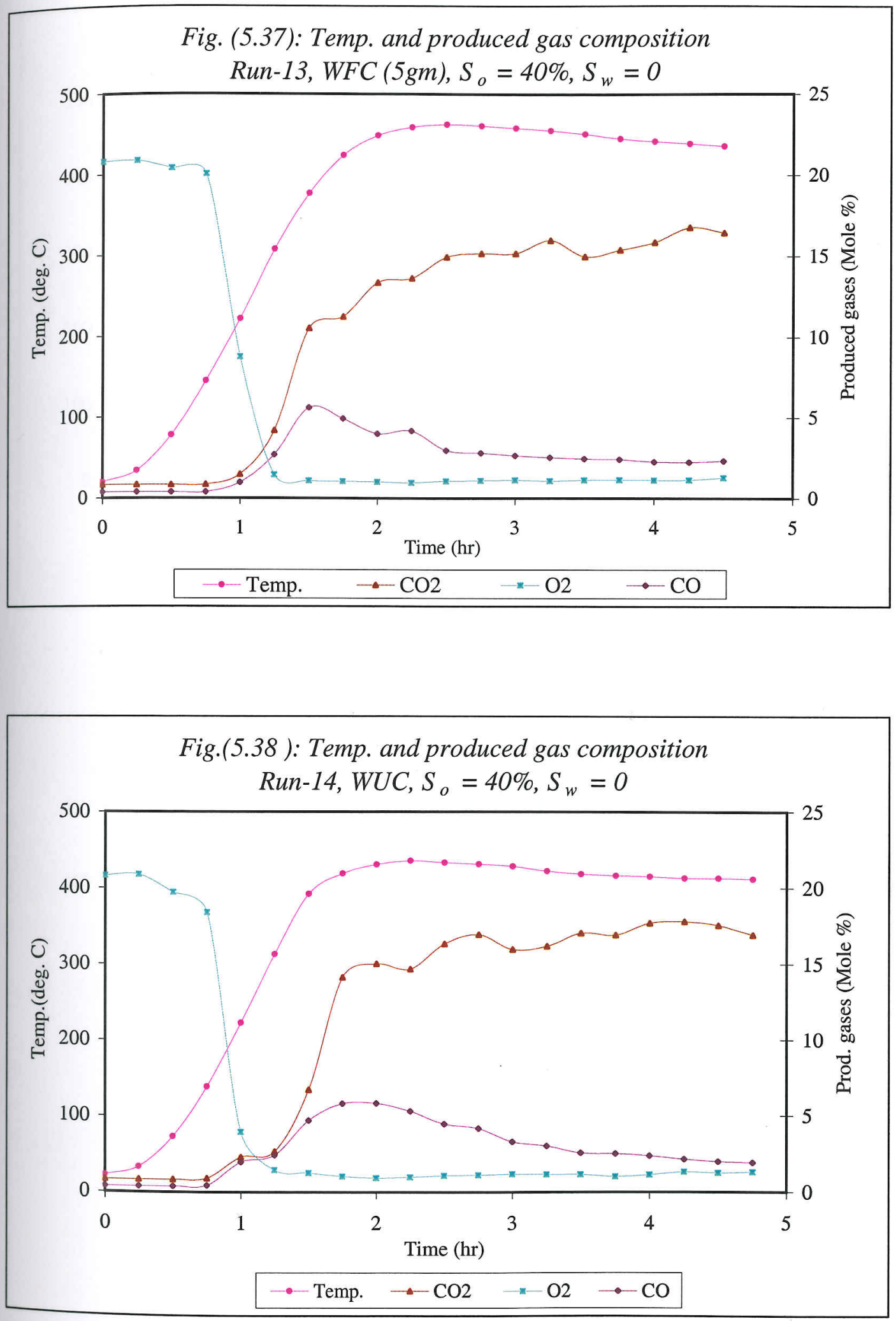

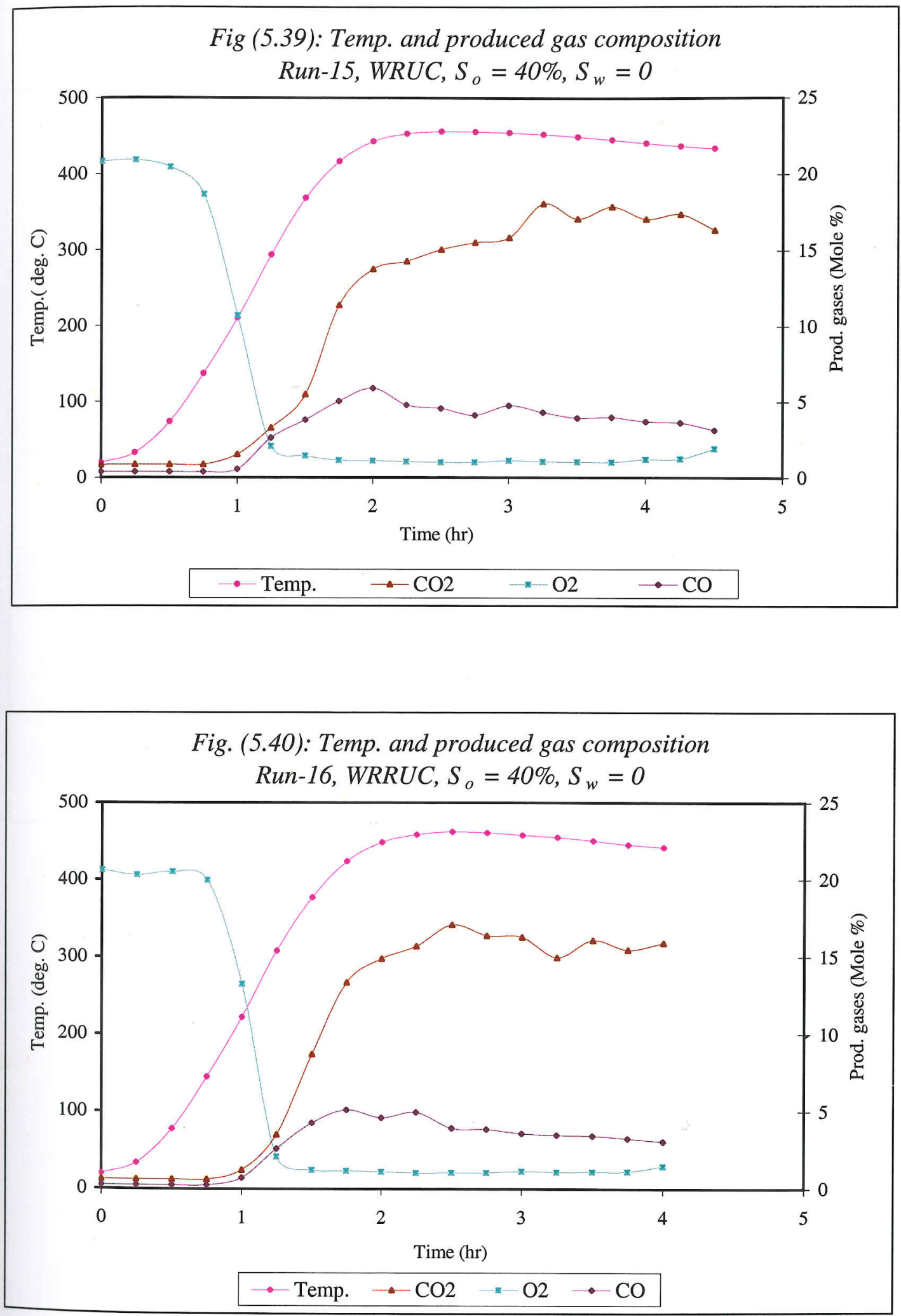


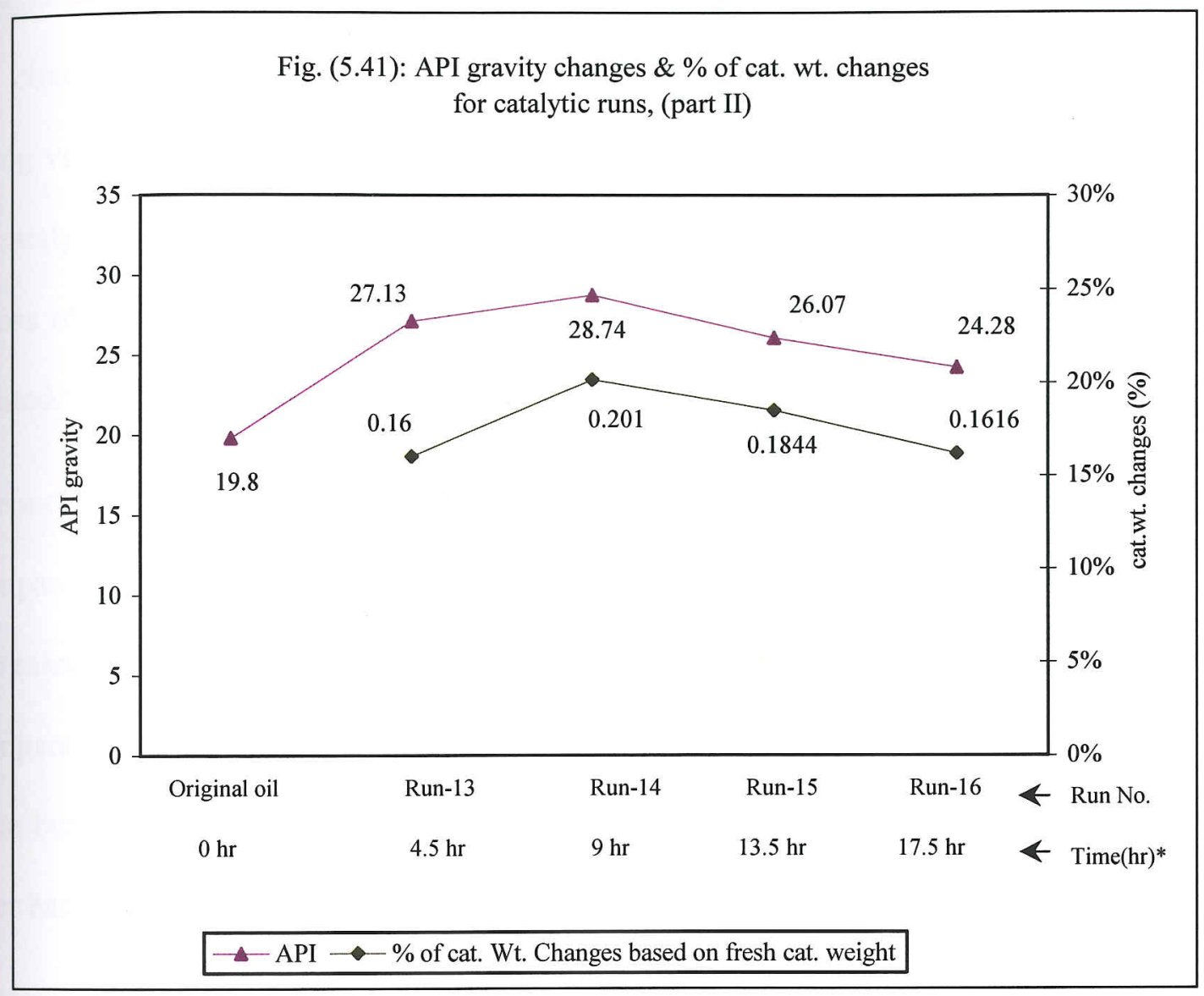


residual oxygen present could convert the sulphide form to oxide and thus reduce the catalyst activity. Also the weight of coke deposit decreased, which may be attributed to the change in its composition when used for longer periods, or to its light fractions being volatilized at high temperature. Xia and Greaves, $(2001$, a) reported that coking of catalyst could reduce its activity. Hughes et al, 1984 stated that most catalysts suffer a loss of activity with time on stream and the life of even the most robust catalyst is limited.

In conclusion, oil upgrading was achieved for all runs, ranging between $\sim 5$ to $9^{\circ} \mathrm{API}$ as compared with the original Clair oil value of $19.8^{\circ}$ API. The coke deposition was increased in the first two runs and decreased steadily in the third and fourth runs as compared to the original catalyst weight. The possible cause for this might be due to coke burning in the high temperature zone, which was present on the catalyst surface after each run. 


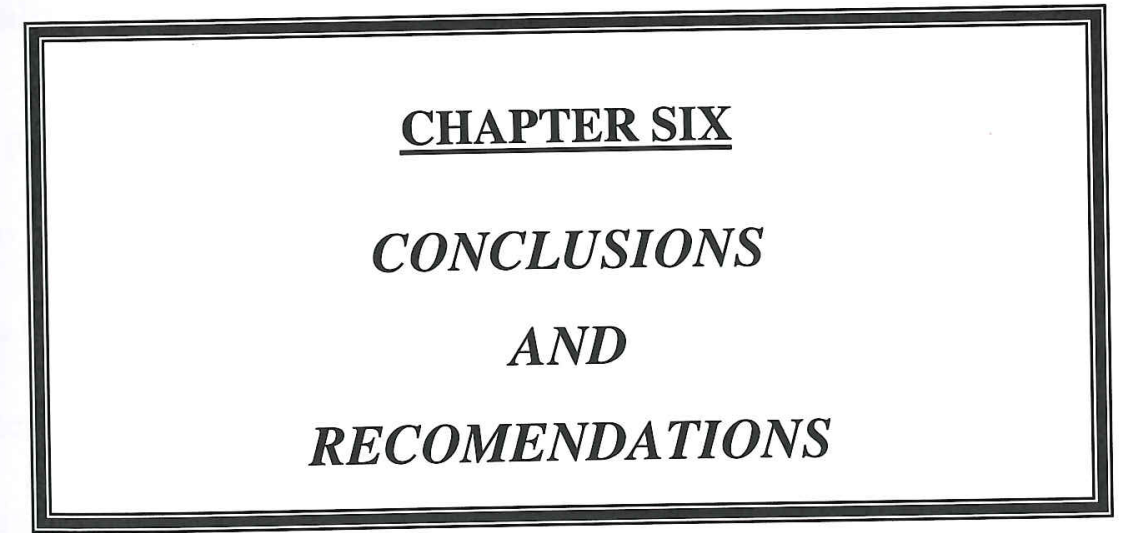




\subsection{CONCLUSIONS}

The in-situ combustion (ISC) experiments have been performed to investigate the criteria of thermo-catalytic upgrading of medium-heavy Clair crude oil $\left(19.8^{\circ} A P I\right)$, using a low-pressure combustion cell. Four series (four runs each) of experiments were conducted using a horizontal tube position. One of these series was conducted using a small perforated tube, which serves as a horizontal well. The experiments were performed for both catalytic and non-catalytic procedures and for both dry and wet combustion runs, using oil/sand mixtures (and water if required), subjected to a heating rate of $5^{\circ} \mathrm{C} / \mathrm{min}$ from room temperature up to $400^{\circ} \mathrm{C}$ and air injection with a flow rate of $250 \mathrm{ml} / \mathrm{min}$.

From the analysis of results obtained during the present work it can be concluded that:

\subsubsection{Centrally Packed Tube Position Experiments}

1. The produced oil from the non-catalytic experiments was thermally upgraded by $\sim 2$ to 5 points depending on the experimental conditions, whereas that produced from the catalytic experiments was much more upgraded, by $\sim 5$ to 10 points due to the combined effects of thermal and catalytic upgrading, as compared with the original Clair crude oil $\left(19.8^{\circ} \mathrm{AP}\right)$. The higher upgrading in the catalytic tests was achieved when more catalyst was loaded ( $5 \mathrm{gm}$ tests), which confirms that the presence and loading of catalysts are beneficial in improved the quality of the produced oil.

2. In contrast, the recovered oil from the catalytic experiments was lower than that recovered from the non-catalytic experiments. This is may be due to the high 
catalyst porosity, which enabled a considerable volume of oil to remain in the heated processing zone and not be produced.

3. The $\mathrm{H} / \mathrm{C}$ and molar ratio $\mathrm{CO} /\left(\mathrm{CO}+\mathrm{CO}_{2}\right)$ decrease with increase in temperature for all runs. The $\mathrm{H} / \mathrm{C}$ value was very high in the early stages of the combustion reaction and decreased as combustion temperature increased and reached the lowest value at the stablised period (HTO region) of the combustion process. The same behavior was noticed for the carbon oxides molar ratio. Its value was lower in the catalytic experiments, due to a lower level of $\mathrm{CO}$, which was mirrored by a higher level of $\mathrm{CO}_{2}$ compared with the non-catalytic runs. This confirms that the presence of catalyst promotes the water gas shift reaction by converting $\mathrm{CO}$ into $\mathrm{CO}_{2}$ and $\mathrm{H}_{2}$ in the presence of steam.

4. During wet combustion tests, for both catalytic and non-catalytic tests, a reduction in peak temperature was noticed and it was observed that the fuel consumption and air requirement were slightly lower, compared with dry forward combustion tests. However, they were slightly higher in the catalytic tests compared with the non-catalytic cases. Also, the recovered oil as a percentage of OIIP and the quality of the produced oil as measured by API gravity were slightly higher than those of the produced oil during dry combustion tests. It is clear that the presence of water improves the combustion processes.

5. From the results obtained from the catalytic tests, in Part II, the catalyst activity was observed to decrease with time. This is probably due to coke deposition on the catalyst surface. 


\subsubsection{Perforated Tube (horizontal producer well) Experiments}

The results obtained from this mode, which served as a horizontal well, followed the same behavior of the first mode, except that the oil recovered and the degree of produced oil upgrading were slightly higher. This could be caused by the location of the sample bed, which was now placed close to the outlet side of the combustion cell compared with that in mode I, when the sample bed was positioned in the centre of the combustion cell.

\subsection{RECOMMENDATIONS FOR FUTURE WORK}

The following recommendations for future work may be made based on the findings of the present study:

1. The present work has investigated the in-situ combustion of heavy-medium Clair crude oil. Hence future work should be consider crudes of higher gravity.

2. Further study should be made to investigate the effects of higher oil saturation.

3. This study has investigated the in-situ combustion process at relatively low pressure; the equipment should be modified for higher pressures.

4. In order to gain more detailed characterization of the produced oil, a SARA fractions analysis should be investigated.

5. In the first series of experiments, the produced oil passed through a long porcelain bead bed, before reaching the outlet production line, which gave a longer production time and thus affected the combustion performance; so a shorter bed of porcelain beads is required.

6. The effect of perforation hole size and density should be investigated. 
7. A complete analysis of the produced gas including hydrogen and hydrocarbons would be a very effective parameter to acquire more knowledge of the processes occurring, especially for the catalytic tests. 


\section{REFERENCES}


- Abu-Khamsin, S. A., Brigham, W. E. and Ramey, H. J.: "Reaction Kinetics of Fuel Formation for In-Situ Combustion". SPE Reservoir Eng., (Nov. 1988), p. 13081316.

- Aguilera, R., Artindale, J. S., Cordell, G. M., Ng, M. C., Nicholl, G. W. and Runions, G. A.: "Horizontal Wells: formation evaluation, drilling and production, including heavy oil recovery". Gulf Publishing Company, Houston, Texas, (1991).

- Ahner, P. F. and Sufi, A. H.: "Physical Model Steam-Flood Studies using Horizontal Wells". Paper SPE 20247, Presented at SPE/DOE $7^{\text {th }}$ symposium on EOR, Tulsa, (April 22-25, 1990).

- Alderman J. H. and Osoba, J. S.: “A Study of Oil Recovery by In-Situ Combustion with the Addition of Water". SPE 3684, Presented at the $42^{\text {nd }}$ Regional Meeting of SPE of AIME, Los Angeles, California, (Nov. 4-5, 1971).

- Alexander, J. D., Martin, W. L. and Dew, J. N.: "Factors Affecting Fuel Availability and Composition During In-Situ Combustion". J. Pet. Tech., Vol. 14, (Oct. 1962), p. 1154-1164.

- Al-Saffar, H., Price, D., Soufi, A. and Hughes, R.: "Distinguishing between Overlapping Low Temperature and High Temperature Oxidation Data obtained from a Pressurized Flow Reactor System using Consolidated Ccore Material”. Fuel 79 (2000), p. $723-732$.

- Al-Saghr, A. M.: "Three-Dimensional Physical Model Studies of Air Injection: 
In-Situ Combustion and Downhole Catalytic Upgrading using Horizontal Wells". Ph. D Thesis, University of Bath, (1998).

- Bagci, A. S.: "The Application of Dry and Wet Combustion on Limestone Containing Heavy Oils with the Analysis of Combustion Reactions Kinetics". Ph. D Thesis, Middle-East Technical University, Turkey, (1986).

- Bagci, A. S., Aybak, T. and Shamsul, A.: "The Performance of Steam Injection in Heavy Oil Reservoirs with Bottom Water Zone Employing Diverse Well Configurations". $7^{\text {th }}$ European Symposium on Improved Oil Recovery, Moscow, (27-29 Oct. 1993), Vol. 2, p. 185-197.

- Bagci, A. S. and Gumrah, F.: "An Examination of Steam Injection Processes in Horizontal and Vertical Wells for Heavy-Oil Recovery". J. of Pet. Science and Engineering, Vol. 8, (1992), p. 59-72.

- Boberg, T. C.: "Thermal Methods of Oil Recovery". An Exxon Monograph, John Wiley \& sons, New York, (1988).

- Bousaid, I. S. and Ramey, H. J. Jr.: “Oxidation of Crude Oil in Porous Media". Soc. Pet. Eng. J., Vol. 8, (June 1968), p. 137-148.

- Burger, J. G. and Sahuquet, B. C.: "Chemical Aspects of In-Situ Combustion - Heat of Combustion and Kinetics". Soc. Pet. Eng. J., Vol. 12, (Oct. 1972), p. 410-422.

- Burger, J., Saurieau, P. and Combarnous, M.: "Thermal Methods of Oil Recovery". Institute Francais du Petrole, (1985). 
- Castanier, L. M. and Brigham, W. E.: “Modifying In-Situ Combustion with Metallic Additives". In Situ 21, (1), (1997), p. 27-45.

- Dabbous, M. K.: "In-Situ Oxidation of Crude Oils in Porous Media". Ph.D. Thesis, University of Pittsburgh, (1971).

- Dabbous, M. K. and Fulton, P. F.: "Low-Temperature Oxidation Reaction Kinetics and Effects on the In-Situ Combustion Process". Soc. Pet. Eng. J., Vol. 14, (June 1974), p. 253-262.

- Dietz, D. N., and Weijdema, J.: "Wet and Partially Quenched Combustion". J. Pet. Tech., Vol. 20, (April 1968), p. 411-415.

- Drici, O. and Vossoughi, S.: "Catalytic Effect of Heavy Metal Oxides on Crude Oil Combustion”. SPE Res. Eng., (Nov. 1987), p. 591-595.

- Egbogah, E. O.: "EOR Target Oil and Techniques of its Estimation". J. of Pet. Science and Engineering, (Oct. 1994), p. 337-449.

- Fassihi, M. R. and Brigham, W. E.: "Analysis of Fuel Oxidation in In-Situ Combustion Oil Recovery". Stanford University, Petroleum Research Institute, Stanford, Ca. SUPRI TR-26, Report submitted to DOE, (June 1981).

- Fassihi, M. R., Brigham, W. E. and Ramey, H. J. Jr.: “Reaction Kinetics of In-Situ Combustion: part 1 - observations". Soc. Pet. Eng. J, Vol. 24, (Aug. 1984), p. 399407.

- Fassihi, M. R., Ramey, H. J. Jr. and Brigham, W. E.: "The Frontal Behaviour of an 
In-Situ Combustion". Paper SPE 8907, Presented at 50 ${ }^{\text {th }}$ Annual California Meeting, (April 9-11, 1980).

- Garon, A. M. and Wygal, R. J.: "A Laboratory Investigation of Fire-Water Flooding". Soc. Pet. Eng. J., Vol. 14, (Dec., 1974), p. 537-544.

- Gates, C. F. and Ramey, H. J., Jr.: "Field Result of South Belridge Thermal Recovery Experiment". Trans, AIME. 213, (1958), p. 236-244.

- Grant, B. F. and Szasz, S. E.: "Development of an Underground Heat Wave for Oil Recovery". J. Pet. Tech., (May 1954), p. 23-32.

- Greaves, M., Field, R. W. and Al-Shalabe, M. I.: "In-Situ Combustion Studies for North Sea Forties and Maya Crude Oils". Chem. Eng. Res. Des., Vol. 65, (Jan. 1987), p. $29-40$.

- $\quad$ Greaves, M., Field, R. W. and Adewusi, V. A.: "In-Situ Combustion Kinetics Studies of Medium Heavy Crude Oil”. Chem. Eng. Res. Des., Vol. 66, (July 1988), p. 328333.

- Greaves, M., Tuwil, A. A. and Bagci, A. S.: "Horizontal Producer Wells in In-Situ Combustion (ISC) Processes”. J. Can. Pet. Tech., Vol. 32, No. 4, (April 1993), p. 5867.

- Greaves, M. and Al-Shamali, O.: "In-Situ Combustion (ISC) Process using Horizontal Wells". J. Can. Pet. Tech., Vol. 35, No. 4, (April 1996), p. 49-55. 
- Greaves, M. and Xia, T.: "CAPRI-Downhole Catalytic Process for Upgrading Heavy Oil: produced oil properties and composition". CIPC Paper No. 2001-23, presented at the Petroleum Society's Canadian International Petroleum Conference 2001, Calgary, Canada, (June 12-14, 2001).

- Hardy, W. C., Fletcher, P. B., Shepard, J. C., Dittman, E. W. and Zadow, D. W.: "In-Situ Combustion in a Thin Reservoir Containing High-Gravity Oil". J. Pet. Tech., Vol. 24, (Feb. 1972), p. 199-208.

- Holm, L. W.: “Miscibility and Miscible Displacement”. J. Pet. Tech., Vol. 38, No. 9, (Aug. 1986), p. 817-818.

- Hughes, R.: "Deactivation of Catalyst". Department of Chemical Engineering, University of Salford, Salford, UK, (1984).

- Hughes, R., Kamath, V. M. and Price, D.: "Kinetics of In-Situ Combustion for Oil Recovery”. Chem. Eng. Res. Des., Vol. 65, (Jan. 1987), p. 23 - 28.

- Hughes, R., Kazi, R. Oklany, J. S. and Price, D.: "'The Effect of Formation Type on Fuel Oxidation Relevant to the In-Situ Combustion Process for the Recovery of Heavy Oil". Chem. E. meeting, Leeds, (April 2-3, 1996).

- Islam, M. R., Chakma, A. and Farouq Ali, S. M.: "State of the Art of In-Situ Combustion Modelling and Operations". Paper SPE 18755, Presented at SPE California Regional Meeting, Bakersfield, (April 5-7, 1989). 
- Jha, K. N. and Verkoczy, B.: "The Role of Thermal Analysis Techniques in the In-Situ Combustion Process". Paper SPE 12677, presented at $4^{\text {th }}$ Symposium on EOR, Tulsa, OK, (April 15-18, 1984).

- Johnson, H. S. and Bright, A.: "Upgrading of Heavy Hydro-carbonaceous Oil using Carbon Monoxide and Steam". Canadian patent 1, 195.639 to Golf Canada Limited, (Oct. 1985).

- Joshi, S. D.: "Augmentation of Well Productivity with Slant and Horizontal Wells". J. Pet. Tech., (June 1988), p. 729-739.

- Joshi, S. D.: “Thermal Oil Recovery with Horizontal Wells". J. Pet. Tech., Vol. 40, No. 6, (Nov. 1991), p. $1302-1304$.

- Kuhn, C. S. and Koch, R. L.: "In-Situ Combustion: Newest Method of Increasing Oil Recovery". Oil and Gas J., (Aug. 1953), Vol. 52, p. $92-114$.

- Kisler, J. P. and Shallcross, D. C.: "The Effect of Metallic Catalysts on Light-Crude Oil Oxidation". In-Situ, 20 (2), (1996), p. 137-160.

- Lerner, S. L., Fleming, G. C. and Lara, P. F.: "Dominant Processes in In-Situ Combustion of Light-Oil Reservoirs". J. Pet. Tech., Vol. 37, (May 1985), p. 889-900.

- Lin, C. Y., Chen, W. H., Lee, S. T. and Culham, W, E.: "Numerical Simulation of Combustion Tube Experiments and the Associated Kinetics of In-Situ Combustion Processes". Soc. Pet. Eng. J., (Dec. 1984), 657-666. 
- McNeil, J. S. and Moss, J. T.: "Three Ways to Improve Oil Recovery". Oil and Gas J., (Jan. 19, 1957), Vol. 57, No. 3, p. 91 - 97.

- Meyers, K. O., Fassihi, M. R. and Basile, P. F.: "Low-Temperature Oxidation of Viscous Crude Oils". Paper SPE 15648, Presented at the $61^{\text {st }}$ Annual Technical Conference and Exhibition of the SPE, New Orleans, LA. (Oct. $5-8,1986$ ).

- Moore, R. G.: "New Strategies of In-Situ Combustion". J. Can. Pet. Tech., (Dec. 1993), Vol. 32, No. 10, p. 11-13.

- Moore, R. G., Bennion, D. W., Ursenbach, M., Gie, D. and Millour, J. P.: "Experimental Basis for Extending the Oil Recovery/ volume burned methods to wet and superwet combustion”. J. Can. Pet. Tech., Vol. 27, No. 26, p. 24-32, (Nov. - Dec., 1988).

- Moore, R. G., Laurshen, C. J., Belgrave, J. D., Ursenbach, M. G., and Metha, S. A., "In-Situ Combustion in Canadian Heavy Oil Reservoirs". Fuel (1995), Volume 74, No. 8, p. 1169-1175.

- Moore, R. G., Laureshen, C. J., Metha, S. A., Ursenbach, M. G., Belgrave, J. D., Weissman, J. G. and Kessler, R. V.: "A Downhole Catalytic Upgrading Process for Heavy Oil using In-Situ Combustion”. J. Can. Pet. Tech., (1999), Vol. 38, No. 13, p. 1-8, Paper 96-72.

- Moore, R. G., Laureshen C. J., Belgrave, J. D., Ursenbach, M. G. and Mehta, S. A.: "In-Situ Combustion in Heavy Oil Reservoirs: problems and perspectives". In Situ, 21(1), 1997, p. $1-26$. 
- Moss, J. T. and Cady, G. V.: "Laboratory Investigation of the Oxygen Combustion Process for Heavy Oil Recovery". Paper SPE 10706 presented at SPE California Regional Meeting, San Francisco, (March 1982), p. 55-68.

- Nelson, T, W. and McNeil, J. S.: "How to Engineer an In-Situ Combustion Project". Oil and Gas j., Vol. 59, No. 23, (June 5, 1961), p. 58 - 65.

- Okandan, E.: “Heavy Crude Oil Recovery". Proceeding of NATO Advanced Study of Heavy Crude Oil Recovery, Ankara, Turkey, (June 1982).

- $\quad$ Ovalles, C., Filgueras, E., Morales, A., Rojas, I., Carlos de Jesus, J. and Berrios, I.: "Use of a Dispersed Molybdenum Catalyst and Mechanistic Studies for Upgrading Extra-Heavy Crude Oil Using Methane as Source of Hydrogen'. Energy and Fuels, (1998), Vol. 12, p. 379-385.

- Parrish, D. R. and Craig, F. F. Jr.: "Laboratory Study of a Combination of Forward Combustion and Waterflooding - The COFCAW Process". J. Pet. Tech., Vol. 21, (June, 1969), p. 753-761.

- Poettmann, F. H.: “Improved Oil Recovery". Interstate Oil Compact Commission, Oklahoma City, (March 1983).

- Prats, M.: “Thermal Recovery”. Monograph series, Soc. Pet. Eng., Vol. 7, (1982).

- $\quad$ Ranjbar, M.: "Improvement of Medium and Light Oil Recovery with Thermo-Catalytic In-Situ Combustion”. J. Can. Pet. Tech., Vol. 34, No. 8, (Oct. 1995), p. 25 - 30.

- Rashidi, F. and Bagci, A, S.: "Effect of Pressure and Clay Content on Combustion 
Kinetics of Heavy Oil in Limestone Medium". Heavy crude and tar sandsHydrocarbons for the $21^{\text {st }}$ century. $5^{\text {th }}$ Unitar conference, (April 4-9, 1991), p. 323327.

- Satman, A., Soliman, M. Y. and Brigham, W. E.: “A Recovery Correlation for Dry In-Situ Combustion Processes". SPE 7130, Presented at the California Regional Meeting of SPE of AIME, San Francisco, California, (April 12 -14, 1978).

- Schumacher, M. M.: "Enhanced Recovery of Residual and Heavy Oil". $2^{\text {nd }}$ edition, Noyes Data Corporation, New Jersey, USA, (1980).

- Shallcross, D. C., De Los Rios, C. F., Castanier, L. M. and Brigham, W. E.: "Modifying In-Situ Combustion Performance by the use of Water-Soluble Additives". SPE Reservoir Eng., (Aug. 1991), p. 287-294.

- Sheinman, A. B., Dubrovai, K. K., Sorokin, N. A., Charvigin, M. M., Zaks, S. L. and Zinchenko, K. F.: "Gasification of Crude Oil in Reservoir Sands-Part 1". Pet. Eng., (Dec. 1938), Vol. 10, p. $27-30$.

- Showalter, W. E.: "Combustion Drive Tests". Soc. Pet. Eng. J., Vol. 3, (March 1963), p. 53-60.

- Smith, F. W. and Perkins, T. K.: "Experimental and Numerical Simulation Studies of the Wet Combustion Recovery Process". J. Can. Pet. Tech., (July-Sept., 1973), p. 4454.

- Speight, J. G.: "The Chemistry and Technology of Petroleum". $2^{\text {nd }}$ edition, Marcel 
Decker, Inc., New York, (1991).

- Stapp, P. R.: “In-Situ Hydrogenation". National institute for Petroleum and Energy Research; IIT Research Institute, Bartlesville, OK, (1989), NIPER - 434.

- Tadema, H. J.: "Mechanism of Oil Production by Underground Combustion". Proc. of the $5^{\text {th }}$ World Petroleum Congress, New York, (1959), Section II, paper 22, p. 279287.

- Tadema, H. J., and Weijdema, J.: "Spontaneous Ignition of Oil Sands". Oil and Gas J., Vol. 68, No. 50, (Dec. 1970), p. 77- 80.

- Tanabe, K.: "Solid Acids and Bases - Their Catalytic Properties". Academic press, New York City, (1970) 2, p. 105 - 127.

- $\quad$ Terwilliger, P. L., Clay, R. R., Wilson, L. A. Jr. and Gonzales-Gerth, E.: “Fireflood of the $\boldsymbol{P}_{2-3}$ Sand Reservoir in the Miga Field of Eastern Venezuela". J. Pet. Tech., (Jan. 1975), p. 9-14.

- Thomas, G. W., Buthod, A. P. and Allag, O.: "An Experimental Study of the Kinetics of Dry Forward Combustion - Final Report”. Fossil Energy Report No. BETC-18201, US. D.O.E., (Feb. 1979).

- Turta, A.: "In-Situ Combustion from Pilot to Commercial Application". DOE/NIPER Symposium on In-Situ Combustion Practices - Past, Present and Future Application, Tulsa, (April 21-22, 1994). 
- Vossoughi, S., Willhite, G. P., Kritikos, W. P., Guvenir, I. M. and El Shoubary, Y.: "Automation of an In-Situ Combustion Tube and Study of the Effect of Clay on the InSitu Combustion Process". Soc. Pet. Eng. J., Vol. 22, (Aug. 1982), p. 493-502.

- Vossoughi, S., Willhite, G. P., El-Shoubary, Y. and Bartlett, G. W.: "Study of the Clay Effect on Crude Oil Combustion by Thermotgravimetry and Differential Scanning Calorimetry". J. Thermal Analysis, (1983), Vol. 27, p. 17-36.

- Vossoughi, S.: "TGA/DSC Techniques as Research Tools for the Study of the In-Situ Combustion Process". Thermo-Chemica Acta., 106, (1986), p. 63-69.

- Weijdema, J.: "Determination of the Oxidation Kinetics of the In-Situ Combustion Process". Report from Koninklijke/Shell, Expolriate En Produktic Laboratorium, Rijswijk, the Netherlands, (1968).

- Weissman, J. G., Kissler, R. V., Sawicki, R. A., Belgrave, J. D., Laureshen, C. J., Mehta, S. A., Moore, R. G. and Ursenbach, M. G.: "Down-hole Catalytic Upgrading of Heavy Crude Oil”. Energy and Fuels, (1996), 10, p. 883-889.

- Weisz, P. B. and Goodwin, R. B.: “Combustion of Carbonaceous Deposits within Porous Catalyst Particles, II Intrinsic During Rate”. J. of Catalyst, (1966), No. 6, p. 227-236.

- White, P. D.: “In-Situ Combustion Appraisal and Status". J. Pet. Tech., (Nov. 1985), p. $1943-1949$.

- Wilson, L. A., Reed, R. L., Clay, R. R. and Harrison, N. H.: "Some Effects of 
Pressure on Forward and Reverse Combustion”. Soc. Pet. Eng. J., (June 1963), p. $127-137$.

- Xia, T. X. and Greaves, M.: “3-D Physical Model Studies of Down-Hole Catalytic Upgrading of Wolf Lake Heavy Oil Using THAI". CIPC Paper No. 2001-17, Canadian International Petroleum Conference, Calgary, Canada, (June 12 - 14, 2001, a).

- Xia, T. X. and Greaves, M.: "Down-Hole Upgrading of Athabasca Tar Sand Bitumen using THAI-SARA Analysis". SPE 69693, presented at SPE international thermal operations and heavy oil symposium, Margarita Island, Venezuela, (March 12, 2001, b). 


\section{APPENDICES}




\section{Appendix-A: Calculation of experimental sample bed requirements}

The total volume of ISC tube, $V_{t}=\pi r^{2} L$

Where: $r$ : radius of $I S C$ tube $=2.65 \mathrm{~cm}$

$L:$ tube length $=53 \mathrm{~cm}$, Then, $V_{t}=1169 \mathrm{ml}$

Calculation of sand, oil and water requirements:

The bulk volume of sand mixture, $V_{b}=\pi r^{2} l$

Where: $r=$ the radius of sample bed, which is equal that of $I S C$ tube $=2.65 \mathrm{~cm}$

$\& l=$ the length of sample bed $=10 \mathrm{~cm}, V_{b}=221 \mathrm{ml}$

The pore volume of sand, $V_{p}=V_{b} * \varnothing$

Where, $\emptyset$ is the porosity, which depends on the type of sand used.

$\emptyset=36.53 \%$ (washed coarse silica sand, W50) \& density, $\rho=2534 \mathrm{~kg} / \mathrm{m}^{3}$

Then, $V_{p}=81 \mathrm{ml}, \quad$ The sand grain volume, $V_{s}=V_{b}-V_{p}=140 \mathrm{ml}$

Weight of sand $=V_{s}^{*} \rho_{s}=0.355 \mathrm{~kg}$

The preparation of sand packs with various saturations of oil and water.

$S_{o}=$ Oil saturation. $S_{w}=$ Water saturation. $V_{o}=$ Oil volume. $V_{w}=$ Water volume

$W_{o}=$ weight of oil.

Clair oil $\left(\mathrm{API}=19.8^{\circ}, \&\right.$ density $\left.=935 \mathrm{~kg} / \mathrm{m}^{3}\right)$ was used for all the experiments,

\section{Fluid saturations}

The oil or water saturation based the sand pore volume $\left(V_{p}=81 \mathrm{ml}\right)$

$S_{w}=0, V_{w}=0, S_{w}=20 \%, V_{w}=16 \mathrm{ml}$

$S_{o}=20 \%, V_{o}=16 \mathrm{ml}, S_{o}=40 \%, V_{o}=32 \mathrm{ml}$ 


\section{Appendix - B: Evaluation of combustion parameters}

Combustion parameters are calculated based on Burger et al (1985). The following results of combustion parameters are from $\mathbf{R} u n-3$, (the data are given in Appendix-C):

Sand weight, $g \quad=355$

Oil volume, $\mathrm{ml}=32$

Water volume, $\mathrm{ml}=16$

Density $\left(\mathrm{kg} / \mathrm{m}^{3}\right): \mathrm{N}_{2}=1.2507, \mathrm{O}_{2}=1.4289, \mathrm{CO}_{2}=1.9768$ and $\mathrm{CO}=1.2501$

Air injected period, $h r=5$

Air flow rate, $\mathrm{ml} / \mathrm{min}=250$

Volume of air injected $(l)=$ time*air flow rate

$$
=\operatorname{time}(h r) * 60(\mathrm{~min} / \mathrm{hr}) * 250(\mathrm{ml} / \mathrm{min}) / 1000(\mathrm{ml} / \mathrm{l})=75 l
$$

$\mathrm{N}_{2}$ injected $=75 * 0.79=59.25 l$

$\mathrm{O}_{2}$ injected $=75^{*} 0.21=15.75 \mathrm{l}$

Stablisid period calculation of combustion parameters:

The stablised period $=2.5 \mathrm{hr}$

Produced gas composition: mole fraction
$\mathrm{CO}_{2}=15.91 \%$
0.15111
$\mathrm{CO}=3.91 \%$
0.03714
$\mathrm{O}_{2}=1.21 \%$
0.01149
$\mathrm{N}_{2}=84.26 \%$
0.80026 
- $\mathrm{H} / \mathrm{C}$ ratio, $\mathrm{x}=\left(1.06-3.06 \mathrm{Y}_{\mathrm{CO}}-5.06\left(\mathrm{Y}_{\mathrm{CO} 2}+\mathrm{Y}_{\mathrm{O} 2}\right)\right) /\left(\mathrm{Y}_{\mathrm{CO} 2}+\mathrm{Y}_{\mathrm{CO}}\right)$

$$
=0.66
$$

- Carbon molar ratio, $\mathrm{m}=\mathrm{CO} /\left(\mathrm{CO}_{2}+\mathrm{CO}\right)=0.197$

- Air fuel requirement $(\mathrm{AFR})=\mathrm{mc}^{*}\left(\mathrm{~b} / \mathrm{Y}_{\mathrm{O} 2}\right) *(2-\mathrm{m}+\mathrm{x} / 2) /(12+\mathrm{x})$

Where,

$\mathrm{b}($ constant $)=11.82 \mathrm{sm}^{3} / \mathrm{kg}$

$\mathrm{Y}_{\mathrm{O} 2}=0.21$ (for air injection)

$\mathrm{mc}=$ mass of fuel burnt $(1 \mathrm{~kg}$ bases $)$

$\mathrm{x}=\mathrm{H} / \mathrm{C}$ ratio, $\mathrm{m}=$ carbon molar ratio, so:

$\mathrm{AFR}=56.3^{*}(2-\mathrm{m}+\mathrm{x} / 2) /(12+\mathrm{x})=9.46 \mathrm{sm}^{3} / \mathrm{kg}$ of fuel.

- Oxygen to fuel requirement $=0.21 * 9.46=2.0 \mathrm{sm}^{3} / \mathrm{kg}$ of fuel.

$\mathrm{O}_{2}$ injected at stablised period $=7.875 l$

$\mathrm{O}_{2}$ consumed $=7.875 * 0.198 / 0.21=7.425 l$

- Amount of fuel burnt $=\mathrm{O}_{2}$ cons. $/ \mathrm{O}_{2}$ to fuel requirement

$$
\begin{aligned}
& =7.425 /(1000 * 2)=0.00371 \mathrm{~kg} \text { of fuel } \\
& =12.3 \% \text { OOIP }
\end{aligned}
$$

- Fuel consumption $\left(\mathrm{kg} / \mathrm{m}^{3}\right)=$ fuel burned, $\mathrm{kg} /$ volume of burnt section, $\mathrm{m}^{3}$

(the volume of burnt section is based on the assumption that all the samole has been burnt is equal with sample volume, which is $\left.=\pi / 4 D^{2} L=(221)^{-6} \mathrm{~m}^{3}\right)$.

- Fuel consumption $=16.79 \mathrm{~kg} / \mathrm{m}^{3}$

- Water produced by combustion reaction

$$
=(\text { mole of CO prd } / \mathrm{m}) *(\mathrm{x} / 2) * 18 * 0.001=0.00112 \mathrm{~kg}
$$


- Air requirement fuel $=$ air flux/combustion front velocity

$$
=\left(6.8 \mathrm{sm}^{3} / \mathrm{m}^{2} \mathrm{hr}\right) /(0.03 \mathrm{~m} / \mathrm{hr})=272 \mathrm{sm}^{3} / \mathrm{m}^{3}
$$

\section{Mass calculation}

Gas phase,

- $\mathrm{N}_{2}$ balance,

$$
\begin{array}{ll}
\mathrm{N}_{2} \text { injected, } \mathrm{kg} & =0.07040 \\
\mathrm{~N}_{2} \text { produced, } \mathrm{kg} & =0.07488 \\
\text { Balance } & =5.98 \%
\end{array}
$$

- $\mathrm{O}_{2}$ balance,

$$
\begin{array}{ll}
\mathrm{O}_{2} \text { injected, } \mathrm{kg} & =0.02138 \\
\mathrm{O}_{2} \text { produced, } \mathrm{kg} & =0.00626 \\
\mathrm{O}_{2} \text { consumed, } \mathrm{kg} & =0.01476 \\
\text { Balance } & =0 \%
\end{array}
$$

- Overall gas balance

$\begin{array}{ll}\mathrm{N}_{2} \text { injected, } \mathrm{kg} & =0.07040 \\ \mathrm{O}_{2} \text { injected, } \mathrm{kg} & =0.02138 \\ \text { Total, } \mathrm{kg} & =0.09178\end{array}$

Produced gas:
$\mathrm{N}_{2}$ produced, $\mathrm{kg}$
$=0.07488$
$\mathrm{O}_{2}$ produced, $\mathrm{kg}$
$=0.00662$
$\mathrm{CO}_{2}$ produced, $\mathrm{kg}$
$=0.01362$ 


$\begin{array}{ll}\text { CO produced, } \mathrm{kg} & =0.00263 \\ \text { Total, } \mathrm{kg} & =0.09775 \\ \text { Balance } & =6.5 \%\end{array}$

Liquid phase

- Oil ablance
OIIP, $\mathrm{kg}$
$=0.030$

Recovered oil, kg

$=0.0204$

Consumed oil as fuel, $\mathrm{kg}=0.0037$

$\begin{array}{lll}\text { Residual oil left, } \mathrm{kg} & =0.0033 \quad \text { (on porcelain beads) } \\ \text { Total oil prod., } \mathrm{kg} & =0.0274 \\ \text { Balance } & =-8.6 \%\end{array}$

- Water balance

Intial water in sand pack, $\mathrm{kg} \quad=0.016$

Water generated by reaction, $\mathrm{kg}=0.0011$

(referred to water produced during reaction)

total water in sand pack, $\mathrm{kg} \quad=0.0171$

Water prod., $\mathrm{kg} \quad=0.0185$

Residual water, $\mathrm{kg}=$ non

Balance $\quad=8.19 \%$

- Overall liquid balance

Initial oil in sand pack, $\mathrm{kg} \quad=0.03$

Initial water in sand pack, $\mathrm{kg} \quad=0.016$ 
Water generated by reaction, $\mathrm{kg}=0.0011$

Total, kg $=0.0471$

Prod. oil, kg $=0.0204$

Consumed oil as fuel, $\mathrm{kg}=0.0037$

Residual oil left $=0.0033$

Prod. water, kg $=0.0185$

Total $=0.0459$

Balance $=-2.5 \%$

- Overall material balance

Material in = material out

(Overall gas + overall liquid $)$ in $=($ overall gas + liquid $)$ out

$(0.09178+0.0471)$

$$
=(0.09775+0.0459)
$$

0.13888

0.14365

Balance $=[(0.14265-0.13888) / 0.13888]^{*} 100=2.7 \%$ 


\section{Appendix-C: Experimental data}

Experimental data: Run-1, $H W O C, S_{o}=20 \%, S_{w}=0$

\begin{tabular}{|c|c|c|c|c|c|c|c|c|c|c|}
\hline \multirow{2}{*}{$\begin{array}{l}\text { Reaction } \\
\text { time, hr }\end{array}$} & \multicolumn{4}{|c|}{ Area count } & \multirow[t]{2}{*}{ Temp. C } & \multicolumn{5}{|c|}{ Mole \% } \\
\hline & $\mathrm{CO}_{2}$ & $\mathrm{O}_{2}$ & $\mathrm{CO}$ & $\mathrm{N}_{2}$ & & $\mathrm{CO}_{2}$ & $\mathrm{O}_{2, \text { Prod. }}$ & $\mathrm{O}_{2, \text { cons. }}$ & $\mathrm{CO}$ & $\mathrm{N} 2$ \\
\hline 0 & 35333 & 2358211 & 0 & 9319999 & 20 & 0.4602 & 20.6684 & 0.3316 & 0.0390 & 79.3164 \\
\hline 0.25 & 37107 & 2369988 & 0 & 9299810 & 37 & 0.4740 & 20.7723 & 0.2277 & 0.0390 & 79.1545 \\
\hline 0.5 & 30331 & 2353594 & 0 & 9369150 & 82 & 0.4214 & 20.6277 & 0.3723 & 0.0390 & 79.7106 \\
\hline 0.75 & 5984 & 2316100 & 0 & 9849345 & 147 & 0.2324 & 20.2970 & 0.7030 & 0.0390 & 83.5617 \\
\hline 1 & 23218 & 2157407 & 17142 & 9905951 & 211 & 0.3662 & 18.8973 & 2.1027 & 0.1434 & 84.0157 \\
\hline 1.25 & 211698 & 878487 & 220629 & 10781698 & 271.5 & 1.8288 & 7.6173 & 13.3827 & 1.3826 & 91.0392 \\
\hline 1.5 & 637525 & 175793 & 422990 & 10641447 & 337 & 5.1332 & 1.4195 & 19.5805 & 2.6150 & 89.9144 \\
\hline 1.75 & 1252014 & 132709 & 576913 & 10317424 & 387.3 & 9.9016 & 95 & 19.9605 & 3.5524 & 87.3157 \\
\hline 2 & 1714345 & 124654 & 676966 & 9814056 & 422.5 & 13.4893 & 0.9684 & 20.0316 & 4.1617 & 83.2787 \\
\hline 2.25 & 1834699 & 119767 & 708004 & 9449448 & 443.1 & 14.4233 & 0.9253 & 20.0747 & 4.3507 & 80.3546 \\
\hline 2.5 & 1924743 & 117382 & 725246 & 9283599 & 453.8 & 15.1220 & 0.9043 & 20.0957 & 4.4557 & 79.0245 \\
\hline 2.75 & 1928704 & 121182 & 645372 & 9558735 & 459.7 & 15.1527 & & 20.0622 & 3.9693 & 81.2311 \\
\hline 3 & 2047399 & 118018 & 568821 & 9782213 & 460.3 & 16.0738 & 0.9099 & 20.0901 & 3.5031 & 83.0233 \\
\hline 3.25 & 1908342 & 120524 & 621926 & 9830556 & 456 & 14.9947 & 0.9320 & 20.0680 & 3.8265 & 83.4111 \\
\hline 3.5 & 1957205 & 120015 & 609374 & 9787495 & 450.4 & 15.3739 & 0.9275 & 20.0725 & 3.7501 & 83.0657 \\
\hline 3.75 & 1976513 & 122587 & 478296 & 9692167 & 445.6 & 15.5237 & 0.9502 & 20.0498 & 2.9518 & 82.3012 \\
\hline 4 & 1082285 & 1012532 & 322012 & 9432278 & 441.1 & 8.5845 & 8.7995 & 12.2005 & 2.0001 & 80.2169 \\
\hline 4.25 & 423118 & 1725229 & 123954 & 9091596 & 436.2 & 3.4694 & 15.0855 & 5.9145 & 0.7939 & 77.4846 \\
\hline 4.5 & 209933 & 2094766 & 77532 & 9904921 & 431.7 & 1.8151 & 18.3448 & 2.6552 & 0.5112 & 84.0075 \\
\hline 4.75 & 166852 & 2108154 & 70760 & 9828415 & 428 & 1.4808 & 18.4629 & 2.5371 & 0.4699 & 83.3939 \\
\hline 5 & 149517 & 2196823 & 61175 & 10113422 & 425 & 1.3463 & 19.2450 & 1.7550 & 0.4116 & 85.6796 \\
\hline
\end{tabular}


Experimental data: Run-2, $H W O C, S_{o}=40 \%, S_{w}=0$

\begin{tabular}{|c|c|c|c|c|c|c|c|c|c|c|}
\hline \multirow{2}{*}{$\begin{array}{l}\text { Reaction } \\
\text { time, } \mathrm{hr}\end{array}$} & \multicolumn{4}{|c|}{ Area count } & \multicolumn{3}{|c|}{ Temp. } & \multicolumn{5}{|c|}{ Mole $\%$} \\
\cline { 9 - 12 } & $\mathrm{CO}_{2}$ & $\mathrm{O}_{2}$ & $\mathrm{CO}$ & $\mathrm{N}_{2}$ & & $\mathrm{CO}_{2}$ & $\mathrm{O}_{2, \text { Prod. }}$ & $\mathrm{O}_{2, \text { cons. }}$ & $\mathrm{CO}$ & $\mathrm{N} 2$ \\
\hline 0 & 5633 & 2506039 & 0 & 9516945 & 19 & 0.2301 & 20.8780 & 0.1220 & 0.0390 & 80.8959 \\
\hline 0.25 & 5198 & 2501771 & 0 & 9799584 & 31.3 & 0.2266 & 20.8427 & 0.1573 & 0.0390 & 83.1627 \\
\hline 0.5 & 6472 & 2475594 & 0 & 9399863 & 70.3 & 0.2366 & 20.6259 & 0.3741 & 0.0390 & 79.9569 \\
\hline 0.75 & 7916 & 2325550 & 0 & 9292029 & 130.5 & 0.2479 & 19.3836 & 1.6164 & 0.0390 & 79.0921 \\
\hline 1 & 45261 & 1824264 & 36783 & 10260814 & 201.6 & 0.5399 & 15.2329 & 5.7671 & 0.2630 & 86.8617 \\
\hline 1.25 & 250634 & 539190 & 257468 & 10991891 & 269.7 & 2.1460 & 4.5925 & 16.4075 & 1.6070 & 92.7250 \\
\hline 1.5 & 639981 & 150141 & 446896 & 11034348 & 335.7 & 5.1907 & 1.3712 & 19.6288 & 2.7606 & 93.0655 \\
\hline 1.75 & 1205860 & 131891 & 580867 & 10376623 & 381.6 & 9.6158 & 1.2201 & 19.7799 & 3.5765 & 87.7905 \\
\hline 2 & 1587291 & 122914 & 687217 & 9762259 & 417.9 & 12.5986 & 1.1457 & 19.8543 & 4.2242 & 82.8633 \\
\hline 2.25 & 1842616 & 119503 & 784432 & 9433053 & 439.9 & 14.5953 & 1.1175 & 19.8825 & 4.8162 & 80.2231 \\
\hline 2.5 & 1937666 & 116273 & 857761 & 9547938 & 452.3 & 15.3385 & 1.0907 & 19.9093 & 5.2628 & 81.1445 \\
\hline 2.75 & 1933104 & 113307 & 815202 & 9517485 & 460 & 15.3029 & 1.0662 & 19.9338 & 5.0036 & 80.9002 \\
\hline 3 & 1989105 & 112335 & 815414 & 9584453 & 461.6 & 15.7408 & 1.0581 & 19.9419 & 5.0049 & 81.4373 \\
\hline 3.25 & 2056539 & 114175 & 780645 & 9839127 & 461.8 & 16.2681 & 1.0734 & 19.9266 & 4.7931 & 83.4798 \\
\hline 3.5 & 2032440 & 114697 & 705645 & 9874408 & 459.4 & 16.0797 & 1.0777 & 19.9223 & 4.3364 & 83.7628 \\
\hline 3.75 & 2197164 & 115474 & 652870 & 10324730 & 456.1 & 17.3678 & 1.0841 & 19.9159 & 4.0150 & 87.3743 \\
\hline 4 & 2048842 & 122449 & 673933 & 9874478 & 452 & 16.2079 & 1.1419 & 19.8581 & 4.1433 & 83.7633 \\
\hline 4.25 & 2107763 & 119464 & 648429 & 9932941 & 447.9 & 16.6687 & 1.1172 & 19.8828 & 3.9879 & 84.2322 \\
\hline 4.5 & 1919242 & 253205 & 586303 & 9764578 & 444.1 & 15.1945 & 2.2245 & 18.7755 & 3.6096 & 82.8819 \\
\hline 4.75 & 953005 & 957232 & 372513 & 9692531 & 440.8 & 7.6385 & 8.0539 & 12.9461 & 2.3076 & 82.3041 \\
\hline
\end{tabular}


Experimental data: Run-3, HWOC, $S_{o}=40 \%, S_{w}=20 \%$

\begin{tabular}{|c|c|c|c|c|c|c|c|c|c|c|}
\hline \multirow{2}{*}{$\begin{array}{l}\text { Reaction } \\
\text { time, } \mathrm{hr}\end{array}$} & \multicolumn{4}{|c|}{ Area count } & \multirow[t]{2}{*}{ Temp. C } & \multicolumn{5}{|c|}{ Mole \% } \\
\hline & $\mathrm{CO}_{2}$ & $\mathrm{O}_{2}$ & $\mathrm{CO}$ & $\mathrm{N}_{2}$ & & $\mathrm{CO}_{2}$ & $\mathrm{O}_{2, \text { Prod. }}$ & $\mathrm{O}_{2, \text { cons. }}$ & $\mathrm{CO}$ & N2 \\
\hline 0 & 5878 & 2912654 & 0 & 11115478 & 20.7 & 0.8330 & 20.8092 & 0.1908 & 0.3800 & 81.6226 \\
\hline 0.25 & 5684 & 07263 & 0 & 1201888 & & 8314 & 20.7708 & 0.2292 & 0.3800 & 82.2231 \\
\hline 0.5 & 5789 & 2899987 & 0 & 11293151 & 74.7 & 0.8323 & 20.7189 & 0.2811 & 0.3800 & 82.8574 \\
\hline 0.75 & 8425 & 2745841 & 0 & 11420576 & 133.8 & 0.8533 & 19.6198 & 1.3802 & 0.3800 & 83.7430 \\
\hline 1 & 49833 & 2061907 & 44555 & 30616 & & 1.1842 & 14.7434 & 6.2566 & 0.6513 & 85.2028 \\
\hline 1.25 & 117992 & 1362169 & 150808 & 12129609 & 288.4 & 1.7288 & 9.7543 & 11.2457 & 1.2984 & 88.6708 \\
\hline 1.5 & 235181 & 674137 & 294101 & 13220564 & 365 & 2.6651 & 4.8486 & 16.1514 & 2.1711 & 96.2529 \\
\hline 1.75 & 699215 & 285199 & 561915 & 12236833 & 411.7 & 6.3727 & 2.0755 & 18.9245 & 3.8021 & 89.4160 \\
\hline 2 & 1607984 & 140464 & 810168 & 11911266 & 437.7 & 13.6338 & 1.0435 & 19.9565 & 5.3139 & 87.1533 \\
\hline 2.25 & 1715231 & 142880 & 958184 & 11619152 & 444.2 & 14.4907 & 1.0607 & 19.9393 & 6.2153 & 85.1231 \\
\hline 2.5 & 41935 & 139269 & 924281 & 11840519 & 444 & 15.5031 & 1.0350 & 19.9650 & 6.0089 & 86.6616 \\
\hline 2.75 & 1906578 & 140456 & 870486 & \begin{tabular}{|l|}
11576715 \\
\end{tabular} & 440.3 & 16.0196 & 1.0435 & 19.9565 & 5.6813 & 84.8282 \\
\hline 3 & 2040627 & 118878 & 722025 & 11749054 & 435.3 & 17.0906 & 0.8896 & 20.1104 & 4.7771 & 86.0259 \\
\hline 3.25 & 2012179 & 142861 & 800286 & 11862336 & 430.1 & 16.8633 & 1.0606 & 19.9394 & 5.2537 & 86.8132 \\
\hline 3.5 & 1896017 & 146164 & 720280 & 11522507 & 425 & 15.9352 & 1.0841 & 19.9159 & 4.7665 & 84.4514 \\
\hline 3.75 & 1887116 & 141967 & 695461 & \begin{tabular}{|l|}
11592210 \\
\end{tabular} & 422.3 & 15.8641 & 1.0542 & 19.9458 & 4.6154 & 84.9359 \\
\hline 4 & 1878787 & 157725 & 709881 & 11604366 & 420 & 15.7975 & 1.1666 & 19.8334 & 4.7032 & 85.0203 \\
\hline 4.25 & 1858649 & 204592 & 710426 & 11562570 & 418 & 15.6366 & 1.5007 & 19.4993 & 4.7065 & 84.7299 \\
\hline 4.5 & 1451878 & 285199 & 630582 & 9753 & 417 & 12.3865 & 2.0755 & 18.9245 & 4.2202 & 72.1569 \\
\hline 4.75 & 985101 & 674137 & 422339 & 9208516 & 416 & 8.6570 & 4.8486 & 16.1514 & 2.9520 & 68.3692 \\
\hline 5 & 603319 & 1362169 & 220615 & 9771665 & 415 & 5.6065 & 9.7543 & 11.2457 & 1.7235 & 72.2831 \\
\hline 5.25 & 241519 & 2061907 & 102683 & 9655545 & 413 & 2.7157 & 14.7434 & 6.2566 & 1.0053 & 71.4760 \\
\hline 5.5 & 148451 & 2445841 & 65583 & 9552059 & 411 & 1.9721 & 17.4808 & 3.5192 & 0.7794 & 70.7568 \\
\hline 5.75 & 115784 & 2745841 & 50745 & 9698941 & 411 & 1.7111 & 19.6198 & 1.3802 & 0.6890 & 71.7776 \\
\hline 6 & 67877 & 2745841 & 33481 & 9641835 & 411 & 1.3283 & 19.6198 & 1.3802 & 0.5839 & 71.3808 \\
\hline
\end{tabular}


Experimental data: Run-4, $H W O C, S_{o}=40 \%, S_{w}=0, A F R=375 \mathrm{ml} / \mathrm{min}$

\begin{tabular}{|c|c|c|c|c|c|c|c|c|c|c|}
\hline \multirow{2}{*}{$\begin{array}{l}\text { Reaction } \\
\text { time, } \mathrm{hr}\end{array}$} & \multicolumn{4}{|c|}{ Area count } & \multirow[t]{2}{*}{ Temp. C } & \multicolumn{5}{|c|}{ Mole \% } \\
\hline & $\mathrm{CO}_{2}$ & $\mathrm{O}_{2}$ & $\mathrm{CO}$ & $\mathrm{N}_{2}$ & & $\mathrm{CO}_{2}$ & $\mathrm{O}_{2, \text { Prod. }}$ & $\mathrm{O}_{2, \text { cons. }}$ & $\mathrm{CO}$ & $\mathrm{N} 2$ \\
\hline 0 & 7094 & 2925458 & & 11711936 & 20.5 & 0.8427 & 20.9005 & 0.0995 & 0.3800 & 85.7680 \\
\hline 0.25 & 7445 & 2884068 & & 11229190 & 34.9 & 0.8455 & 20.6054 & 0.3946 & 0.3800 & 82.4129 \\
\hline 0.5 & 6770 & 2901548 & & 11854985 & 81.5 & 0.8401 & 20.7300 & 0.2700 & 0.3800 & 86.7621 \\
\hline 0.75 & 11867 & 2081100 & & 11853701 & 148 & 0.8808 & 14.8802 & 6.1198 & 0.3800 & 86.7532 \\
\hline 1 & 108692 & 1074195 & & 13127463 & 226 & 1.6544 & 7.7010 & 13.2990 & 0.3800 & 95.6059 \\
\hline 1.25 & 540958 & 235705 & 119022 & 13104146 & 314.8 & 5.1083 & 1.7226 & 19.2774 & 1.0037 & 95.4438 \\
\hline 1.5 & 1500294 & 2219 & 466731 & 12840314 & 390 & 12.7733 & 1.2699 & 19.7301 & 2.8257 & 93.6102 \\
\hline 1.75 & 1689790 & 161422 & 978645 & 12039352 & 437.7 & 14.2874 & 1.1929 & 19.8071 & 5.5081 & 88.0435 \\
\hline 2 & 1856991 & 156616 & 1016166 & 11997987 & 453.5 & 15.6234 & 1.1587 & 19.8413 & 5.7047 & 87.7560 \\
\hline 2.25 & 2021978 & 153085 & \begin{tabular}{|l|}
1075239 \\
\end{tabular} & 13249040 & 454.3 & 16.9416 & 1.1335 & 19.8665 & 6.0143 & 96.4508 \\
\hline 2.5 & 2038177 & 152493 & 1041801 & 12842361 & 450 & 17.0710 & 1.1293 & 19.8707 & 5.8390 & 93.6244 \\
\hline 2.75 & 1951275 & 156630 & 903964 & 11659521 & 445.6 & 16.3767 & 1.1588 & 19.8412 & 5.1168 & 85.4037 \\
\hline 3 & 2042709 & 206735 & 915928 & 12496559 & 440.6 & 17.1072 & 1.5160 & 19.4840 & 5.1795 & 91.2211 \\
\hline 3.25 & 1422239 & 595442 & 723825 & 12627555 & 436.7 & 12.1497 & 4.2875 & 16.7125 & 4.1728 & 92.1315 \\
\hline 3.5 & 839906 & 1285412 & 488531 & 12557180 & 432.2 & 7.4968 & 9.2070 & 11.7930 & 2.9399 & 91.6424 \\
\hline 3.75 & 680326 & 1818349 & 426735 & 12101946 & 427.9 & 6.2218 & 13.0068 & 7.9932 & 2.6161 & 88.4785 \\
\hline 4 & 455954 & 2189103 & 232451 & 11994937 & 423.6 & 4.4291 & 15.6503 & 5.3497 & 1.5980 & 87.7348 \\
\hline 4.25 & 399564 & 2495330 & 201065 & 11815995 & 419.6 & 3.9785 & 17.8337 & 3.1663 & 1.4336 & 86.4912 \\
\hline 4.5 & 255032 & 2598305 & 104999 & 11717634 & 415 & 2.8237 & 18.5679 & 2.4321 & 0.9302 & 85.8076 \\
\hline 4.75 & 229935 & 2685402 & 100055 & 11707939 & 410 & 2.6232 & 19.1889 & 1.8111 & 0.9043 & 85.7402 \\
\hline
\end{tabular}


Experimental data: Run-5, WC, $S_{o}=20 \%, S_{w}=0,1 \mathrm{gm}$ of catalyst.

\begin{tabular}{|c|c|c|c|c|c|c|c|c|c|c|}
\hline \multirow{2}{*}{$\begin{array}{l}\text { Reaction } \\
\text { time, hr }\end{array}$} & \multicolumn{3}{|c|}{ Area count } & \multirow{2}{*}{ Temp. C } & \multicolumn{4}{|c|}{ Mole \% } \\
\cline { 2 - 6 } \cline { 7 - 10 } & $\mathrm{CO}_{2}$ & $\mathrm{O}_{2}$ & $\mathrm{CO}$ & $\mathrm{N}_{2}$ & & $\mathrm{CO}_{2}$ & $\mathrm{O}_{2, \text { Prod. }}$ & $\mathrm{O}_{2, \text { cons. }}$ & $\mathrm{CO}$ & $\mathrm{N} 2$ \\
\hline 0 & 4888 & 2381111 & & 9099999 & 18.8 & 0.2242 & 19.8436 & 1.1564 & 0.0390 & 77.5520 \\
\hline 0.25 & 4873 & 2328909 & & 9225107 & 31.4 & 0.2241 & 19.4114 & 1.5886 & 0.0390 & 78.5554 \\
\hline 0.5 & 4823 & 2303336 & & 9509598 & 68.7 & 0.2237 & 19.1996 & 1.8004 & 0.0390 & 80.8370 \\
\hline 0.75 & 5603 & 2247665 & & 9114714 & 132.4 & 0.2298 & 18.7387 & 2.2613 & 0.0390 & 77.6700 \\
\hline 1 & 27311 & 2068090 & 18278 & 10617080 & 203.4 & 0.3996 & 17.2518 & 3.7482 & 0.1503 & 89.7190 \\
\hline 1.25 & 262360 & 582074 & 268087 & 10790179 & 276 & 2.2377 & 4.9476 & 16.0524 & 1.6716 & 91.1072 \\
\hline 1.5 & 727065 & 139725 & 484404 & 10838614 & 343.6 & 5.8716 & 1.2849 & 19.7151 & 2.9890 & 91.4957 \\
\hline 1.75 & 1625625 & 127213 & 608474 & 10036133 & 392.8 & 12.8984 & 1.1813 & 19.8187 & 3.7446 & 85.0598 \\
\hline 2 & 1887398 & 121102 & 661830 & 10268444 & 430.3 & 14.9455 & 1.1307 & 19.8693 & 4.0695 & 86.9229 \\
\hline 2.25 & 2085430 & 115367 & 601930 & 10221864 & 449.9 & 16.4941 & 1.0832 & 19.9168 & 3.7048 & 86.5493 \\
\hline 2.5 & 1979066 & 112266 & 667556 & 9774311 & 458.4 & 15.6623 & 1.0576 & 19.9424 & 4.1044 & 82.9600 \\
\hline 2.75 & 2029059 & 115206 & 558637 & 9688243 & 462.9 & 16.0532 & 1.0819 & 19.9181 & 3.4411 & 82.2697 \\
\hline 3 & 2148244 & 114862 & 485502 & 9916972 & 458.6 & 16.9853 & 1.0791 & 19.9209 & 2.9957 & 84.1041 \\
\hline 3.25 & 2144293 & 118797 & 352933 & 9806441 & 457.8 & 16.9544 & 1.1116 & 19.8884 & 2.1884 & 83.2177 \\
\hline 3.5 & 1991103 & 120286 & 288254 & 9446230 & 454.4 & 15.7564 & 1.1240 & 19.8760 & 1.7945 & 80.3288 \\
\hline 3.75 & 1795711 & 277963 & 283882 & 9246997 & 450.5 & 14.2285 & 2.4295 & 18.5705 & 1.7678 & 78.7309 \\
\hline 4 & 1134297 & 907483 & 251597 & 9204539 & 447.1 & 9.0562 & 7.6420 & 13.3580 & 1.5712 & 78.3904 \\
\hline 4.25 & 610635 & 1506895 & 225362 & 9470346 & 444 & 4.9612 & 12.6051 & 8.3949 & 1.4115 & 80.5222 \\
\hline 4.5 & 273757 & 1981656 & 119896 & 9568285 & 440.9 & 2.3268 & 16.5361 & 4.4639 & 0.7692 & 81.3076 \\
\hline 4.75 & 174101 & 2162580 & 76769 & 9692934 & 437.8 & 1.5475 & 18.0342 & 2.9658 & 0.5065 & 82.3073 \\
\hline 5 & 151226 & 2224869 & 68117 & 9770131 & 435.5 & 1.3686 & 18.5499 & 2.4501 & 0.4538 & 82.9265 \\
\hline 5.25 & 126648 & 2277440 & 47231 & 9597791 & 433.1 & 1.1764 & 18.9852 & 2.0148 & 0.3266 & 81.5443 \\
\hline
\end{tabular}


Experimental data: Run-6, WC, $S_{o}=40 \%, S_{w}=0,1 \mathrm{gm}$ of catalyst.

\begin{tabular}{|c|c|c|c|c|c|c|c|c|c|c|}
\hline \multirow{2}{*}{$\begin{array}{l}\text { Reaction } \\
\text { time, hr }\end{array}$} & \multicolumn{4}{|c|}{ Area count } & \multirow[t]{2}{*}{ Temp. C } & \multicolumn{5}{|c|}{ Mole \% } \\
\hline & $\mathrm{CO}_{2}$ & $\mathrm{O}_{2}$ & $\mathrm{CO}$ & $\mathrm{N}_{2}$ & & $\mathrm{CO}_{2}$ & $\mathrm{O}_{2 \text {. Prod. }}$ & $\mathrm{O}_{2, \text { cons. }}$ & $\mathrm{CO}$ & $\mathrm{N} 2$ \\
\hline 0 & 5221 & 2512830 & & 9543595 & 19.4 & 0.2268 & 20.9342 & 0.0658 & 0.0391 & 81.1096 \\
\hline 0.25 & 5028 & 2518921 & & 557906 & 33.8 & 0.2253 & 20.9847 & 0.0153 & 0.0391 & 81.2244 \\
\hline 0.5 & 4847 & 2508732 & & 536204 & 72.4 & 0.2239 & 20.9003 & 0.0997 & 0.0391 & 81.0504 \\
\hline 0.75 & 6016 & 2471681 & & 9742385 & 132 & 0.2330 & 20.5935 & 0.4065 & 0.0391 & 82.7039 \\
\hline 1 & 27453 & 2057460 & 25527 & 10264050 & 198.5 & 0.4007 & 17.1638 & 3.8362 & 0.1907 & 86.8877 \\
\hline 1.25 & 80377 & 1298159 & 89922 & 10517395 & 265.7 & 0.8145 & 10.8768 & 10.1232 & 0.5732 & 88.9195 \\
\hline 1.5 & 511181 & 177954 & 375398 & 11111905 & 336.5 & 4.1834 & 1.6015 & 19.3985 & 2.2690 & 93.6875 \\
\hline 1.75 & 45065 & 129625 & 660911 & 10199992 & 390.8 & 9.9224 & 1.2013 & 19.7987 & 3.9649 & 86.3739 \\
\hline 2 & 1474035 & 131995 & 720030 & 10245528 & 429.8 & 11.7130 & 1.2209 & 19.7791 & 4.3161 & 86.7391 \\
\hline 2.25 & 1788068 & 118248 & 871858 & 9377485 & 452.3 & 14.1687 & 1.1071 & 19.8929 & 5.2179 & 79.7774 \\
\hline 2.5 & 1939897 & 112322 & 821648 & 9425521 & 461.1 & 15.3560 & 1.0580 & 19.9420 & 4.9197 & 80.1627 \\
\hline 2.75 & 1928860 & 111944 & 832219 & 9257781 & 465.2 & 15.2697 & 1.0549 & 19.9451 & 4.9825 & 78.8174 \\
\hline 3 & 1959601 & 111959 & 686656 & 9408526 & 463.8 & 15.5101 & 1.0550 & 19.9450 & 4.1178 & 80.0264 \\
\hline 3.25 & 2062703 & 116014 & 562031 & 9651033 & 460.8 & 16.3163 & 1.0886 & 19.9114 & 3.3776 & 81.9713 \\
\hline 3.5 & 2027296 & 117539 & 509126 & 9363597 & 458.1 & 16.0395 & 1.1012 & 19.8988 & 3.0633 & 79.6660 \\
\hline 3.75 & 2193168 & 122229 & 500129 & 9768004 & 455 & 17.3366 & 1.1401 & 19.8599 & 3.0099 & 82.9094 \\
\hline 4 & 2064718 & 117431 & 485533 & 9256634 & 451.8 & 16.3321 & 1.1003 & 19.8997 & 2.9232 & 78.8082 \\
\hline 4.25 & 1979562 & 120557 & 440359 & 9521398 & 448.1 & 15.6662 & 1.1262 & 19.8738 & 2.6548 & 80.9316 \\
\hline 4.5 & 2093291 & 199303 & 395300 & 9928114 & 444.3 & 16.5555 & 1.7782 & 19.2218 & 2.3872 & 84.1935 \\
\hline 4.75 & 1558649 & 550620 & 330582 & 9753508 & 440.8 & 12.3746 & 4.6871 & 16.3129 & 2.0028 & 82.7931 \\
\hline 5 & 1071878 & 1114782 & 222339 & 9208516 & 437.3 & 8.5681 & 9.3584 & 11.6416 & 1.3598 & 78.4223 \\
\hline 5.25 & 585101 & 1678945 & 220615 & 9771665 & 434 & 4.7615 & 14.0297 & 6.9703 & 1.3496 & 82.9388 \\
\hline 5.5 & 403319 & 1953178 & 102683 & 9655545 & 430.8 & 3.3400 & 16.3003 & 4.6997 & 0.6490 & 82.0075 \\
\hline 5.75 & 221519 & 2227335 & 65583 & 9552059 & 427.9 & 1.9183 & 18.5703 & 2.4297 & 0.4287 & 81.1775 \\
\hline 6 & 148451 & 2322405 & 50745 & 9698941 & 425.5 & 1.3469 & 19.3575 & 1.6425 & 0.3405 & 82.3555 \\
\hline
\end{tabular}


Experimental data: Run-7, WC, $S_{o}=40 \%, S_{w}=0,5$ gm of catalyst.

\begin{tabular}{|c|c|c|c|c|c|c|c|c|c|c|}
\hline \multirow{2}{*}{$\begin{array}{l}\text { Reaction } \\
\text { time, } \mathrm{hr}\end{array}$} & \multicolumn{4}{|c|}{ Area count } & \multirow[t]{2}{*}{ Temp. C } & \multicolumn{5}{|c|}{ Mole \% } \\
\hline & $\mathrm{CO}_{2}$ & $\mathrm{O}_{2}$ & $\mathrm{CO}$ & $\mathrm{N}_{2}$ & & $\mathrm{CO}_{2}$ & $\mathrm{O}_{2, \text { Prod. }}$ & $\mathrm{O}_{2, \text { cons. }}$ & $\mathrm{CO}$ & $\mathrm{N} 2$ \\
\hline 0 & 9985 & 2929898 & & 11054787 & 19 & 0.8658 & 20.9322 & 0.0678 & 0.3800 & 81.2008 \\
\hline 0.25 & 9878 & 2887978 & & 11199879 & 32.9 & 0.8649 & 20.6333 & 0.3667 & 0.3800 & 82.2092 \\
\hline 0.5 & 11245 & 2845711 & & 11175487 & 79.2 & 0.8758 & 20.3319 & 0.6681 & 0.3800 & 82.0396 \\
\hline 0.75 & 30944 & 2102267 & & 10572187 & 146.8 & 1.0332 & 15.0312 & 5.9688 & 0.3800 & 77.8467 \\
\hline 1 & 150826 & 981985 & 165564 & 13181657 & 234 & 1.9911 & 7.0436 & 13.9564 & 1.3568 & 95.9825 \\
\hline 1.25 & 495966 & 199621 & 429637 & 13085026 & 322 & 4.7488 & 1.4653 & 19.5347 & 2.9149 & 95.3109 \\
\hline 1.5 & 1305621 & 164315 & 786266 & 12284676 & 393.1 & 11.2179 & 1.2136 & 19.7864 & 5.0190 & 89.7485 \\
\hline 1.75 & 1617720 & 144594 & 828291 & 10892825 & 434.4 & 13.7116 & 1.0730 & 19.9270 & 5.2669 & 80.0751 \\
\hline 2 & 1846613 & 142439 & 828564 & 11744509 & 451.6 & 15.5404 & 1.0576 & 19.9424 & 5.2685 & 85.9943 \\
\hline 2.25 & 1831621 & 140013 & 823446 & 11593906 & 459 & 15.4207 & 1.0403 & 19.9597 & 5.2383 & 84.9476 \\
\hline 2.5 & 1841985 & 135481 & 715690 & 11940756 & 461 & 15.5035 & 1.0080 & 19.9920 & 4.6026 & 87.3583 \\
\hline 2.75 & 1861197 & 135430 & 680220 & 11652115 & 460.2 & 15.6570 & 1.0076 & 19.9924 & 4.3933 & 85.3522 \\
\hline 3 & 1873498 & 142316 & 597101 & 11085255 & 458.7 & 15.7552 & 1.0567 & 19.9433 & 3.9029 & 81.4125 \\
\hline 3.25 & 1958335 & 143374 & 518290 & 11533165 & 454.2 & 16.4331 & 1.0643 & 19.9357 & 3.4379 & 84.5255 \\
\hline 3.5 & 1990478 & 138518 & 455883 & 11498754 & 450 & 16.6899 & 1.0296 & 19.9704 & 3.0697 & 84.2863 \\
\hline 3.75 & 1952558 & 154781 & 359875 & 11204578 & 444 & 16.3869 & 1.1456 & 19.8544 & 2.5033 & 82.2418 \\
\hline 4 & 1998987 & 150145 & 346357 & 10987521 & 443 & 16.7579 & 1.1125 & 19.8875 & 2.4235 & 80.7333 \\
\hline 4.25 & 2012121 & 167737 & 336546 & 11524369 & 441 & 16.8628 & 1.2380 & 19.7620 & 2.3656 & 84.4644 \\
\hline 4.5 & 1937877 & 164215 & 309333 & 11112454 & 439 & 16.2696 & 1.2129 & 19.7871 & 2.2051 & 81.6016 \\
\hline 4.75 & 2052455 & 164477 & 266545 & 10214578 & 437.6 & 17.1851 & 1.2147 & 19.7853 & 1.9526 & 75.3613 \\
\hline 5 & 2067527 & 242650 & 255208 & 11651808 & 435 & 17.3055 & 1.7721 & 19.2279 & 1.8857 & 85.3501 \\
\hline 5.25 & 1919242 & 253205 & 216303 & 9764578 & 434 & 16.1207 & 1.8474 & 19.1526 & 1.6562 & 72.2338 \\
\hline 5.5 & 1553005 & 707232 & 202513 & 9692531 & 432.2 & 13.1945 & 5.0846 & 15.9154 & 1.5748 & 71.7331 \\
\hline 5.75 & 1015875 & 1168120 & 168517 & 9811585 & 430 & 8.9028 & 8.3707 & 12.6293 & 1.3743 & 72.5605 \\
\hline 6 & 638778 & 1592639 & 102749 & 10148005 & 428.4 & 5.8898 & 11.3975 & 9.6025 & 0.9862 & 74.8986 \\
\hline 6.25 & 432591 & 1891584 & 94155 & 9887468 & 426 & 4.2424 & 13.5290 & 7.4710 & 0.9355 & 73.0879 \\
\hline 6.5 & 266228 & 2254771 & 92749 & 9691048 & 424.3 & 2.9132 & 16.1185 & 4.8815 & 0.9272 & 71.7228 \\
\hline 6.75 & 160896 & 2437375 & 82749 & 9775253 & 422 & 2.0716 & 17.4205 & 3.5795 & 0.8682 & 72.3080 \\
\hline 7 & 140896 & 2537375 & 62749 & 9887468 & 420 & 1.9118 & 18.1335 & 2.8665 & 0.7502 & 73.0879 \\
\hline 7.25 & 140021 & 2555585 & 62012 & 9989875 & 418.2 & 1.9048 & 18.2633 & 2.7367 & 0.7459 & 73.7996 \\
\hline
\end{tabular}


Experimental data: Run-8, WC, $S_{o}=40 \%, S_{w}=20 \%, 5$ gm of catalyst.

\begin{tabular}{|c|c|c|c|c|c|c|c|c|c|c|}
\hline \multirow{2}{*}{$\begin{array}{l}\text { Reaction } \\
\text { time, hr }\end{array}$} & \multicolumn{4}{|c|}{ Area count } & \multirow[t]{2}{*}{ Temp. C } & \multicolumn{5}{|c|}{ Mole \% } \\
\hline & $\mathrm{CO}_{2}$ & $\mathrm{O}_{2}$ & $\mathrm{CO}$ & $\mathrm{N}_{2}$ & & $\mathrm{CO}_{2}$ & $\mathrm{O}_{2, \text { Prod. }}$ & $\mathrm{O}_{2, \text { cons. }}$ & $\mathrm{CO}$ & $\mathrm{N} 2$ \\
\hline 0 & 6640 & 2955648 & & 10510167 & 22.4 & 0.8391 & 20.8202 & 0.1798 & 0.3800 & 77.4157 \\
\hline 0.25 & 6744 & 2966231 & & 11224983 & 33 & 0.8399 & 20.8946 & 0.1054 & 0.3800 & 82.3836 \\
\hline 0.5 & 5695 & 2798347 & & 11865638 & 73 & 0.8315 & 19.7144 & 1.2856 & 0.3800 & 86.8362 \\
\hline 0.75 & 15539 & 2610818 & 7853 & 12227772 & 138.8 & 0.9102 & 18.3961 & 2.6039 & 0.4346 & 89.3530 \\
\hline 1 & 189173 & 556569 & 228943 & 13888092 & 22.5 & 2.2975 & 3.9547 & 17.0453 & 1.9712 & 100.8922 \\
\hline 1.25 & 236086 & 199137 & 294032 & 13981296 & 312.9 & 2.6723 & 1.4419 & 19.5581 & 2.4235 & 101.5400 \\
\hline 1.5 & 742210 & 173450 & 622633 & 12804721 & 392 & 6.7163 & 1.2614 & 19.7386 & 4.7073 & 93.3628 \\
\hline 1.75 & 1670455 & 139949 & 781364 & 12190569 & 418.9 & 14.1329 & 1.0258 & 19.9742 & 5.8105 & 89.0945 \\
\hline 2 & 1780491 & 124511 & 785985 & 11677295 & 430.7 & 15.0121 & 0.9173 & 20.0827 & 5.8426 & 85.5272 \\
\hline 2.25 & 1738564 & 133723 & 708817 & 10931144 & 435.7 & 14.6771 & 0.9821 & 20.0179 & 5.3063 & 80.3415 \\
\hline 2.5 & 1944881 & 148837 & 589643 & 11842 & & 16.3256 & 1.0883 & 19.9117 & 4.4780 & 86.6773 \\
\hline 2.75 & 2021943 & 152500 & 547932 & 11939 & & 16.9413 & 1.1141 & 19.8859 & 4.1881 & 87.3507 \\
\hline 3 & 1898696 & 162489 & 420814 & 11578802 & 428.2 & 15.9566 & 1.1843 & 19.8157 & 3.3047 & 84.8427 \\
\hline 3.25 & 1924120 & 159705 & 382240 & 11886793 & 422 & 16.1597 & 1.1647 & 19.8353 & 3.0366 & 86.9832 \\
\hline 3.5 & 2034286 & 160868 & 316710 & 120 & 1 & 17.0399 & 1.1729 & 19.8271 & 2.5811 & 87.8712 \\
\hline 3.75 & 2019241 & 140147 & 308330 & 11611889 & 416 & 16.9197 & 1.0272 & 19.9728 & 2.5229 & 85.0726 \\
\hline 4 & 2117363 & 157869 & 289280 & 12094062 & 415 & 17.7037 & 1.1518 & 19.8482 & 2.3905 & 88.4237 \\
\hline 4.25 & 2129105 & 184748 & 255318 & 12010618 & & 17.7975 & 1.3408 & 19.6592 & 2.1545 & 87.8438 \\
\hline 4.5 & 2098877 & 173729 & 232752 & 12068024 & 413 & 17.5560 & 1.2633 & 19.7367 & 1.9976 & 88.2428 \\
\hline 4.75 & 2021454 & 181245 & 224545 & 11939675 & 412 & 16.9374 & 1.3162 & 19.6838 & 1.9406 & 87.3507 \\
\hline 5 & 1995454 & 195421 & 201212 & 11214541 & 410.5 & 16.7297 & 1.4158 & 19.5842 & 1.7784 & 82.3111 \\
\hline 5.25 & 2003485 & 353205 & 175451 & 12012145 & & 16.7938 & 2.5250 & 18.4750 & 1.5994 & 87.8544 \\
\hline 5.5 & 1587877 & 957232 & 112124 & 11021454 & 409 & 13.4731 & 6.7713 & 14.2287 & 1.1593 & 80.9691 \\
\hline 5.75 & 1078788 & 1408120 & 75478 & 12332218 & 407 & 9.4055 & 9.9411 & 11.0589 & 0.9046 & 90.0789 \\
\hline 6 & 545465 & 1954877 & 45451 & 11240544 & 407 & 5.1443 & 13.7848 & 7.2152 & 0.6959 & 82.4918 \\
\hline 6.25 & 251454 & 2404771 & 10245 & 10658777 & 406 & 2.7951 & 16.9475 & 4.0525 & 0.4512 & 78.4485 \\
\hline 6.5 & 143545 & 2687375 & 8987 & 11012144 & 405 & 1.9329 & 18.9342 & 2.0658 & 0.4425 & 80.9044 \\
\hline 6.75 & 88787 & 2785214 & 7987 & 12012131 & 404 & 1.4954 & 19.6221 & 1.3779 & 0.4355 & 87.8543 \\
\hline 7 & 76544 & 2829989 & 8012 & 9998578 & 403 & 1.3976 & 19.9368 & 1.0632 & 0.4357 & 73.8601 \\
\hline 7.25 & 70787 & 2881245 & 7547 & 10214541 & 402 & 1.3516 & 20.2972 & 0.7028 & 0.4325 & 75.3611 \\
\hline 7.5 & 68787 & 2901245 & 7145 & 12335454 & 402 & 1.3356 & 20.4378 & 0.5622 & 0.4297 & 90.1014 \\
\hline
\end{tabular}


Experimental data: Run-9, PWOC, $S_{o}=40 \%, S_{w}=0$

\begin{tabular}{|c|c|c|c|c|c|c|c|c|c|c|}
\hline \multirow{2}{*}{$\begin{array}{l}\text { Reaction } \\
\text { time, hr }\end{array}$} & \multicolumn{4}{|c|}{ Area count } & \multirow[t]{2}{*}{ Temp. C } & \multicolumn{5}{|c|}{ Mole \% } \\
\hline & $\mathrm{CO}_{2}$ & $\mathrm{O}_{2}$ & $\mathrm{CO}$ & $\mathrm{N}_{2}$ & & $\mathrm{CO}_{2}$ & $\mathrm{O}_{2, \text { Prod. }}$ & $\mathrm{O}_{2, \text { cons. }}$ & $\mathrm{CO}$ & $\mathrm{N} 2$ \\
\hline 0 & 6765 & 2956487 & & 11157046 & 20.8 & 0.6342 & 20.7374 & 0.2626 & 0.2610 & 82.7476 \\
\hline 0.25 & 6823 & 2933489 & & 11212940 & 40 & 0.6346 & 20.5764 & 0.4236 & 0.2610 & 83.1489 \\
\hline 0.5 & 7187 & 2975458 & & 10952238 & 90 & 0.6372 & 20.8702 & 0.1298 & 0.2610 & 81.2771 \\
\hline 0.75 & 102450 & 2878785 & 13924 & 11054528 & 143 & 1.3165 & 20.1935 & 0.8065 & 0.3379 & 82.0115 \\
\hline 1 & 33044 & 2770936 & 87403 & 11281417 & 213.9 & 0.8216 & 19.4386 & 1.5614 & 0.7435 & 83.6406 \\
\hline 1.25 & 96990 & 1799641 & 182342 & 11821238 & 290 & 1.2775 & 12.6395 & 8.3605 & 1.2675 & 87.5165 \\
\hline 1.5 & 545991 & 356729 & 439444 & 12133085 & 351.2 & 4.4789 & 2.5391 & 18.4609 & 2.6867 & 89.7556 \\
\hline 1.75 & 1395460 & 257923 & 659915 & 11720766 & 400.2 & 10.5356 & 1.8475 & 19.1525 & 3.9037 & 86.7951 \\
\hline 2 & 1432970 & 178123 & 612329 & 12156381 & 422.4 & 10.8031 & 1.2889 & 19.7111 & 3.6411 & 89.9228 \\
\hline 2.25 & 1871010 & 182781 & 743536 & 12002949 & 434.7 & 13.9263 & 1.3215 & 19.6785 & 4.3653 & 88.8212 \\
\hline & 1891740 & 181120 & 772745 & 11478705 & 441.2 & 14.0741 & 1.3098 & 19.6902 & 4.5266 & 85.0571 \\
\hline 2.75 & 1957118 & 184938 & 787965 & 12139446 & 447.9 & 14.5403 & 1.3366 & 19.6634 & 4.6106 & 89.8012 \\
\hline 3 & 2067078 & 189873 & 851352 & 11377722 & 454.7 & 15.3243 & & 19.6289 & 4.9605 & 84.3320 \\
\hline 3.25 & 2102246 & & 770578 & 11630113 & 458.7 & 15.5750 & 1.2943 & 19.7057 & 4.5146 & 86.1442 \\
\hline 3.5 & 2000819 & 190375 & 859052 & 11559791 & 454.5 & 14.8518 & 1.3746 & 19.6254 & 5.0030 & 85.6393 \\
\hline 3.75 & 2067960 & 212433 & 741418 & 11906155 & 451.5 & 15.3306 & 1.5290 & 19.4710 & 4.3536 & 88.1262 \\
\hline 4 & 1857423 & 226625 & 670818 & 11873268 & 449.3 & 13.8294 & 1.6284 & 19.3716 & 3.9639 & 87.8901 \\
\hline 4.25 & 1945130 & 218475 & 671927 & 12322106 & 447.1 & 14.4548 & 1.5713 & 19.4287 & 3.9700 & 91.1127 \\
\hline 4.5 & 1789890 & 229971 & 586143 & 11718688 & 445.5 & 13.3479 & 1.6518 & 19.3482 & 3.4965 & 86.7802 \\
\hline 4.75 & 1463565 & 254544 & 537169 & 11856864 & 444.4 & 11.0212 & 1.8238 & 19.1762 & 3.2262 & 87.7723 \\
\hline 5 & & 1069052 & 455767 & 11875016 & 442.8 & & 7.5254 & 13.4746 & 2.7768 & 87.9026 \\
\hline 5.25 & 901324 & 1399223 & 332487 & 12167075 & 441 & 7.0124 & 9.8366 & 11.1634 & 2.0963 & 89.9996 \\
\hline 5.5 & 298177 & 2209796 & 198550 & 11903477 & 440 & 2.7120 & 15.5106 & 5.4894 & 1.3570 & 88.1070 \\
\hline 5.75 & 32545 & 2756475 & 120508 & 11755653 & 440 & 2.2440 & 19.3373 & 1.6627 & 0.9262 & 87.0456 \\
\hline 6 & 184971 & 2851087 & 100121 & 11715562 & 439 & 1.9048 & 19.9996 & 1.0004 & 0.8137 & 86.7577 \\
\hline 6.25 & 16241 & 2833320 & 75321 & 11598754 & 437 & 0.7018 & 19.8752 & 1.1248 & 0.6768 & 85.9191 \\
\hline 6.5 & 15454 & 2824135 & 56545 & 11654875 & 434 & 0.6962 & 19.8109 & 1.1891 & 0.5731 & 86.3220 \\
\hline
\end{tabular}


Experimental data: Run-10, PWC, $S_{o}=40 \%, S_{w}=0,5 \mathrm{gm}$ of catalyst.

\begin{tabular}{|c|c|c|c|c|c|c|c|c|c|c|}
\hline \multirow{2}{*}{$\begin{array}{l}\text { Reaction } \\
\text { time, hr }\end{array}$} & \multicolumn{4}{|c|}{ Area count } & \multirow[t]{2}{*}{ Temp. C } & \multicolumn{5}{|c|}{ Mole $\%$} \\
\hline & $\mathrm{CO}_{2}$ & \begin{tabular}{l|l}
$\mathrm{O}_{2}$ \\
\end{tabular} & $\mathrm{CO}$ & $\mathrm{N}_{2}$ & & $\mathrm{CO}_{2}$ & $\mathrm{O}_{2 \text {, Prod. }}$ & $\mathrm{O}_{2, \text { cons. }}$ & $\mathrm{CO}$ & $\mathrm{N} 2$ \\
\hline 0 & 6765 & \begin{tabular}{|l|}
2902147 \\
\end{tabular} & & 11157046 & 23.1 & 0.6373 & 20.6472 & 0.3528 & 0.2610 & 82.7476 \\
\hline 0.25 & 6823 & 2901245 & & 11212940 & 41.8 & 0.6378 & 20.6408 & 0.3592 & 0.2610 & 83.1489 \\
\hline 0.5 & 7187 & 2885523 & & 10952238 & 91.7 & 0.6405 & 20.5292 & 0.4708 & 0.2610 & 81.2771 \\
\hline 0.75 & 10518 & \begin{tabular}{|l|}
2812789 \\
\end{tabular} & & 11196696 & 157.4 & 0.6658 & 20.0128 & 0.9872 & 0.2610 & 83.0323 \\
\hline 1 & 101167 & 2513033 & 88421 & 12327376 & 235.5 & 1.3539 & 17.8845 & 3.1155 & 0.7845 & 91.1506 \\
\hline 1.25 & 291994 & 2208148 & 249203 & 12461589 & 312 & 2.8022 & 15.7199 & 5.2801 & 1.7363 & 92.1142 \\
\hline 1.5 & 406699 & 470770 & 525103 & 12437272 & 387 & 3.6728 & 3.3845 & 17.6155 & 3.3696 & 91.9396 \\
\hline 1.75 & 1252192 & 177542 & 634769 & 12054232 & 428 & 10.0901 & 1.3025 & 19.6975 & 4.0188 & 89.1894 \\
\hline 2 & 1249738 & 165097 & 816337 & 11408571 & 447 & 10.0715 & 1.2142 & 19.7858 & 5.0937 & 84.5535 \\
\hline 2.25 & 1785166 & 160975 & 604993 & 11003704 & 464.7 & 14.1354 & 1.1849 & 19.8151 & 3.8426 & 81.6466 \\
\hline 2.5 & 1841356 & 163390 & 694424 & 10682130 & 477 & 14.5619 & 1.2021 & 19.7979 & 4.3720 & 79.3377 \\
\hline 2.75 & 2018865 & 153264 & 690336 & 11000656 & 485 & 15.9092 & 1.1302 & 19.8698 & 4.3478 & 81.6247 \\
\hline 3 & 2069705 & 153507 & 544359 & 11335165 & 490 & 16.2951 & 1.1319 & 19.8681 & 3.4836 & 84.0265 \\
\hline 3.25 & 2064513 & 152548 & 462746 & 11228573 & 486.6 & 16.2557 & 1.1251 & 19.8749 & 3.0005 & 83.2612 \\
\hline 3.5 & 2069223 & 155995 & 481284 & 11007554 & 478.3 & 16.2914 & 1.1496 & 19.8504 & 3.1102 & 81.6742 \\
\hline 3.75 & 2012145 & 150121 & 441884 & 11459719 & 474.4 & 15.8582 & 1.1079 & 19.8921 & 2.8770 & 84.9208 \\
\hline 4 & 2139056 & 153245 & 371244 & 11294802 & 472.6 & 16.8214 & 1.1300 & 19.8700 & 2.4588 & 83.7367 \\
\hline 4.25 & 2021454 & 155424 & 371244 & 11294802 & 471.9 & 15.9288 & 1.1455 & 19.8545 & 2.4588 & 83.7367 \\
\hline 4.5 & 1987056 & 156455 & 371244 & 11294802 & 469.3 & 15.6678 & 1.1528 & 19.8472 & 2.4588 & 83.7367 \\
\hline 4.75 & 1934929 & 653741 & 395421 & 11451268 & 467 & 15.2721 & 4.6836 & 16.3164 & 2.6019 & 84.8601 \\
\hline 5 & 1532454 & 1054161 & 379789 & 10750912 & 465 & 12.2173 & 7.5265 & 13.4735 & 2.5094 & 79.8315 \\
\hline 5.25 & 1451183 & 1191302 & 350288 & 11486304 & 466 & 11.6005 & 8.5002 & 12.4998 & 2.3347 & 85.1117 \\
\hline 5.5 & 1033278 & 1826129 & 296774 & 10890594 & 465 & 8.4286 & 13.0075 & 7.9925 & 2.0179 & 80.8345 \\
\hline 5.75 & 332545 & 2356475 & 220508 & 11755653 & 460 & 3.1100 & 16.7730 & 4.2270 & 1.5664 & 87.0456 \\
\hline 6 & 184971 & 2651087 & 150121 & 11015562 & 456 & 1.9899 & 18.8647 & 2.1353 & 1.1497 & 81.7317 \\
\hline 6.25 & 183271 & 2841222 & 150012 & 11121454 & 451 & 1.9770 & 20.2147 & 0.7853 & 1.1491 & 82.4920 \\
\hline 6.5 & 172325 & 2845897 & 148787 & 11013254 & 448 & 1.8939 & 20.2479 & 0.7521 & 1.1418 & 81.7152 \\
\hline
\end{tabular}


Experimental data: Run-11, PWOC, $S_{o}=40 \%, S_{w}=20 \%$

\begin{tabular}{|c|c|c|c|c|c|c|c|c|c|c|}
\hline \multirow{2}{*}{$\begin{array}{l}\text { Reaction } \\
\text { time, } \mathrm{hr}\end{array}$} & \multicolumn{4}{|c|}{ Area count } & \multirow[t]{2}{*}{ Temp. C } & \multicolumn{5}{|c|}{ Mole \% } \\
\hline & $\mathrm{CO}_{2}$ & $\mathrm{O}_{2}$ & $\mathrm{CO}$ & $\mathrm{N}_{2}$ & & $\mathrm{CO}_{2}$ & $\mathrm{O}_{2, \text { Prod. }}$ & $\mathrm{O}_{2, \text { cons. }}$ & $\mathrm{CO}$ & $\mathrm{N} 2$ \\
\hline 0 & 8562 & 2902147 & & 11357701 & 19.5 & 0.6619 & 20.6472 & 0.3528 & 0.2610 & 84.1883 \\
\hline 0.25 & 7114 & 2901245 & & 11458376 & 46.5 & 0.6490 & 20.6408 & 0.3592 & 0.2610 & 84.9111 \\
\hline 0.5 & 7541 & 2885523 & & 12216556 & 81.5 & 0.6528 & 20.5292 & 0.4708 & 0.2610 & 90.3549 \\
\hline 0.75 & 8500 & 2735309 & & 11476559 & 129 & 0.6613 & 19.4627 & 1.5373 & 0.2610 & 85.0417 \\
\hline 1 & 34738 & 1930406 & & 12099140 & 196.9 & 0.8938 & 13.7479 & 7.2521 & 0.2610 & 89.5118 \\
\hline 1.25 & 159438 & 978029 & 44284 & 12571861 & 275.5 & 1.9986 & 6.9860 & 14.0140 & 0.5232 & 92.9060 \\
\hline 1.5 & 776188 & 361624 & 470823 & 13097951 & 348.8 & 7.4630 & 2.6095 & 18.3905 & 3.0483 & 96.6833 \\
\hline 1.75 & 1040772 & 360078 & 539880 & 12145547 & 390 & 9.8072 & 2.5986 & 18.4014 & 3.4571 & 89.8450 \\
\hline 2 & 1356581 & 350227 & 616333 & 11839354 & 410 & 12.6053 & 2.5286 & 18.4714 & 3.9097 & 87.6466 \\
\hline 2.25 & 1305503 & 251735 & 611877 & 11616465 & 427 & 12.1528 & 1.8293 & 19.1707 & 3.8833 & 86.0462 \\
\hline 2.5 & 1438394 & 247360 & 674480 & 11488577 & 437.5 & 13.3302 & 1.7983 & 19.2017 & 4.2539 & 85.1280 \\
\hline 2.75 & 1634480 & 252337 & 650621 & 11757162 & 441 & 15.0675 & 1.8336 & 19.1664 & 4.1127 & 87.0564 \\
\hline 3 & 1651472 & 286223 & 633297 & 11311709 & 444.6 & 15.2180 & 2.0742 & 18.9258 & 4.0101 & 83.8581 \\
\hline 3.25 & 1671659 & 305621 & 654545 & 11437159 & 440 & 15.3969 & 2.2119 & 18.7881 & 4.1359 & 84.7588 \\
\hline 3.5 & 1662115 & 323194 & 557133 & 11471660 & 436.6 & 15.3123 & 2.3367 & 18.6633 & 3.5592 & 85.0065 \\
\hline 3.75 & 1699972 & 369544 & 567929 & 11627038 & 434 & 15.6478 & 2.6658 & 18.3342 & 3.6231 & 86.1221 \\
\hline 4 & 1670780 & 411671 & 560183 & 11578996 & 431 & 15.3891 & 2.9649 & 18.0351 & 3.5773 & 85.7772 \\
\hline 4.25 & 1628683 & 453649 & 539150 & 11537972 & 430 & 15.0161 & 3.2629 & 17.7371 & 3.4528 & 85.4826 \\
\hline 4.5 & 1432617 & 376036 & 493223 & 11582723 & 429 & 13.2790 & 2.7119 & 18.2881 & 3.1809 & 85.8040 \\
\hline 4.75 & 1402806 & 482803 & 484971 & 11434888 & 427.2 & 13.0149 & 3.4699 & 17.5301 & 3.1320 & 84.7425 \\
\hline 5 & 1287285 & 877322 & 414896 & 11662891 & 425 & 11.9913 & 6.2710 & 14.7290 & 2.7172 & 86.3796 \\
\hline 5.25 & 1078826 & 1247602 & 320806 & 11791454 & 423 & 10.1444 & 8.9000 & 12.1000 & 2.1602 & 87.3026 \\
\hline 5.5 & 924520 & 1719975 & 259260 & 11398120 & 422 & 8.7772 & 12.2538 & 8.7462 & 1.7958 & 84.4785 \\
\hline 5.75 & 629572 & 2167360 & 200703 & 11351785 & 419 & 6.1640 & 15.4303 & 5.5697 & 1.4492 & 84.1458 \\
\hline 6 & 370477 & 2474804 & 93034 & 11979166 & 417 & 3.8684 & 17.6131 & 3.3869 & 0.8118 & 88.6504 \\
\hline 6.25 & 140547 & 2762144 & 11021 & 11124547 & 415 & 1.8312 & 19.6532 & 1.3468 & 0.3262 & 82.5142 \\
\hline 6.5 & 75454 & 2890010 & 10121 & 11012145 & 414 & 1.2545 & 20.5611 & 0.4389 & 0.3209 & 81.7072 \\
\hline
\end{tabular}


Experimental data: Run-12, PWC, $S_{o}=40 \%, S_{w}=20 \%, 5$ gm of catalyst.

\begin{tabular}{|c|c|c|c|c|c|c|c|c|c|c|}
\hline \multirow{2}{*}{$\begin{array}{l}\text { Reaction } \\
\text { time, hr }\end{array}$} & \multicolumn{4}{|c|}{ Area count } & \multirow[t]{2}{*}{ Temp. C } & \multicolumn{5}{|c|}{ Mole \% } \\
\hline & $\mathrm{CO}_{2}$ & $\mathrm{O}_{2}$ & $\mathrm{CO}$ & $\mathrm{N}_{2}$ & & $\mathrm{CO}_{2}$ & $\mathrm{O}_{2 \text {. Prod. }}$ & $\mathrm{O}_{2, \text { cons. }}$ & $\mathrm{CO}$ & $\mathrm{N} 2$ \\
\hline 0 & 6666 & 2902157 & & 11514267 & 18 & 0.6442 & 20.6473 & 0.3527 & 0.2610 & 85.3124 \\
\hline 0.25 & 7500 & 2901412 & & 11814567 & 48.3 & 0.6515 & 20.6420 & 0.3580 & 0.2610 & 87.4686 \\
\hline 0.5 & 7646 & 2900012 & & 11552175 & 94.5 & 0.6527 & 20.6321 & 0.3679 & 0.2610 & 85.5846 \\
\hline 0.75 & 12546 & 2894745 & & 12083322 & 145.6 & 0.6955 & 20.5947 & 0.4053 & 0.2610 & 89.3983 \\
\hline 1 & 15344 & 2546915 & & 11627068 & 219.1 & 0.7200 & 18.1251 & 2.8749 & 0.2610 & 86.1223 \\
\hline 1.25 & 548044 & 403117 & 389872 & 13330331 & 300 & 5.3704 & 2.9041 & 18.0959 & 1.5554 & 98.3518 \\
\hline 1.5 & 969164 & 301644 & 600735 & 13178890 & 357 & 9.0468 & 2.1837 & 18.8163 & 2.2554 & 97.2644 \\
\hline 1.75 & 1153768 & 258728 & 655782 & 12301664 & 397.6 & 10.6584 & 1.8790 & 19.1210 & 2.4382 & 90.9659 \\
\hline 2 & 1678792 & 213091 & 705679 & 11662159 & 418.3 & 15.2419 & 1.5549 & 19.4451 & 2.6039 & 86.3743 \\
\hline 2.25 & 1799163 & 222254 & 696063 & 11272000 & 432 & 16.2927 & 1.6200 & 19.3800 & 2.5719 & 83.5730 \\
\hline 2.5 & 1784211 & 216455 & 675982 & 11388128 & 439.2 & 16.1622 & 1.5788 & 19.4212 & 2.5053 & 84.4068 \\
\hline 2.75 & 1863493 & 215775 & 616637 & 11749732 & 443.9 & 16.8543 & 1.5740 & 19.4260 & 2.3082 & 87.0031 \\
\hline 3 & 1906565 & 213568 & 608336 & 11328814 & 448.8 & 17.2303 & 1.5583 & 19.4417 & 2.2807 & 83.9809 \\
\hline 3.25 & 1836568 & 218764 & 654624 & 11535095 & 451.7 & 16.6192 & 1.5952 & 19.4048 & 2.4344 & 85.4620 \\
\hline 3.5 & 1988661 & 225227 & 561016 & 11889572 & 444 & 17.9470 & 1.6411 & 19.3589 & 2.1236 & 88.0071 \\
\hline 3.75 & 1938923 & 260095 & 635838 & 11174793 & 440 & 17.5128 & 1.8887 & 19.1113 & 2.3720 & 82.8750 \\
\hline 4 & 1844819 & 282757 & 634217 & 11496627 & 437 & 16.6913 & 2.0496 & 18.9504 & 2.3666 & 85.1858 \\
\hline 4.25 & 1906179 & 303096 & 548813 & 11534882 & 434 & 17.2269 & 2.1940 & 18.8060 & 2.0831 & 85.4605 \\
\hline 4.5 & 1913246 & 308287 & 462102 & 11332777 & 431 & 17.2886 & 2.2308 & 18.7692 & 1.7952 & 84.0093 \\
\hline 4.75 & 1853246 & 491683 & 489030 & 11995938 & 428 & 16.7648 & 3.5329 & 17.4671 & 1.8846 & 88.7708 \\
\hline 5 & 1654765 & 663433 & 485212 & 11631417 & 425 & 15.0321 & 4.7524 & 16.2476 & 1.8719 & 86.1536 \\
\hline 5.25 & 1478454 & 809493 & 465103 & 12550986 & 424 & 13.4929 & 5.7894 & 15.2106 & 1.8051 & 92.7561 \\
\hline 5.5 & 1242321 & 1218477 & 425913 & 12150484 & 422 & 11.4315 & 8.6932 & 12.3068 & 1.6750 & 89.8805 \\
\hline 5.75 & 1015790 & 1479738 & 355975 & 11901111 & 421 & 9.4538 & 10.5481 & 10.4519 & 1.4428 & 88.0900 \\
\hline 6 & 958787 & 1587577 & 325424 & 11678787 & 420 & 8.9562 & 11.3138 & 9.6862 & 1.3414 & 86.4937 \\
\hline 6.25 & 920638 & 1706458 & 304300 & 11784696 & 418 & 8.6232 & 12.1579 & 8.8421 & 1.2713 & 87.2541 \\
\hline 6.5 & 786535 & 1921167 & 262806 & 11738397 & 415 & 7.4525 & 13.6823 & 7.3177 & 1.1335 & 86.9217 \\
\hline 6.75 & 650524 & 2123252 & 228674 & 11505485 & 414 & 6.2651 & 15.1171 & 5.8829 & 1.0202 & 85.2494 \\
\hline 7 & 453328 & 2380378 & 168898 & 11696025 & 413 & 4.5436 & 16.9427 & 4.0573 & 0.8217 & 86.6175 \\
\hline 7.25 & 125451 & 2687878 & 121451 & 11542452 & 412 & 1.6812 & 19.1259 & 1.8741 & 0.6642 & 85.5148 \\
\hline 7.5 & 80121 & 2802454 & 80214 & 11675480 & 410 & 1.2855 & 19.9394 & 1.0606 & 0.5273 & 86.4699 \\
\hline
\end{tabular}


Experimental data: Run-13, WC, $S_{o}=40 \%, S_{w}=0$,

\begin{tabular}{|c|c|c|c|c|c|c|c|c|c|c|}
\hline \multirow{2}{*}{$\begin{array}{l}\text { Reaction } \\
\text { time, } \mathrm{hr}\end{array}$} & \multicolumn{9}{|c|}{ Area count } & \multicolumn{2}{|c|}{ Temp. $\mathrm{C}$} & \multicolumn{5}{|c|}{ Mole \% } \\
\cline { 9 - 11 } & $\mathrm{CO}_{2}$ & $\mathrm{O}_{2}$ & $\mathrm{CO}$ & $\mathrm{N}_{2}$ & & $\mathrm{CO}_{2}$ & $\mathrm{O}_{2, \text { Prod. }}$ & $\mathrm{O}_{2, \text { cons. }}$ & $\mathrm{CO}$ & $\mathrm{N} 2$ \\
\hline 0 & 6640 & 2955648 & & 10510167 & 20 & 0.8391 & 20.8202 & 0.1798 & 0.3800 & 77.4157 \\
\hline 0.25 & 6744 & 2966231 & & 11224983 & 34 & 0.8399 & 20.8946 & 0.1054 & 0.3800 & 82.3836 \\
\hline 0.5 & 5695 & 2898347 & & 11865638 & 77.8 & 0.8315 & 20.4174 & 0.5826 & 0.3800 & 86.8362 \\
\hline 0.75 & 8996 & 2848177 & & 11361862 & 145 & 0.8579 & 20.0647 & 0.9353 & 0.3800 & 83.3349 \\
\hline 1 & 86182 & 1235977 & 101366 & 10846026 & 221.8 & 1.4746 & 8.7309 & 12.2691 & 0.9669 & 79.7499 \\
\hline 1.25 & 425998 & 198473 & 397359 & 11541216 & 308 & 4.1897 & 1.4373 & 19.5627 & 2.6807 & 84.5815 \\
\hline 1.5 & 1218263 & 147994 & 901804 & 11089023 & 377 & 10.5199 & 1.0824 & 19.9176 & 5.6014 & 81.4387 \\
\hline 1.75 & 1307573 & 144134 & 786139 & 10000083 & 424 & 11.2335 & 1.0553 & 19.9447 & 4.9317 & 73.8706 \\
\hline 2 & 1572460 & 137970 & 623676 & 10756576 & 448.7 & 13.3500 & 1.0119 & 19.9881 & 3.9911 & 79.1282 \\
\hline 2.25 & 1606968 & 131762 & 655454 & 10503497 & 458.7 & 13.6257 & 0.9683 & 20.0317 & 4.1751 & 77.3693 \\
\hline 2.5 & 1771886 & 144221 & 444586 & 11035887 & 462.4 & 14.9434 & 1.0559 & 19.9441 & 2.9542 & 81.0694 \\
\hline 2.75 & 1799233 & 149103 & 418487 & 11176947 & 460.8 & 15.1619 & 1.0902 & 19.9098 & 2.8030 & 82.0498 \\
\hline 3 & 1799174 & 155000 & 390555 & 11630694 & 458 & 15.1614 & 1.1317 & 19.8684 & 2.6413 & 85.2033 \\
\hline 3.25 & 1902630 & 147730 & 369182 & 11684062 & 455.2 & 15.9880 & 1.0805 & 19.9195 & 2.5176 & 85.5742 \\
\hline 3.5 & 1776818 & 155748 & 356742 & 11614104 & 450.8 & 14.9828 & 1.1369 & 19.8631 & 2.4455 & 85.0880 \\
\hline 3.75 & 1830661 & 156625 & 350320 & 11675878 & 445.5 & 15.4130 & 1.1431 & 19.8569 & 2.4084 & 85.5174 \\
\hline 4 & 1890147 & 153461 & 325160 & 11400365 & 442.2 & 15.8883 & 1.1208 & 19.8792 & 2.2627 & 83.6025 \\
\hline 4.25 & 2005507 & 156669 & 320521 & 11688919 & 439 & 16.8100 & 1.1434 & 19.8566 & 2.2358 & 85.6080 \\
\hline 4.5 & 1964422 & 178058 & 335954 & 11923973 & 436 & 16.4817 & 1.2937 & 19.7063 & 2.3252 & 87.2416 \\
\hline
\end{tabular}


Experimental data: Run-14, WC, $S_{o}=40 \%, S_{w}=0$

\begin{tabular}{|c|c|c|c|c|c|c|c|c|c|c|}
\hline \multirow{2}{*}{$\begin{array}{l}\text { Reaction } \\
\text { time, hr }\end{array}$} & \multicolumn{4}{|c|}{ Area count } & \multirow[t]{2}{*}{ Temp. C } & \multicolumn{5}{|c|}{ Mole \% } \\
\hline & $\mathrm{CO}_{2}$ & $\mathrm{O}_{2}$ & $\mathrm{CO}$ & $\mathrm{N}_{2}$ & & $\mathrm{CO}_{2}$ & $\mathrm{O}_{2, \text { Prod. }}$ & $\mathrm{O}_{2, \text { cons. }}$ & $\mathrm{CO}$ & $\mathrm{N} 2$ \\
\hline 0 & 6640 & 2955648 & & 10510167 & 22.4 & 0.8391 & 20.8202 & 0.1798 & 0.3800 & 77.4157 \\
\hline 0.25 & 6744 & 2966231 & & 11224983 & 33 & 0.8399 & 20.8946 & 0.1054 & 0.3800 & 82.3836 \\
\hline 0.5 & 5695 & 2798347 & & 11865638 & 73 & 0.8315 & 19.7144 & 1.2856 & 0.3800 & 86.8362 \\
\hline 0.75 & 15539 & 2610818 & 7853 & 12227772 & 138.8 & 0.9102 & 18.3961 & 2.6039 & 0.4346 & 89.3530 \\
\hline 1 & 189173 & 556569 & 228943 & 13888092 & 222.5 & 2.2975 & 3.9547 & 17.0453 & 1.9712 & 100.8922 \\
\hline 1.25 & 236086 & 199137 & 294032 & 13981296 & 312.9 & 2.6723 & 1.4419 & 19.5581 & 2.4235 & 101.5400 \\
\hline 1.5 & 742210 & 173450 & 622633 & 12804721 & & 6.7163 & 1.2614 & 19.7386 & 4.7073 & 93.3628 \\
\hline 1.75 & 1670455 & 139949 & 781364 & 12190569 & 418.9 & 14.1329 & 1.0258 & 19.9742 & 5.8105 & 89.0945 \\
\hline 2 & 1780491 & 124511 & 785985 & 11677295 & 430.7 & 15.0121 & 0.9173 & 20.0827 & 5.8426 & 85.5272 \\
\hline 2.25 & 1738564 & 133723 & 708817 & 10931144 & 435.7 & 14.6771 & 0.9821 & 20.0179 & 5.3063 & 80.3415 \\
\hline 2.5 & 1944881 & 148837 & 589643 & 11842778 & 433 & 16.3256 & 1.0883 & 19.9117 & 4.4780 & 86.6773 \\
\hline 2.75 & 2021943 & 152500 & 547932 & 11939675 & 431 & 16.9413 & 1.1141 & 19.8859 & 4.1881 & 87.3507 \\
\hline 3 & 1898696 & 162489 & 420814 & 11578802 & 428.2 & 15.9566 & 1.1843 & 19.8157 & 3.3047 & 84.8427 \\
\hline 3.25 & 1924120 & 159705 & 382240 & 11886793 & & 16.1597 & 1.1647 & 19.8353 & 3.0366 & 86.9832 \\
\hline 3.5 & 2034286 & 160868 & 316710 & 12014558 & 418 & 17.0399 & 1.1729 & 19.8271 & 2.5811 & 87.8712 \\
\hline 3.75 & 2019241 & 140147 & 308330 & 11611889 & 416 & 16.9197 & 1.0272 & 19.9728 & 2.5229 & 85.0726 \\
\hline 4 & 2117363 & 157869 & 289280 & 12094062 & & 17.7037 & 1.1518 & 19.8482 & 2.3905 & 88.4237 \\
\hline 4.25 & 2129105 & 184748 & 255318 & 12010618 & 413 & 17.7975 & 1.3408 & 19.6592 & 2.1545 & 87.8438 \\
\hline 4.5 & 2098877 & 173729 & 232752 & 12068024 & 413 & 17.5560 & 1.2633 & 19.7367 & 1.9976 & 88.2428 \\
\hline 4.75 & 2021454 & 181245 & 224545 & 11939675 & 412 & 16.9374 & 1.3162 & 19.6838 & 1.9406 & 87.3507 \\
\hline
\end{tabular}


Experimental data: Run-15, WC, $S_{o}=40 \%, S_{w}=0$,

\begin{tabular}{|c|c|c|c|c|c|c|c|c|c|c|}
\hline \multirow{2}{*}{$\begin{array}{l}\text { Reaction } \\
\text { time, } \mathrm{hr}\end{array}$} & \multicolumn{4}{|c|}{ Area count } & \multirow[t]{2}{*}{ Temp. C } & \multicolumn{5}{|c|}{ Mole \% } \\
\hline & $\mathrm{CO}_{2}$ & \begin{tabular}{l|l|}
$\mathrm{O}_{2}$ & \\
\end{tabular} & $\mathrm{CO}$ & $\mathrm{N}_{2}$ & & $\mathrm{CO}_{2}$ & $\mathrm{O}_{2, \text { Prod. }}$ & $\mathrm{O}_{2, \text { cons. }}$ & $\mathrm{CO}$ & $\mathrm{N} 2$ \\
\hline 0 & 9012 & 2955642 & & 11322561 & 19.6 & 0.8580 & 20.8202 & 0.1798 & 0.3800 & 83.0618 \\
\hline 0.25 & 588 & 2966541 & & 1763617 & 32.8 & 0.8626 & 20.8968 & 1032 & 3800 & 86.1271 \\
\hline 0.5 & 9699 & 2899965 & & 11692926 & 73.3 & 0.8635 & 20.4288 & 0.5712 & 0.3800 & 85.6358 \\
\hline 0.75 & 9598 & 2646102 & & 10673427 & 136.9 & 0.8627 & 18.6441 & 2.3559 & .3800 & 78.5503 \\
\hline & 2660 & 1511436 & 31100 & & 210.2 & 1.5264 & 10.6674 & 10.3326 & 0.5601 & 89.6624 \\
\hline 1.25 & 310421 & 285516 & 384482 & 14210 & 293 & 3.2663 & 2.0492 & 18.9508 & 2.6062 & 103.1311 \\
\hline 1.5 & 585482 & 195452 & 586641 & 13248009 & 367.8 & 5.4640 & 1.4160 & 19.5840 & 3.7767 & 96.4437 \\
\hline 1.75 & 962 & 344 & 801408 & & 416 & 11.3405 & 200 & 19.8800 & 0202 & \\
\hline 2 & 1615344 & 150509 & 949069 & 11275193 & 442.5 & 13.6926 & 1.1001 & 19.8999 & 5.8751 & 82.7326 \\
\hline 2.25 & 1681173 & 142672 & 754817 & 10641517 & 452.3 & 14.2186 & 1.0450 & 19.9550 & 4.7504 & 78.3285 \\
\hline 2.5 & 77049 & 135681 & 715763 & 10892466 & 455.4 & 14.9846 & 0.9958 & 20.0042 & 4.5243 & 80.0726 \\
\hline 2.75 & 35493 & 134702 & 637513 & 10187753 & 455.3 & 15.4516 & 0.9890 & 20.0110 & 4.0712 & 75.1749 \\
\hline 3 & 1876796 & 148924 & 747984 & 11159850 & 454 & 15.7816 & 1.0889 & 19.9111 & 4.7108 & 81.9310 \\
\hline 3.25 & 58726 & 139770 & 668317 & 12733177 & 452 & 18.0342 & 1.0246 & 19.9754 & 4.2496 & 92.8656 \\
\hline 3.5 & 2035314 & 137105 & 607133 & 12765401 & 449 & 17.0482 & 1.0058 & 19.9942 & 3.8953 & 93.0895 \\
\hline 3.75 & 2136664 & 135547 & 616064 & 12898299 & 445 & 17.8579 & 0.9949 & 20.0051 & 3.9470 & 94.0132 \\
\hline 4 & 2036757 & 161289 & 567992 & 11450268 & 440.8 & 17.0597 & 1.1759 & 19.8241 & 3.6687 & 83.9494 \\
\hline 4.25 & 2079867 & 165943 & 556355 & 11318901 & 437 & & & 19.7914 & 3.6013 & 83.0364 \\
\hline 4.5 & 1948920 & 262387 & 470101 & 12265316 & 434 & 16.3579 & 1.8866 & 19.1134 & 3.1019 & 89.6139 \\
\hline
\end{tabular}


Experimental data: Run-16, WC, $S_{o}=40 \%, S_{w}=0$

\begin{tabular}{|c|r|c|c|c|c|c|c|c|c|c|}
\hline \multirow{2}{*}{$\begin{array}{l}\text { Reaction } \\
\text { time, } \mathrm{hr}\end{array}$} & \multicolumn{5}{|c|}{ Area count } & \multirow{2}{*}{ Temp. $\mathrm{C}$} & \multicolumn{4}{|c|}{ Mole \% } \\
\cline { 2 - 7 } & $\mathrm{CO}_{2}$ & \multicolumn{1}{|c}{$\mathrm{O}_{2}$} & $\mathrm{CO}$ & $\mathrm{N}_{2}$ & & $\mathrm{CO}_{2}$ & $\mathrm{O}_{2, \text { Prod. }}$ & $\mathrm{O}_{2, \text { cons. }}$ & $\mathrm{CO}$ & $\mathrm{N} 2$ \\
\hline 0 & 6742 & 2901239 & & 11265022 & 19 & 23.01258 & 0.04200 & 20.95800 & 74.8354 & 2.64014 \\
\hline 0.25 & 6302 & 2856399 & & 11709311 & 31.3 & 22.66596 & 0.04200 & 20.95800 & 77.7766 & 2.64022 \\
\hline 0.5 & 6605 & 2885987 & & 11315576 & 70.3 & 22.89468 & 0.04200 & 20.95800 & 75.1701 & 2.64050 \\
\hline 0.75 & 6578 & 2808998 & & 10946998 & 130.5 & 22.29955 & 0.04200 & 20.95800 & 72.7301 & 2.64094 \\
\hline 1 & 84298 & 1856982 & 68071 & 12462527 & 201.6 & 14.94047 & 0.52530 & 20.47470 & 82.7629 & 2.64145 \\
\hline 1.25 & 380125 & 288989 & 353989 & 13369998 & 269.7 & 2.81988 & 2.55532 & 18.44468 & 88.7704 & 2.64194 \\
\hline 1.5 & 1048774 & 168901 & 604001 & 12440727 & 335.7 & 1.89160 & 4.33041 & 16.66959 & 82.6186 & 2.64241 \\
\hline 1.75 & 1659012 & 161642 & 732113 & 11881475 & 381.6 & 1.83549 & 5.24000 & 15.76000 & 78.9164 & 2.64274 \\
\hline 2 & 1850453 & 151234 & 655012 & 11008571 & 417.9 & 1.75504 & 4.69259 & 16.30741 & 73.1377 & 2.64300 \\
\hline 2.25 & 1953961 & 141222 & 708765 & 11273333 & 439.9 & 1.67765 & 5.07423 & 15.92577 & 74.8905 & 2.64316 \\
\hline 2.5 & 2140520 & 144422 & 551998 & 11562025 & 452.3 & 1.70238 & 3.96119 & 17.03881 & 76.8016 & 2.64325 \\
\hline 2.75 & 2041199 & 143898 & 543002 & 11452325 & 460 & 1.69833 & 3.89731 & 17.10269 & 76.0754 & 2.64330 \\
\hline 3 & 2030458 & 153987 & 502115 & 11501995 & 462.4 & 1.77632 & 3.60702 & 17.39298 & 76.4042 & 2.64332 \\
\hline 3.25 & 1859023 & 151802 & 486336 & 11057254 & 461.8 & 1.75943 & 3.49499 & 17.50501 & 73.46 & 2.64332 \\
\hline 3.5 & 2002222 & 152367 & 477999 & 11409898 & 459.4 & 1.76380 & 3.43579 & 17.56421 & 75.7945 & 2.64330 \\
\hline 3.75 & 1919236 & 153198 & 453687 & 11149618 & 456.1 & 1.77022 & 3.26318 & 17.73682 & 74.0715 & 2.64327 \\
\hline 4 & 1979678 & 201025 & 424326 & 10591234 & 452 & 2.13992 & 3.05471 & 17.94529 & 70.375 & 2.64325 \\
\hline
\end{tabular}

